\title{
COMPOSIÇÃO, HISTÓRIA NATURAL, DIVERSIDADE E DISTRIBUIÇÃO DAS SERPENTES NO MUNICÍPIO DE SÃO PAULO, SP
}

\author{
FAUSTO ERRITTO BARBO
}

Dissertação apresentada ao Programa de Pós- Graduação Interunidades em Biotecnologia USP/Instituto Butantan/IPT, para obtenção do Título de Mestre em Biotecnologia

São Paulo

2008 


\section{COMPOSIÇÃO, HISTÓRIA NATURAL, DIVERSIDADE E DISTRIBUIÇÃO DAS SERPENTES NO MUNICÍPIO \\ DE SÃO PAULO, SP}

FAUSTO ERRITTO BARBO

Dissertação apresentada ao Programa de Pós- Graduação Interunidades em Biotecnologia USP/Instituto Butantan/IPT, para obtenção do Título de Mestre em Biotecnologia

Área de Concentração: Biotecnologia

Orientador: Prof. Dr. Ricardo J. Sawaya 
DADOS DE CATALOGAÇÃO NA PUBLICAÇÃO (CIP)

Serviço de Biblioteca e Informação Biomédica do

Instituto de Ciências Biomédicas da Universidade de São Paulo

(C) reprodução total

Barbo, Fausto Erritto.

Composição, história natural, diversidade e distribuição das serpentes no município de São Paulo, SP / Fausto Erritto Barbo. -São Paulo, 2007.

Orientador: Ricardo Jannini Sawaya.

Dissertação (Mestrado) - Universidade de São Paulo. Instituto de Ciências Biomédicas. Programa de Pós-Graduação Interunidades em Biotecnologia EP/IPT/ICB/Butantan. Área de concentração:

Biotecnologia. Linha de pesquisa: História natural e ecologia.

Versão do título para o inglês: Composition, natural history, diversity and distribution of snakes in municipality of São Paulo, SP.

Descritores: 1. Serpentes 2. História natural 3. Diversidade 4. São Paulo 5. Distribuição 6. I. Sawaya, Ricardo Jannini II. Universidade de São Paulo III. Título. 
Título da Dissertação: Composição, história natural, diversidade e distribuição das serpentes no município de São Paulo, SP.

Orientador(a): $\quad$ Ricardo Jannini Sawaya.

A Comissão Julgadora dos trabalhos de Defesa da Dissertação de Mestrado, em sessão pública realizada a I. I.................,

\section{( ) Aprovado(a) ( ) Reprovado(a)}

Examinador(a): Assinatura:

Nome:

Instituição:

Examinador(a): Assinatura:

Nome:

Instituição:

Presidente: Assinatura:

Nome:

Instituição: 
(CEUAIB)

São Paulo, 23 de junho de 2006.

Dr. Ricardo J. Sawaya

Laboratório de Herpetologia

Instituto Butantan

Referente Projeto: "Composição, história natural, diversidade e distribuição de serpentes no município de São Paulo, SP".

Prezado Pesquisador,

A Comissão de Ética no Uso de Animais do Instituto Butantan (CEUAIB) informa não haver necessidade da submissão à análise do projeto acima referido, visto que o mesmo utilizará apenas material biológico preservado em coleções científicas.

Sem mais para o momento,

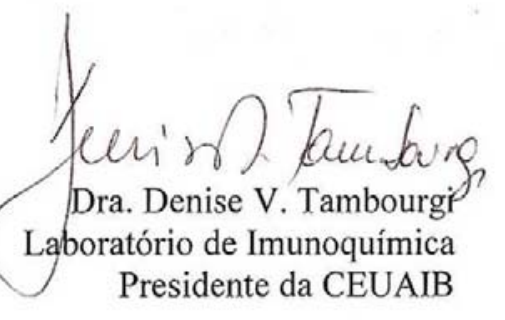


Aos meus pais, Ricardo e Marcia, e ao meu irmão Heitor, pelo apoio incondicional e pelo constante incentivo, fundamentais nessa conquista!

À minha querida Marília, por encher a minha estrada de flores, tornando a vida mais bonita e valiosa! 


\section{AGRADECIMENTOS}

Nada na vida, nem mesmo entre os seres mais elementares, é realizado sem a mútua colaboração e a somatória de esforços de diversos organismos. Por menores que sejam determinadas tarefas, elas farão diferença no resultado final. Desta forma, eu tentei (de coração) agradecer a todas as pessoas que contribuíram para a realização desse trabalho.

Aos meus pais Ricardo e Marcia pelo incentivo, pelo valor que empregaram e investiram em meus estudos, pelos ensinamentos éticos, pelo "paitrocínio" e "mãetrocínio" nas horas mais difíceis e pela paciência!!! Vocês foram (e sempre serão) essenciais para tudo!! Ao meu irmão Heitor, pelo companheirismo, cumplicidade e pela força em todos os anos da minha vida!

À Marília Cristina Duarte, pelo amor, carinho companheirismo e paciência! Obrigado por aturar a minha chatice nesses últimos meses de mestrado e por me tirar um pouco das obrigações e mostrar as outras coisas boas da vida, e mais ainda por existir nela!!

Ao meu grande mestre e orientador Ricardo J. Sawaya, pela grande amizade, orientação e discussões científicas, pelas agradabilíssimas viagens de campo, churrascos e cervejadas!! Agradeço sempre pelos ensinamentos e críticas, que serão fundamentais para minha vida profissional.

Ao Otavio Marques, pela grande amizade, orientação, pelo exemplo de ética e profissionalismo, por dividir comigo (e com tantas outras pessoas) seu enorme conhecimento sobre a história natural de serpentes brasileiras, e também pelas fotografias gentilmente cedidas

Ao Hebert Ferrarezzi, pela grande amizade, efervescentes discussões científicas que botam a cabeça pra funcionar, e pela ajuda e sempre boa vontade durante as madrugadas!! 
À Selma Almeida-Santos, pela grande amizade, pela ajuda em diversas etapas deste trabalho (e de outros também!), pelo constante bom humor, e pelos ensinamentos sobre a reprodução de serpentes brasileiras.

Ao grande mestre Valdir J. Germano, uma das pessoas mais importantes da herpetologia no Brasil, pela amizade, dedicação ao trabalho, paciência, competência, e pelas agradáveis viagens de campo.

Aos demais pesquisadores, funcionários e colegas do Instituto Butantan, pela amizade, companheirismo e agradável convívio diário durante esses cinco anos: Francisco "Kiko" L. Franco, Maria da Graça Salomão, Alessandra Bizerra, André Eterovic, Antonio Carlos ("Garotinho"), Joãozinho, Eládio, Amauri, Carlinhos, Marlene, Mariza, Fátima Cagnotto, D. Vera, José Pedro, Gileno, Regina, Myriam, Eliana, Marcelo, Fátima Furtado, Wilson Fernandes, Silvia, Marisa e Rosângela.

Agradeço a D. Maria e à Darina pelas conversas e risadas logo no início do dia, e pelo cafezinho. Obrigado por me tratarem como "filho" e por se preocuparem e torcerem sempre por mim!

Aos estagiários (e ex-estagiários) do Laboratório, companheiros de bancada, de "fixação de cobra", de trabalho, de festas, de café, de boteco, de campo, etc...: Antonio ("Totô"), Rodrigo ("Laranja”), Donizete, Leonardo ("ZL"), Lílian, Murilo, Fernanda Stender, Fernanda Centeno, Lígia, Einat, Thais, Rafael, Laura, Adriano, Carol Parpinelli, Cláudio Rojas, Cybele, Fernando Couto, Ricardo (“Anão”), César, Victor, Renatinha, Tiagones, Karina, Cláudia ("Jones”), Edson, Mary, Letícia, Jorge, Ana Bárbara, Beto, Luciana, Lívia, Vivian, Daniel, Priscila, Cristina, Renato, leda, Marília, Cristian, Paulo, Adri.

Agradeço a Maria da Graça Salomão, Miguel Trefaut Rodrigues e Otavio Marques, pelas valiosas sugestões e contribuições durante a banca do exame de qualificação! 
Agradeço a atenção e paciência dos funcionários da biblioteca, em nome de Eva Aparecida de Oliveira, que durante as correções da dissertação demonstrou boa vontade e muita competência. São pessoas assim que a Biotecnologia necessita!!

Aos colegas do Departamento de Ecologia (e visitantes) e de Zoologia da USP, pela amizade, pelas conversas, festas e viagens de campo: Marcio Martins, Maria Ermelinda de Oliveira, Cínthia Brasileiro, Hilton Oyamaguchi, Thereza (Tetê), Elaine, Pedro Nunes e Felipe Curcio.

Aos colegas Léo Malagoli e Rogério Bertani, que contribuíram com exemplares valiosos e informações de campo.

Aos amigos de longa data, do Instituto de Botânica, pelas filosofias, cervejadas, e pelas informações e fornecimento das serpentes do Parque do Estado: Clóvis, Cesão, Igor "Papito", Maitê, ("A Sociedade”), Dra. Claudia, Cecília, Bia, Rodrigo "Turco", Marcelo e Paulo.

Ao IDEA WILD pelo fornecimento dos equipamentos para a coleta dos dados de biometria e distribuição das serpentes.

À FAPESP (Proc.05/57796-5) pela bolsa de mestrado e apoio financeiro, essenciais para a realização desse trabalho.
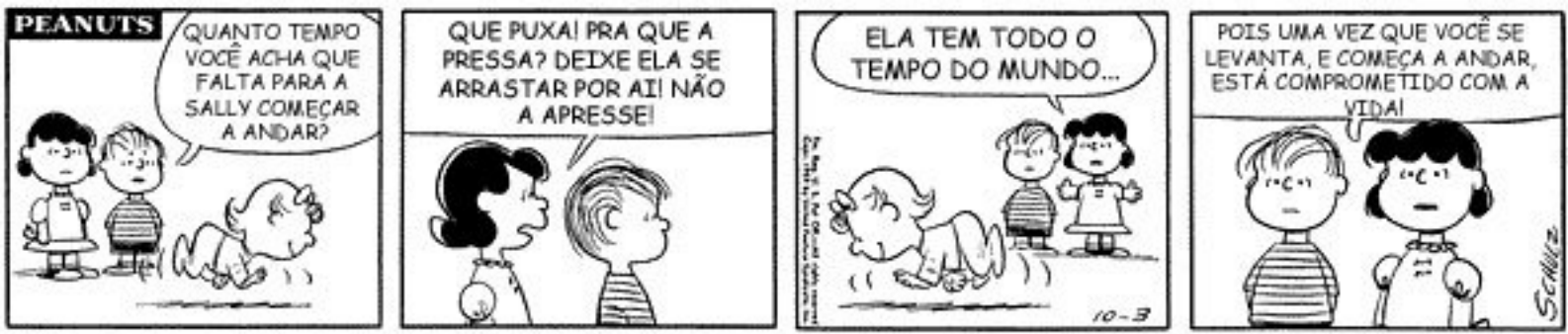
Canção do Novo Mundo

(Beto Guedes e Ronaldo Bastos)

Quem sonhou

Só vale se já sonhou demais

Vertente de muitas gerações

Gravado em nosso corações

Um nome se escreve fundo

As canções em nossa memória

Vão ficar

Profundas raízes vão crescer

A luz das pessoas

Me faz crer

E eu sinto que vamos juntos

Oh! Nem o tempo amigo

Nem a força bruta

Pode um sonho apagar

Quem perdeu o trem da história por querer

Saiu do juízo sem saber

Foi mais um covarde a se esconder

Diante de um novo mundo

Quem souber dizer a exata explicação

Me diz como pode acontecer

Um simples canalha mata um rei

Em menos de um segundo

Oh! Minha estrela amiga

Porque você não fez a bala parar

Oh! Nem o tempo amigo

Nem a força bruta

Pode um sonho apagar

Quem perdeu o trem da história por querer

Saiu do juízo sem saber

Foi mais um covarde a se esconder

Diante de um novo mundo 


\section{RESUMO}

Barbo, F.E. Composição, História Natural, Diversidade e Distribuição das Serpentes no Município de São Paulo, SP. 2008. 90 f. Dissertação (Mestrado em Biotecnologia) - Instituto de Ciências Biomédicas, Universidade de São Paulo, São Paulo, 2008.

As informações disponíveis sobre taxocenoses de serpentes em fisionomias brasileiras têm aumentado na última década, porém poucos estudos detalhados sobre comunidades em fragmentos urbanos foram realizados. O município de São Paulo possui 62.356 ha e apenas $16 \%$ de áreas verdes, distribuídas em fragmentos pequenos e dispersos. Este trabalho teve como objetivos analisar a composição e história natural das espécies, enfocando aspectos da diversidade (riqueza, dominância e abundância relativa de espécies) e distribuição. Cinco unidades climáticas do município foram agrupadas em três áreas (Norte, Central e Sul). A distribuição foi caracterizada através do georreferenciamento dos endereços de captura de serpentes recebidas pelo Instituto Butantan. Ao longo de 44 meses de amostragem, foram registradas 38 espécies de cinco famílias. Houve predominância de espécies terrícolas e batracófagas. Maior abundância foi observada na estação chuvosa, e deve estar relacionada à maior disponibilidade de presas e/ou a reprodução. A espécie dominante foi Oxyrhopus guibei, com 24 \% de dominância, seguida de Sibynomorphus mikanii (21 \%) e Bothrops jararaca (16 \%). Outras seis espécies foram consideradas comuns, seis de abundância intermediária e 23 foram consideradas raras. As três áreas não apresentaram diferenças significativas em relação à riqueza de espécies, porém a Área Sul apresentou a menor diversidade, pois a dominância observada foi significativamente maior em relação às estimadas para as Áreas Norte e Central. A Área Central apresentou a maior diversidade, com espécies típicas de diferentes fisionomias vegetais, como o Cerrado, Serra do Mar e Serra da Mantiqueira. Nas áreas Norte e Sul predominaram as espécies da Serra da Mantiqueira e Serra do Mar, respectivamente. Historicamente, a região onde se insere o município de São Paulo apresentava um mosaico de diferentes formações vegetais e, atualmente, apesar de encontrarem-se bastante fragmentadas devido ao crescimento urbano, ainda abrigam conjuntamente alta diversidade de espécies de serpentes.

Palavras-chave: serpentes, diversidade, história natural, distribuição, município de São Paulo 


\begin{abstract}
Barbo, F.E. Composition, Natural History, Diversity and Distribution of Snakes in Municipality of São Paulo, SP. 2008. $90 \mathrm{f}$. Master thesis (Biotechnology) Instituto de Ciências Biomédicas, Universidade de São Paulo, São Paulo, 2008.
\end{abstract}

The information on snakes assemblages in Brazilian physiognomies have increased in the last decade. However, few detailed studies about communities in urban fragments were realized. The municipality of São Paulo has 62,356 ha, and only $16 \%$ of green areas, distributed in small and disperse fragments. The present work aimed evaluate the species composition and natural history, focusing the aspects of diversity (richness, dominance and relative abundance of species) and distribution. Five climatic units of the municipality were grouped in three areas (North, Central and South). The distribution was characterized through georeferencing the capture addresses of snakes received by Instituto Butantan. Throughout 44 months of sampling, we registered 38 species belonging to five families. The terrestrial and anurophagous species were predominant. Greater abundance was observed during the rainy season, and should be related to prey availability and/or reproduction. The dominant species was Oxyrhopus guibei, with $24 \%$ of dominance, followed by Sibynomorphus mikanii (21 \%), and Bothrops jararaca (16\%). Other six species were common, six were of intermediate abundance, and 23 were considered rare. The three areas did not show significant differences in species richness. But the South Area showed the smaller diversity, because its observed dominance was significantly greater than the estimated dominance of North and Central Areas. The Central Area presented the greater diversity, with typical species from different physiognomic forms as the Cerrado, the Serra do Mar and the Serra da Mantiqueira. The species of Serra da Mantiqueira and Serra do Mar were predominant In North and South areas, respectively. Historically, the region where the municipality of São Paulo is inserted showed a mosaic of different physiognomic forms and despite of being fragmented nowadays due to the urban growth, they still enclose together a high diversity of snake species.

Key-words: snakes, diversity, natural history, distribution, municipality of São Paulo 


\section{LISTA DE FIGURAS}

FIGURA 1. Área de estudo: Imagem de satélite do Município de São Paulo, destacando a vegetação remanescente e a área urbanizada. 6

FIGURA 2. Área de estudo: Unidades climáticas do município de São Paulo. 7

FIGURA 3. Área de estudo: A - Variação histórica da pluviosidade mensal, temperatura máxima e mínima mensais, e B - do período de agosto de 2003 a março de 2007, no Município de São Paulo.

8

FIGURA 4. (4.1 até 4.42) Prancha de Fotos: Espécies registradas para o Município de São Paulo entre de agosto de 2003 e março 2007. 16 a 22

FIGURA 5. História Natural: abundância sazonal de Liotyphlops beui. 14

FIGURA 6. História Natural: abundância sazonal de Apostolepis assimilis. 24

FIGURA 7. História Natural: abundância sazonal de Liophis miliaris 30

FIGURA 8. História Natural: ciclo reprodutivo das fêmeas de Oxyrhopus guibei... 32

FIGURA 9. História Natural: abundância sazonal de Oxyrhopus guibei.. 33

FIGURA 10. História Natural: abundância sazonal de Philodryas patagoniensis..... 35

FIGURA 11. História Natural: ciclo reprodutivo de fêmeas de Sibynomorphus mikanii.. 36

FIGURA 12. História Natural: abundância sazonal de Sibynomorphus mikanii. 37

FIGURA 13. História Natural: abundância sazonal de Tomodon dorsatus. 40 
FIGURA 14. História Natural: abundância sazonal de Bothrops jararaca

FIGURA 15. História Natural: número absoluto e porcentagem do uso do substrato pelas espécies.

FIGURA 16. História Natural: número absoluto e porcentagem de itens da dieta das espécies.

FIGURA 17. História Natural: abundância sazonal das serpentes recebidas no período de 44 meses de amostragem

FIGURA 18. Diversidade e Distribuição: Abundância relativa de espécies.

FIGURA 19. Diversidade e Distribuição: Curva de rarefação de espécies.

FIGURA 20. Diversidade e Distribuição: Distribuição das serpentes nas três áreas do Município de São Paulo.

FIGURA 21. Diversidade e Distribuição: Abundância relativa de espécies nas três áreas do Município de São Paulo

FIGURA 22. Diversidade e Distribuição: Curvas de rarefação de espécies das três áreas do Município de São Paulo. 


\section{LISTA DE TABELAS}

Tabela 1. Composição de espécies: lista de espécies de serpentes registradas no Município de São Paulo entre agosto de 2003 e março de 2007

Tabela 2. Número de indivíduos, riqueza e dominância observada e estimada por rarefação, das serpentes encontradas nas três áreas do Município de São Paulo 


\section{LISTA DE ABREVIATURAS E SIGLAS}

CRC - Comprimento rostro-cloacal

CC - Comprimento da cauda

Fig. - figura

ha - hectare

$\mathrm{m}$ - metro

$\mathrm{mm}$ - milímetros

MSP - Município de São Paulo

MZUSP - Museu de Zoologia da Universidade de São Paulo 


\section{SUMÁRIO}

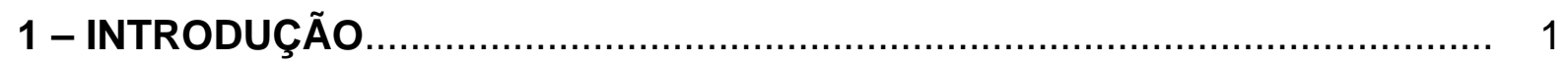

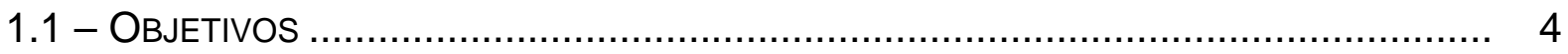

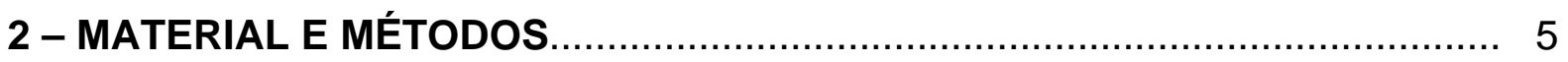

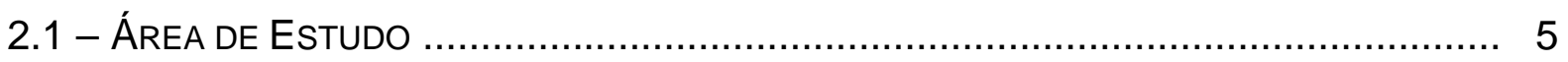

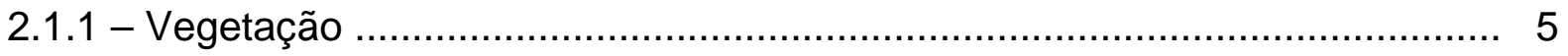

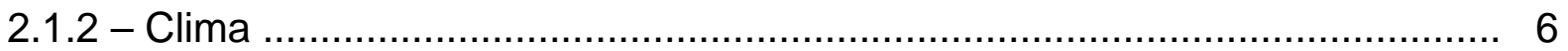

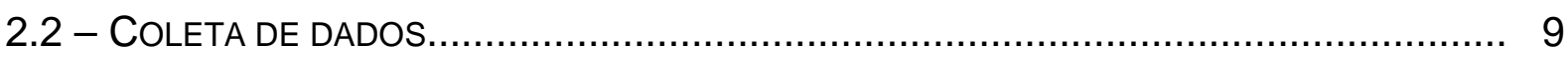

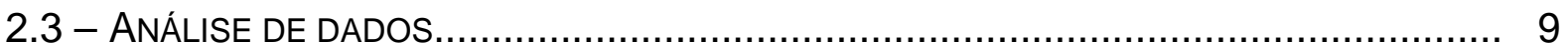

3 - RESULTADOS

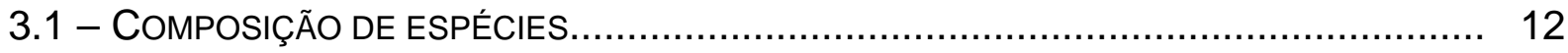

3.1.1 - Lista de espécies.................................................................. 12

3.1.2 - Comentários taxonômicos................................................................ 12

3.2 - HISTÓRIA NATURAL DAS ESPÉCIES....................................................... 13

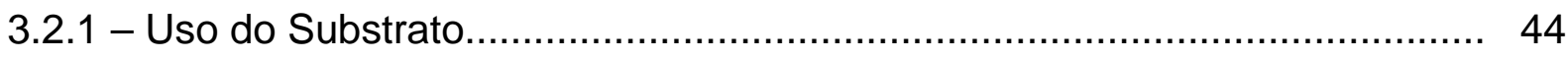

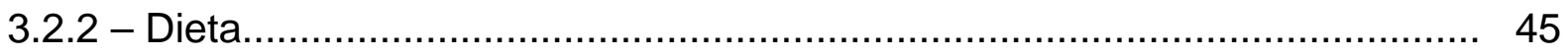

3.2.3 - Atividade Sazonal ..................................................................... 45

3.3 - DIVERSIDADE E DISTRIBUIÇÃO ........................................................... 46

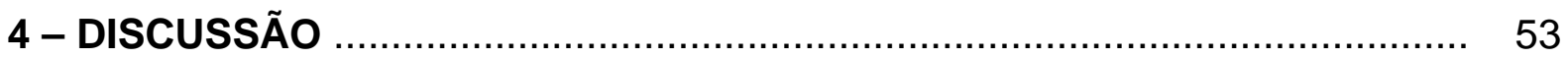

4.1 - COMPOSIÇÃO DE ESPÉCIES................................................................ 53

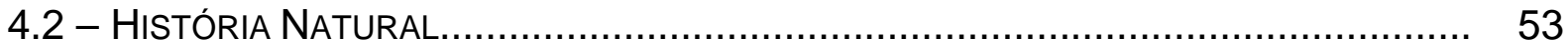

4.3 - DIVERSIDADE E DISTRIBUIÇÃO........................................................ 55

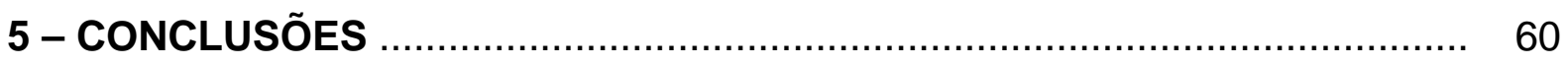

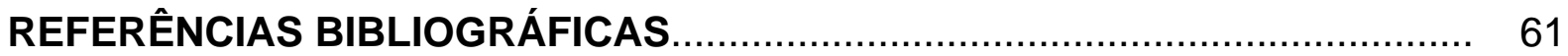




\section{1 - INTRODUÇÃO}

A história natural descreve onde estão os organismos e o que fazem em seus respectivos ambientes, incluindo as interações entre eles (GREENE, 1994). É fundamental para diversas áreas da biologia, como ecologia, biologia evolutiva e conservação (GREENE e LOSOS, 1988; HILLIS, 1995). A ecologia de comunidades enfoca a história natural das várias espécies em uma localidade ou ao longo do ambiente, os padrões de diversidade (e. g. riqueza, dominância e abundância relativa de espécies), distribuição, uso de recursos e os processos e mecanismos que geram esses padrões (POUGH et al., 2004). A estrutura de uma comunidade ou taxocenose inclui a composição e diversidade de espécies, padrões morfológicos, forma de utilização de recursos e distribuição ao longo do espaço e do tempo (RICKLEFS, 1990; POUGH et al., 2004; SAWAYA, 2004). A estruturação de uma comunidade ou taxocenose pode ser influenciada por fatores históricos, como biogeografia (CADLE e GREENE, 1993; MARTINS, 1994; MARQUES, 1998; SAWAYA, 2004), história de irradiação das linhagens de espécies e filogenia, e/ou fatores ecológicos, como condições ambientais (SAWAYA, 2004), competição (HENDERSON; DIXON e SOINI, 1979; VITT e VANGILDER, 1983), predação e parasitismo.

Informações sobre distribuição de espécies são raramente disponíveis para estudos biogeográficos ou indicação de áreas prioritárias para conservação (PIMM, et al., 1995; CRISCl, 2001). Os padrões de distribuição de espécies não são uniformes e contínuos no espaço e no tempo (CAUGHLEY, 1978), e a identificação dos fatores que influenciam esta variação é uma questão fundamental da ecologia (e.g. ELTON, 1927; KREBS, 1978; BROWN, 1984; NIX e GILLISON, 1985). Sabe-se que fatores como temperatura, precipitação ou disponibilidade de refúgios podem afetar a distribuição geográfica das espécies (HUTCHINSON, 1957; UDVARDY, 1969; MACARTHUR, 1972).

Trabalhos sobre distribuição, história natural e ecologia de serpentes brasileiras são escassos (SAZIMA e HADDAD, 1992). Assim, a caracterização de padrões alimentares, reprodutivos, comportamentais e evolutivos destes animais é dificultada, impedindo o planejamento efetivo para a conservação e manejo de remanescentes florestais e, conseqüentemente, das serpentes. Os poucos estudos mais abrangentes sobre serpentes têm contribuído de forma muito menos 
significativa para a formulação de hipóteses relativas à ecologia de comunidades do que estudos sobre peixes, pequenos mamíferos, aves e lagartos (VITT,1987). Com exceção de alguns trabalhos recentes e detalhados realizados com algumas espécies de áreas tropicais do sudeste do Brasil (e.g. LAPORTA-FERREIRA; SALOMÃO e SAWAYA, 1986; SAZIMA, 1992; MARQUES e PUORTO, 1991, 1994; MARQUES, 1992; 1996, 1998; JORDÃO, 1996; MARQUES; ETEROVIC e ENDO, 2000; MARQUES; ETEROVIC e SAZIMA, 2001; OLIVEIRA, 2001; ALMEIDASANTOS e SALOMÃO, 2002; MARTINS; MARQUES e SAZIMA, 2002; PIZZATTO e MARQUES, 2002; OUTEIRAL e CECHIN, 2003; HARTMANN e MARQUES, 2005; BIZERRA; MARQUES e SAZIMA, 2005; MARQUES et al. 2006), o conhecimento sobre história natural de serpentes neotropicais ainda é precário para a maioria das espécies. O estudo com serpentes preservadas em coleções científicas, entretanto, tem permitido a obtenção da maioria dos dados básicos sobre alimentação, reprodução e forma do corpo, contribuindo para o aumento do conhecimento sobre a história natural de algumas espécies (e.g. MARQUES, 1998; OLIVEIRA, 2001; NOGUEIRA; SAWAYA e MARTINS, 2003; SAWAYA, 2004; MARQUES et al., 2006). Além disto, informações sobre história natural obtidas em coleções permitem 0 desenvolvimento de teorias sobre os padrões de distribuição de espécies e aplicações em análises de biodiversidade e conservação (GRAHAM et al., 2004).

A alimentação e a reprodução podem ser estudadas a partir de animais preservados em coleções científicas e são aspectos amplamente estudados em história natural de serpentes (e.g. MUSHINSKY, 1987; SEIGEL e FORD, 1987; MARQUES, 1998). Fornecem informações importantes para diferentes áreas como sistemática, etologia e ecologia evolutiva (STEARNS, 1992), além de estarem relacionadas a aspectos morfológicos, comportamentais, fisiológicos e filogenéticos (POUGH e GROVES, 1983; VITT e VANGILDER, 1983; MARTINS, 1994; MARTINS et al., 2001). As serpentes apresentam grande diversidade de hábitos alimentares (MUSHINSKY, 1987; GREENE, 1997). Além de diversos grupos de invertebrados, podem se alimentar de vertebrados, incluindo peixes, anfíbios, anfisbenídeos, lagartos, serpentes, aves e mamíferos (GREENE,1997). As características reprodutivas estão intimamente relacionadas aos hábitos alimentares de serpentes, uma vez que o sucesso reprodutivo depende das reservas energéticas obtidas a partir da ingestão de alimentos (STEARNS, 1992). As serpentes de áreas tropicais são mais difíceis de serem caracterizadas em relação à sazonalidade reprodutiva 
(FITCH 1970, 1982). Isso se deve, em parte, à complexidade dos climas tropicais (MARQUES, 1998). Embora em regiões tropicais as temperaturas oscilem menos do que em áreas temperadas, algumas regiões podem apresentar um ou mais ciclos de seca e chuvas e, além disso, diferenças topográficas têm efeitos acentuados no clima de localidades próximas (GREENE, 1997).

A Floresta Atlântica brasileira apresenta fragmentos florestais relativamente antigos e possui um dos mais elevados níveis de endemismo de animais e plantas entre as florestas tropicais (KLEIN, 1980; PRANCE, 1982 a, b; BROWN, 1987; LEITÃO FILHO, 1994; THOMAS et al., 1998). Apesar de iniciados a cerca de 500 anos, a maior parte dos desmatamentos neste bioma ocorreu nos últimos 100 anos e seus efeitos sobre a biota ainda são relativamente desconhecidos (MMA, 2003). Mesmo antes do descobrimento, a região do Planalto Paulistano já era um núcleo de povoamento importante para os índios tupiniquins, que provavelmente modificaram a vegetação original (PETRONE, 1995).

Em um dos primeiros trabalhos sobre a vegetação do município de São Paulo, Usteri (1911) considerou não haver mais Mata Atlântica primária na região. O longo histórico de perturbação antrópica e a conseqüente modificação das condições naturais tornam mais difícil a reconstituição da vegetação original do município de São Paulo. Acredita-se, porém, que a região apresentava uma paisagem original predominantemente florestal, com áreas de várzea, campos de altitude e florestas (USTERI, 1911), às vezes com a presença de Araucaria angustifolia, e a ocorrência de Cerrado em campos confinados a áreas com condições de solo particulares (AB'SÁBER, 1963, 1970). Em meados do século XIX, com a expansão da cultura cafeeira, a maior parte da cobertura florestal da região foi devastada, desde a Serra da Cantareira até os limites da Serra do Mar (MANTOVANI, 2000). No início do século XX, com a construção da Represa Guarapiranga e posteriormente da Represa Billings, na região sul, extensas regiões cobertas por vegetação nativa foram ocupadas pelos dois reservatórios (MANTOVANI, 2000). Pouco resta da vegetação nativa do Planalto Paulistano, e as raras áreas cobertas por florestas naturais se apresentam como fragmentos pequenos e dispersos (DISLICH; CERSÓSIMO e MANTOVANI, 2001). Os efeitos da fragmentação sobre florestas causam mudanças físicas e bióticas, resultando na perda de ambiente e efeitos de insularização (LOVEJOY et al., 1986; LAURANCE, 1990). 
Com exceção de alguns trabalhos direcionados exclusivamente para o estudo de comunidades de serpentes em fisionomias brasileiras: (e. g. Amazônia: MARTINS, 1994; Caatinga: VITT e VANGILDER, 1983; Campo: CECHIN, 1999; Pantanal: STRÜSSMANN e SAZIMA, 1993; Mata de Araucária: DI-BERNARDO, 1998; Mata Atlântica: MARQUES, 1998; Cerrado: SAWAYA, 2004), não há nenhum estudo detalhado sobre comunidades de serpentes em fragmentos florestais urbanos. Para o município de São Paulo, o conhecimento sobre a fauna de serpentes é limitado a uma lista de 26 espécies recebidas no Instituto Butantan no período de 1989 e 1990 (PUORTO; LAPORTA-FERREIRA e SAZIMA, 1991), e a ocorrência de 16 espécies exóticas, recebidas pelo instituto entre 1995 e 2000 (ETEROVIC e DUARTE, 2001) e encontradas com freqüência em parques e pequenos fragmentos urbanos.

\section{1 - OBJETIVOS}

Este trabalho teve como objetivos o estudo da composição, história natural, diversidade, e distribuição de serpentes no Município de São Paulo, enfocando os seguintes aspectos:

1) caracterizar a composição e a diversidade (riqueza, dominância e abundância relativa de espécies);

2) caracterizar aspectos da história natural das espécies mais abundantes, incluindo uso do substrato, dieta, atividade sazonal e ciclo reprodutivo;

3) caracterizar a distribuição das espécies no município de São Paulo e seus remanescentes florestais; e

4) a partir das informações obtidas, avaliar a influência de fatores ecológicos (e.g. condições climáticas, estado de conservação, fragmentação de ambientes) e históricos na distribuição atual das espécies (e.g. influências das faunas da Serra do Mar e da Serra da Mantiqueira). 


\section{2 - MATERIAL E MÉTODOS}

\section{1 - AREA DE ESTUDO}

O Município de São Paulo (MSP) apresenta área total de aproximadamente 62.356 ha, dos quais 35.950 ha (cerca de 57,7\%) correspondem a áreas urbanizadas e alteradas, onde vive cerca de 65\% da população, estimada em 10 milhões de habitantes (PREFEITURA DO MUNICÍPIO DE SÃO PAULO, 2002). Entre estas áreas urbanizadas e alteradas, apenas 16,4\% (10.226 ha) são ocupados por áreas verdes, sendo 10,2\% (6.360 ha) na zona urbana e 6,1\% (3.803 ha) na zona rural (SILVA, 1993). Esses números refletem a escassez de áreas verdes existentes e a crescente supressão de espaço na zona rural, afetando de forma significativa a biodiversidade no território do município.

\subsection{1 - Vegetação}

Atualmente, a cidade de São Paulo é constituída basicamente por fragmentos de vegetação secundária, que ainda resistem ao processo de expansão urbana (Fig. 1). Os maciços florestais nativos estão confinados nos limites do município: ao sul, principalmente na Área de Proteção Ambiental (APA) de Capivari - Monos, na península do Bororé e na margem direita da Represa Guarapiranga, onde se destacam as formações de Floresta Ombrófila Densa e Mata Nebular, além de campos naturais e formações de várzea; e ao Norte, nos Parques Estaduais do Jaraguá e da Cantareira, além do Parque Municipal do Anhangüera, que abrangem os remanescentes de Floresta Ombrófila Montana e campos de altitude (PREFEITURA DO MUNICÍPIO DE SÃO PAULO, 2002); e no extremo leste do município, onde as porções remanescentes correspondem as APAs do Carmo e Iguatemi.

O Parque Estadual das Fontes do Ipiranga (Parque do Estado) se destaca por estar totalmente envolvido por área urbana, apresentando-se como uma ilha de vegetação com formações significativas, características de Floresta Ombrófila Densa, Floresta Estacional e Cerrado (PREFEITURA DO MUNICÍPIO DE SÃO PAULO, 2002). 


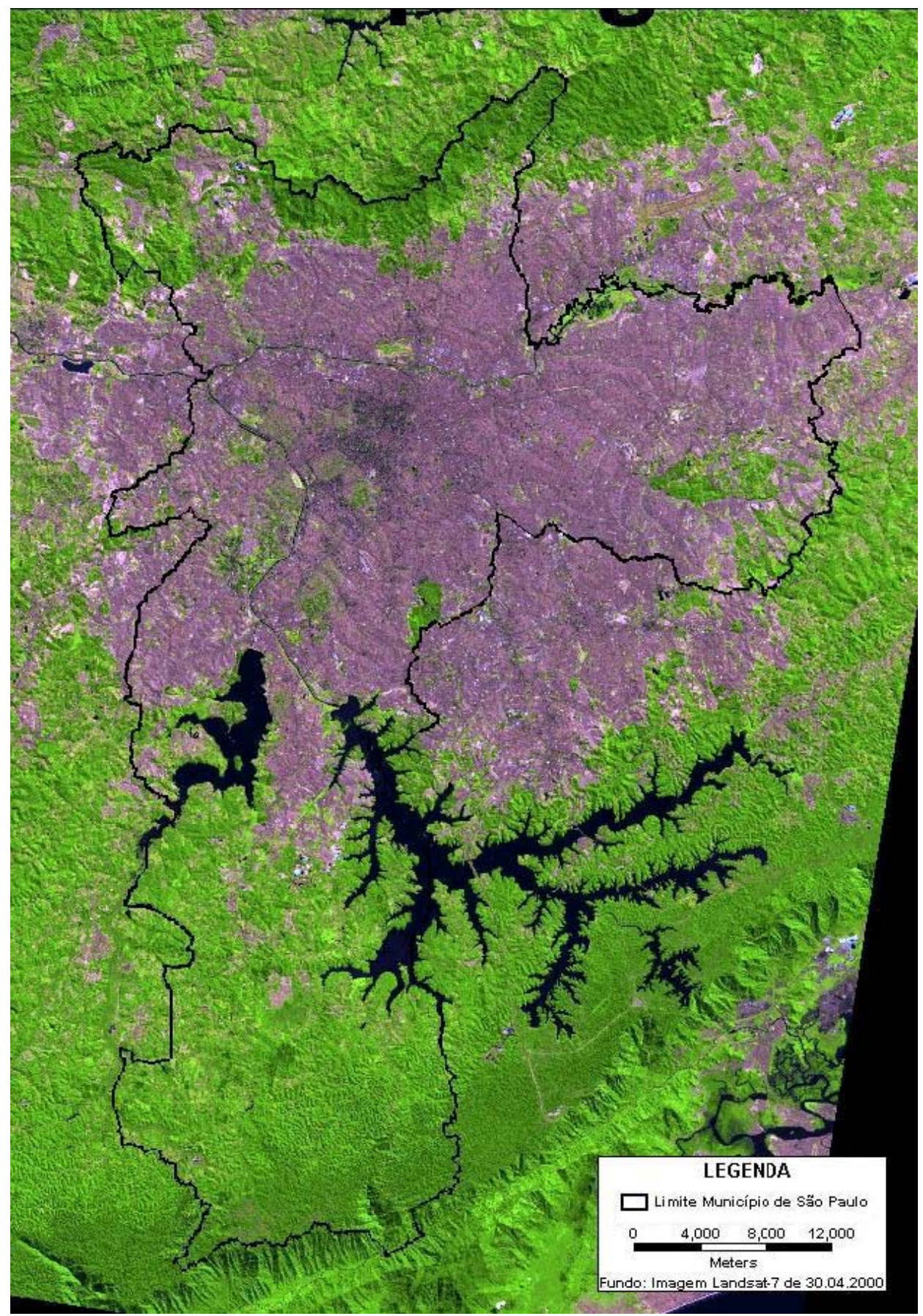

FIGURA 1. Imagem de satélite do Município de São Paulo, destacando a vegetação remanescente (em verde) e a área urbanizada (em roxo)

\subsection{2 - Clima}

O clima da cidade de São Paulo foi dividido em cinco unidades climáticas principais (Fig. 2), a partir de análises apresentadas no Atlas Ambiental do Município de São Paulo (PREFEITURA DO MUNICÍPIO DE SÃO PAULO, 2002), sendo: a 
Unidade I, definida como Clima Tropical Úmido de Altitude do Planalto Atlântico, ocupando a área da Bacia Sedimentar de São Paulo; a Unidade II, como Clima Tropical Úmido Serrano da Cantareira-Jaraguá; a Unidade III, como Clima Tropical Úmido de Altitude do Alto Juquerí, definida na face norte da Serra da Cantareira e do Pico do Jaraguá, entre 720 a 800 m de altitude; a Unidade IV, como Clima Tropical Sub-oceânico Superúmido do Reverso do Planalto Atlântico, ao sul da represa de Guarapiranga; e a Unidade V, denominada Clima Tropical Oceânico Superúmido da Fachada Oriental do Planalto Atlântico.

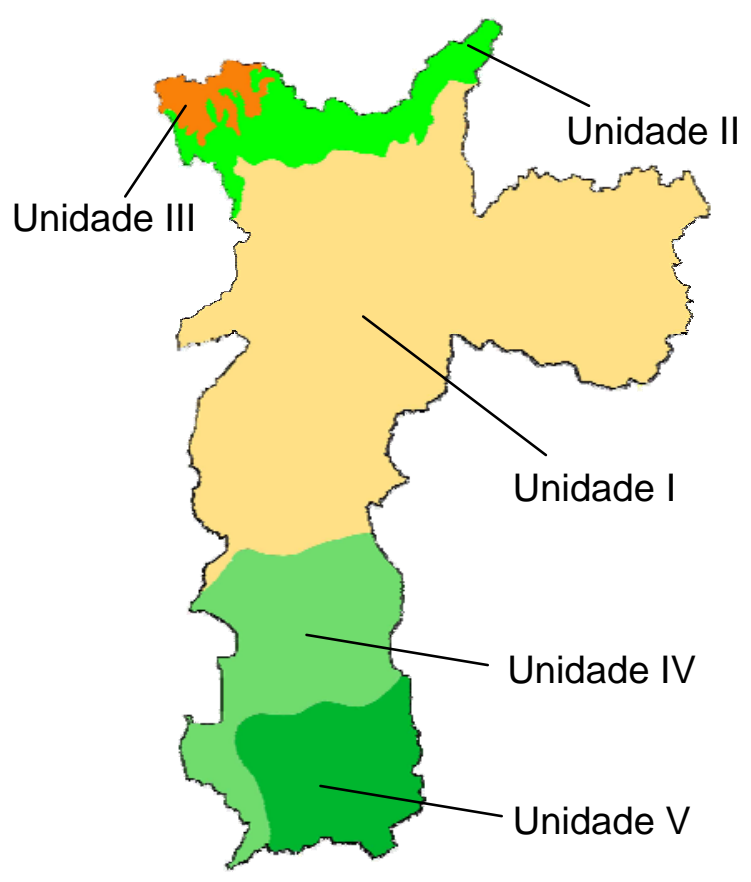

FIGURA 2. Unidades climáticas do município de São Paulo

Duas estações podem ser observadas ao longo do ano. Uma seca, entre abril e setembro, e uma chuvosa, entre outubro e março (Fig. 3A). No período de amostragem, entre agosto de 2003 e março de 2007, a precipitação mensal variou entre 2,7 e 141,2 mm, a temperatura mínima entre 6,9 e $13,7^{\circ} \mathrm{C}$, e a máxima entre 26 e $35,3^{\circ} \mathrm{C}$ durante a estação seca. Durante a estação chuvosa, a precipitação mensal variou entre 31 e $193 \mathrm{~mm}$, a temperatura mínima entre 6,2 e 18,3 ${ }^{\circ} \mathrm{C}$ e a temperatura máxima 30,7 e 35,3 ${ }^{\circ} \mathrm{C}$ (Fig. 3B). 

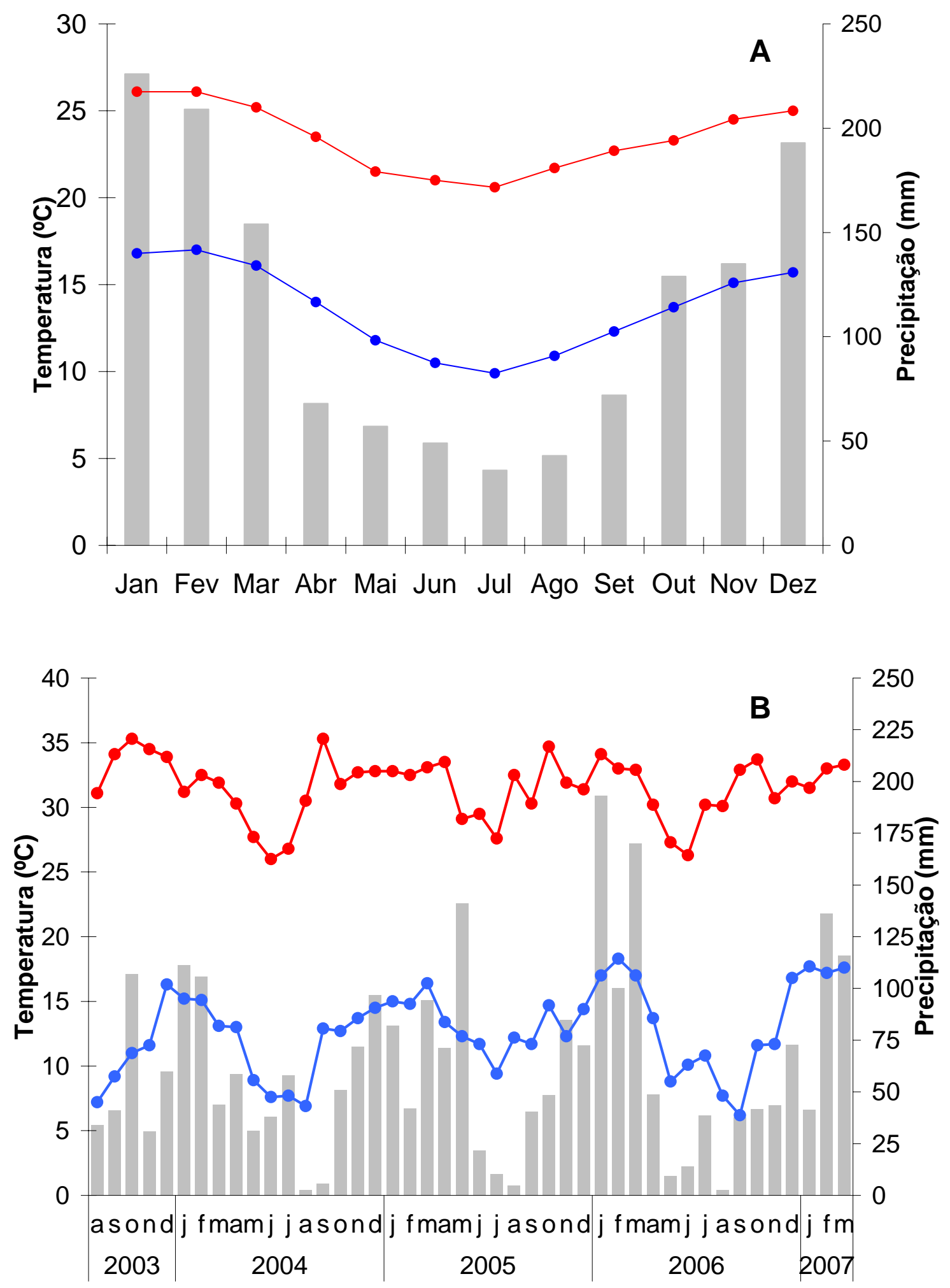

FIGURA 3. - A. Médias históricas (1950-2000) de temperaturas máximas (linha vermelha), mínimas (linha azul) e pluviosidade (barras) para o Município de São Paulo. B. Variação da pluviosidade mensal (barras), temperatura máxima (linha vermelha) e mínima (linha azul) mensais, entre agosto de 2003 e março de 2007, no Município de São Paulo. 


\section{2 - COLETA DE DADOS}

A amostragem correspondeu aos registros de todas as serpentes provenientes do Município de São Paulo (MSP) recebidas diariamente pelo Instituto Butantan entre agosto de 2003 e março de 2007 (44 meses). Foram registradas as seguintes informações de cada indivíduo: comprimento rostro-cloacal (CRC; mm) e da cauda ( $C$; mm), com régua milimetrada; massa (g); sexo; e informações adicionais, incluindo dados sobre dieta, reprodução e o endereço de captura.

A história natural das espécies registradas foi caracterizada através da coleta de dados em laboratório e dados disponíveis na literatura. Para a caracterização dos hábitos alimentares, foram feitas incisões ventrais ao longo dos dois terços posteriores do corpo das serpentes para o exame do tubo digestivo (cf. GREENE, 1989). No caso das presas inteiras, foi medido o comprimento do corpo e da cauda (régua milimetrada; mm). A massa de cada presa também foi obtida com dinamômetros portáteis (g). Para cada presa também foi anotado o sentido de ingestão, quando possível.

Para o registro de informações sobre ciclo reprodutivo de fêmeas (ciclo folicular), foi medido o comprimento do maior folículo ovariano ou ovo (paquímetro; 0,01 mm, cf. SHINE, 1977). Para análise da fecundidade foram contados os folículos grandes, maiores do que cinco milímetros, ou ovos/embriões nos ovidutos (MARQUES et al., 2006).

As informações sobre uso do substrato e atividade diária (hábitos diurnos, noturnos ou ambos) foram obtidas através de dados disponíveis na literatura, observação pessoal e dados fornecidos por pesquisadores.

\section{3 - ANÁLISE DE DADOS}

Durante os 44 meses de coleta de dados foi registrada a composição e a riqueza de espécies do município. Além da riqueza, um dos parâmetros de diversidade utilizado foi a dominância, determinada pelo índice de Berger-Parker (sensu MAGURRAN, 1988), que corresponde a porcentagem da espécie mais abundante em relação ao número total de indivíduos. O outro parâmetro de diversidade, a abundância relativa de espécies, foi caracterizado em uma tabela de freqüências com o número de indivíduos registrado para cada espécie e porcentagens em relação ao número total de indivíduos. A abundância relativa de espécies também foi caracterizada visualmente em gráfico de colunas. Para verificar 
se foram registradas todas as espécies que ocorrem no MSP foi confeccionada uma curva de rarefação de espécies (sensu GOTELLI, 2001) considerando cada indivíduo como uma amostra, no programa EstimateS 8.00 (COLWELL, 1997), com 1000 aleatorizações. O programa gera as curvas de rarefação a partir de 1000 curvas de acumulação de espécies aleatorizando a ordem das amostras sem reposição, ou seja, cada ponto da curva corresponde à média das 1000 curvas geradas e está associado a um desvio padrão.

Os dados de história natural incluíram informações sobre tamanho do corpo, uso do substrato, atividade diária e sazonal, dieta e reprodução. Dados de reprodução incluíram época de ovulação e nascimento/eclosão dos filhotes (recrutamento). A dieta foi caracterizada de forma qualitativa, a partir de registros da literatura, e, quando possível, quantitativa a partir das categorias de presas encontradas durante o trabalho de laboratório. A atividade sazonal de todas as espécies também foi caracterizada a partir da abundância mensal de serpentes registrada na recepção do Laboratório de Herpetologia. Para verificar se houve diferença significativa na abundância sazonal de serpentes entre a estação chuvosa e a estação seca, foi utilizado o teste de Qui-quadrado (ZAR, 1996).

A distribuição das espécies e indivíduos foi analisada através de mapeamento das coordenadas geográficas obtidas para cada indivíduo. As coordenadas geográficas foram obtidas a partir do georreferenciamento dos registros de serpentes com endereço exato de captura no programa Maplink (http://maplink.uol.com.br). Estes registros foram então mapeados com o programa DIVA-GIS ${ }^{\circledR}$ versão 5.2.0.4 (HIJMANS, et al., 2001). O programa utiliza um sistema de informações geográficas (SIG) para análises de dados de biodiversidade, no qual é possível analisar a distribuição geográfica das espécies em relação à ocorrência e diversidade. Devido ao baixo número de registros para a região sul do município e maior concentração na região central, as cinco unidades climáticas do município (veja acima Fig. 2, pág. 7) foram agrupadas em três áreas (veja Fig. 20, pág.49): Área Norte (unidade II + unidade III), Área Central (unidade I) e Área Sul (unidade IV + unidade V). Essas áreas foram recortadas do mapa do município de São Paulo e transformadas em arquivos de superfícies (shapefiles) no programa ArcView GIS 3.2 (ESRI, 1999). Esses arquivos de superfícies e os registros de serpentes foram então inseridos no programa Diva-GIS para comparação da composição e diversidade de serpentes entre as áreas Norte, Central e Sul. 
A riqueza de espécies das três áreas foi comparada através de curvas de rarefação de espécies (sensu GOTELLI, 2001), no programa EstimateS 8.00 (COLWELL, 1997), com 1000 aleatorizações. Para a confecção das curvas, cada indivíduo foi considerado uma amostra.

Geralmente, a riqueza de espécies é altamente correlacionada com o número de indivíduos amostrados (MELO et al., 2003). Assim, para comparar a riqueza e a dominância entre as três áreas do MSP, foi utilizado o método da rarefação de espécies (SANDERS, 1968). Este método estima a riqueza e a dominância de amostras com maior número de indivíduos, retirando aleatoriamente destas o número de indivíduos da menor amostra, tornando-as comparáveis. As análises de rarefação foram feitas no programa Ecosim 7.00, com 1000 aleatorizações (GOTELLI e ENTSMINGER, 2001; ZAR, 1996). 


\section{3 - RESULTADOS}

\section{1 - COMPOSIÇÃO DE ESPÉCIES}

\subsection{1 - Lista de Espécies}

Entre agosto de 2003 e março de 2007, foram registradas 1742 serpentes, distribuídas em cinco famílias, 24 gêneros e 38 espécies (Tabela 1).

\subsection{2 - Comentários Taxonômicos}

Foram utilizadas neste estudo, as denominações de subespécies apenas para as espécies que podem incluir mais de uma forma sob o mesmo nome específico.

O nome Erythrolamprus aesculapii (LINNAEUS, 1766) pode incluir duas formas distintas na região sudeste (cf. MARQUES e PUORTO, 1991), atualmente denominadas Erythrolamprus aesculapii monozona JAN, 1863, distribuída principalmente na faixa litorânea da Serra do Mar, e E. a. venustissimus (WIED, 1821), que ocorre na porção oeste do continente e no Cerrado. Erythrolamprus a. monozona possui uma seqüência de anéis brancos estreitos interpostos entre os pretos e os vermelhos (do tipo mônades), enquanto que a $E$. a. venustissimus, possui seqüências de dois anéis pretos, separados por um anel branco (do tipo díades), sendo cada um dos pretos em contato com o vermelho. Apesar de ocuparem fisionomias distintas, são simpátricas em algumas áreas de transição, como o município de São Paulo. Atualmente, o status taxonômico de E. aesculapii spp. ainda se encontra indefinido e em fase de estudos (F. CURCIO, 2007) ${ }^{1}$.

O gênero Echinanthera Cope, vem sendo estudado há algum tempo por diversos autores (e.g. DI-BERNARDO, 1992, 1996; MYERS e CADLE, 1994; SCHARGEL; FUENMAYOR e MYERS, 2005), porém ainda apresenta sua taxonomia pouco resolvida. Recentemente, um trabalho desenvolvido por Schargel, et al., 2005, analisando a folidose e algumas outras características da anatomia do hemipênis, concluiu que as espécies E. affinis, E. persimilis, E. bilineata e $E$. occipitalis apresentam caracteres não compartilhados com as outras espécies do gênero Echinanthera.

\footnotetext{
${ }^{1}$ CURCIO, F. F. São Paulo, 2007. (comunicação pessoal)
} 
TABELA 1 - Lista de espécies de serpentes registradas no Município de São Paulo, entre agosto de 2003 e março de 2007 ( $N=1742$ ), número de indivíduos $(\mathrm{N})$ e porcentagem em relação ao número total de indivíduos (\%).

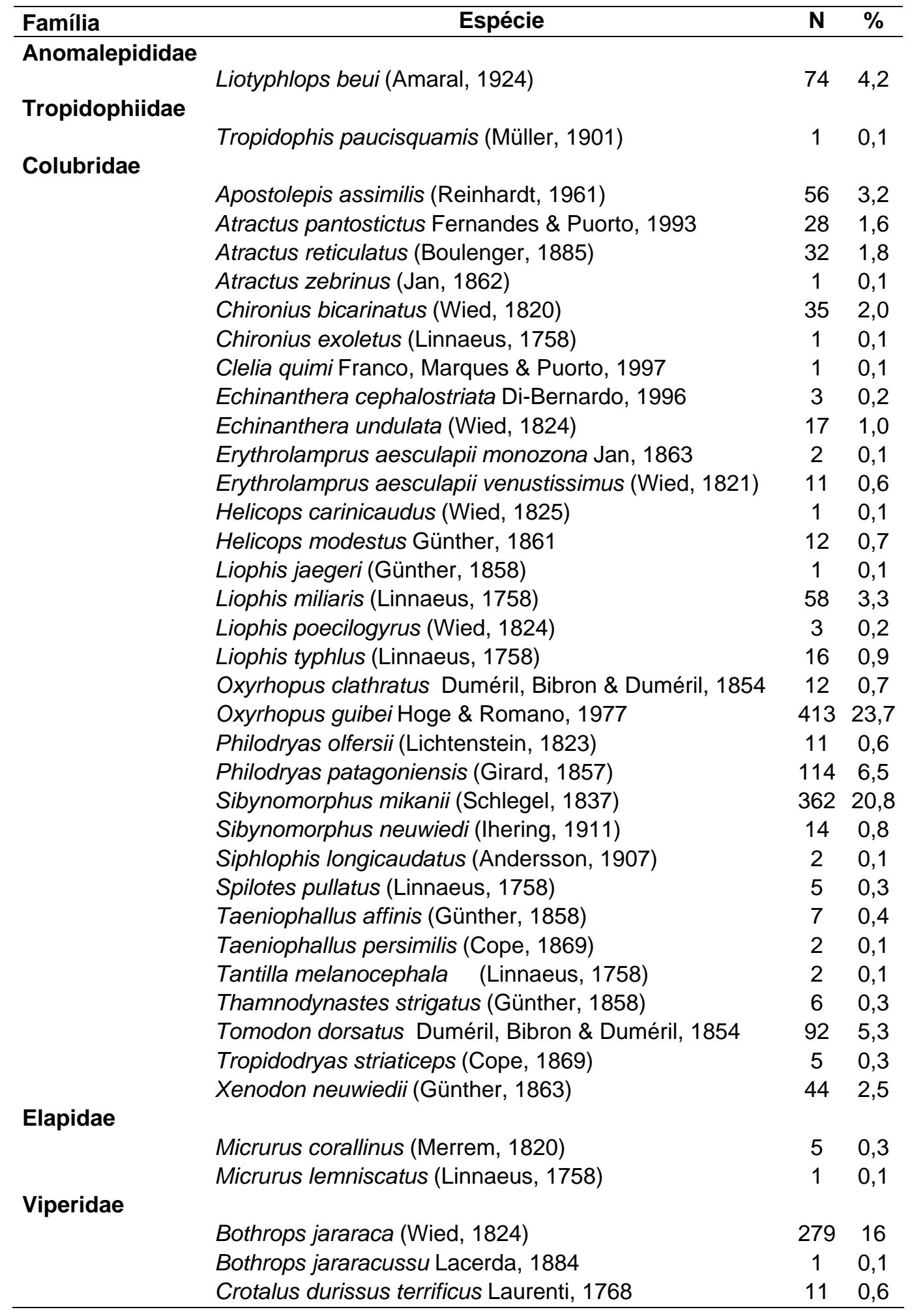


Portanto, para a região sudeste, o gênero Echinanthera é composto atualmente pelas espécies E. amoena, E. cephalostriata, E. cephalomaculata e E. undulata, e o gênero Taeniophallus Cope pelas espécies $T$. affinis, $T$. bilineata, $T$. occipitalis e $T$. persimilis.

\section{2 - HISTÓRIA NATURAL DAS ESPÉCIES}

\section{Família Anomalepididae TAYLOR, 1939}

Liotyphlops beui (AMARAL, 1924), “cobra-cega”, (Fig. 4.1)

Espécie comum no Município de São Paulo (MSP) $(N=74)$. Apresenta hábitos fossoriais e atividade predominantemente noturna (PARPINELLI, 2007) ${ }^{2}$.

A atividade sazonal, caracterizada pela abundância mensal de espécimes, apresentou picos no início da estação chuvosa, em outubro $(\mathrm{N}=13)$ e, no final, em $\operatorname{março~}(\mathrm{N}=13)$ (Fig. 5).

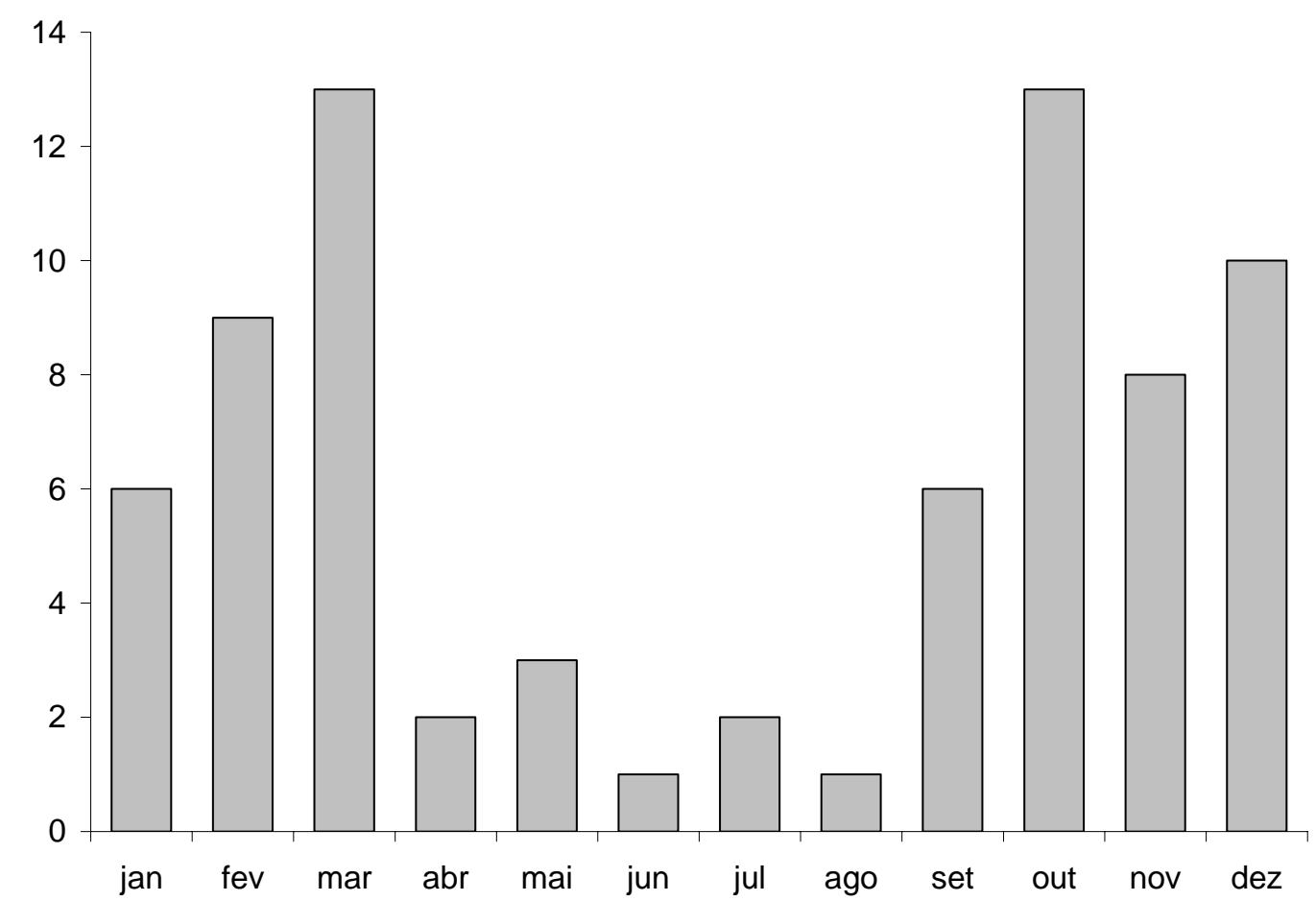

FIGURA 5. Atividade sazonal de Liotyphlops beui, caracterizada pela abundância mensal de espécimes entre agosto de 2003 e março de 2007.

\footnotetext{
${ }^{2}$ PARPINELLI, L. São Paulo, 2007. (comunicação pessoal)
} 
A dieta é especializada em larvas e pupas de formigas, principalmente Solenopsis sp. (PARPINELLI, 2007) ${ }^{3}$.

Essa espécie é ovípara e uma fêmea $(C R C=280)$ recebida no mês de setembro, continha sete ovos no oviduto, o maior deles com diâmetro de 8,31 mm. Outra fêmea $(C R C=314)$, recebida no final de outubro apresentava quatro folículos vitelogênicos, o maior com 12,85 mm de diâmetro. Foi encontrada com freqüência nas áreas Central e Norte.

${ }^{3}$ PARPINELLI, L. São Paulo, 2007. (comunicação pessoal) 


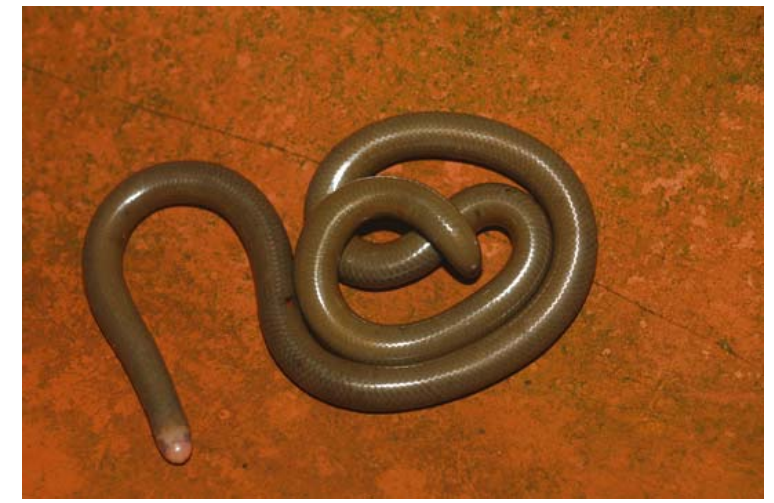

FIGURA 4.1. Liotyphlops beui (cobra-cega), Anomalepididae. $(\mathrm{N}=74)$.

CRC médio $=218 \mathrm{~mm}$

Foto: Antonio C.O.R. da Costa

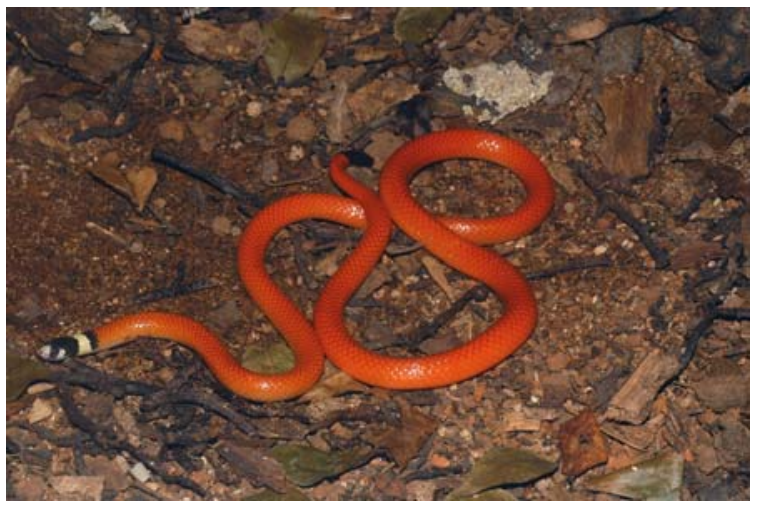

FIGURA 4.3. Apostolepis assimilis (falsacoral), Colubridae. $(\mathrm{N}=56)$. $\mathrm{CRC}$ médio $=318 \mathrm{~mm}$

Foto: Antonio C.O.R. da Costa

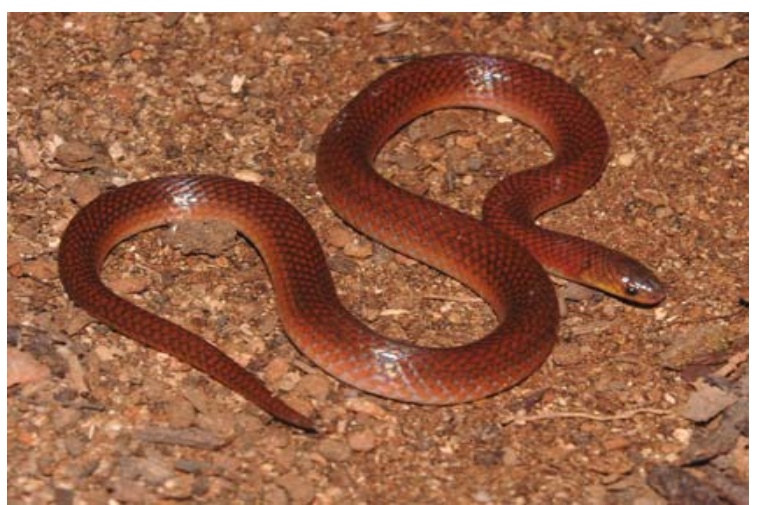

FIGURA 4.5. Atractus reticulatus (fura-terra), Colubridae. $(\mathrm{N}=32)$. CRC médio $=254,2 \mathrm{~mm}$

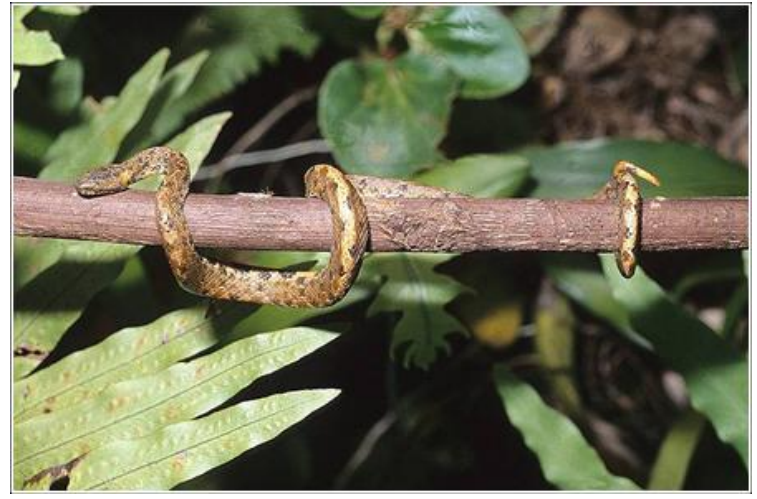

FIGURA 4.2. Tropidophis paucisquamis (jiboinha), Tropidophiidae. $(\mathrm{N}=1)$. $\mathrm{CRC}=294 \mathrm{~mm}$

Foto: Otavio A.V. Marques

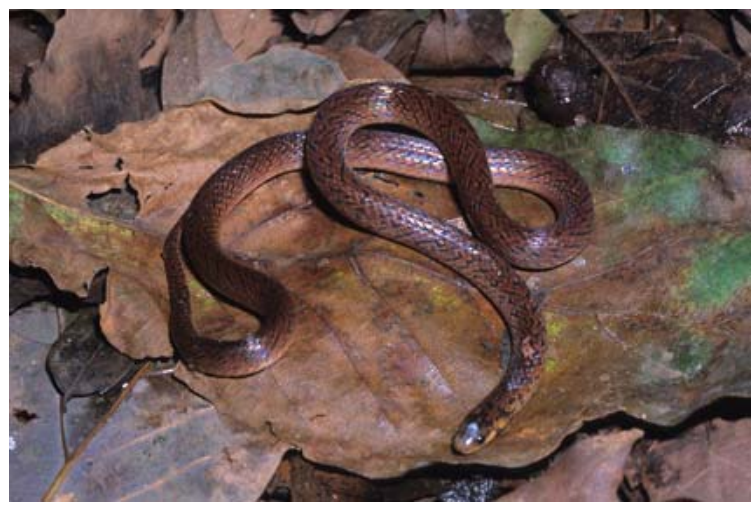

FIGURA 4.4. Atractus pantostictus (furaterra), Colubridae. $(\mathrm{N}=28)$. CRC médio $=246,5 \mathrm{~mm}$ Foto: Otavio A. V. Marques

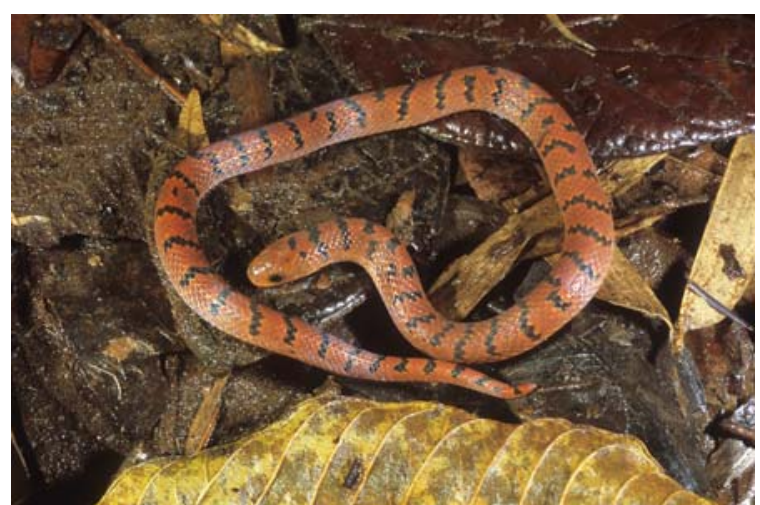

FIGURA 4.6. Atractus zebrinus (fura-terra), Colubridae. $(\mathrm{N}=1)$.

$\mathrm{CRC}=184 \mathrm{~mm}$

Foto: Ricardo J. Sawaya 


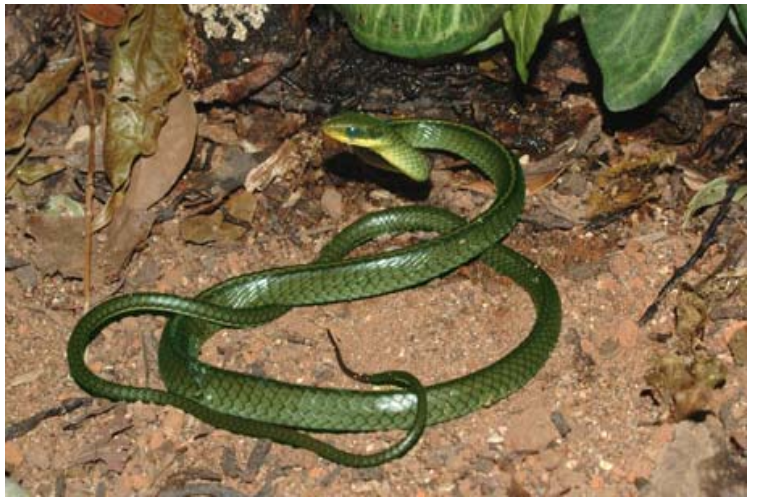

FIGURA 4.7. Chironius bicarinatus (cobracipó), Colubridae. $(\mathrm{N}=28)$.

CRC médio $=500 \mathrm{~mm}$

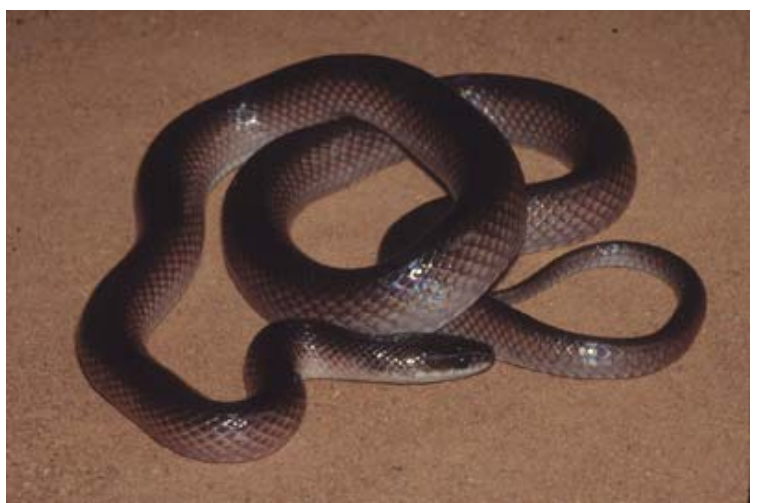

FIGURA 4.9. Clelia quimi (muçurana), Colubridae. $(\mathrm{N}=1)$.

$\mathrm{CRC}=390 \mathrm{~mm}$

Foto: Giuseppe Puorto

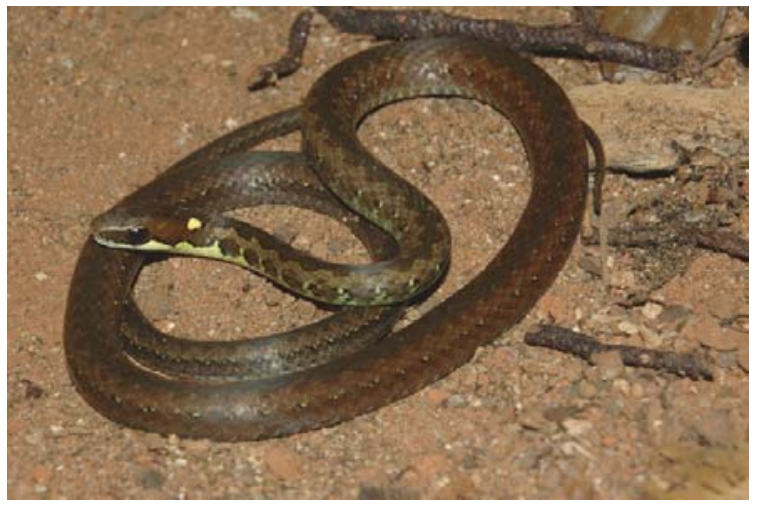

FIGURA 4.11. Echinanthera undulata (paparã), Colubridae. $(\mathrm{N}=17)$. CRC médio $=266 \mathrm{~mm}$

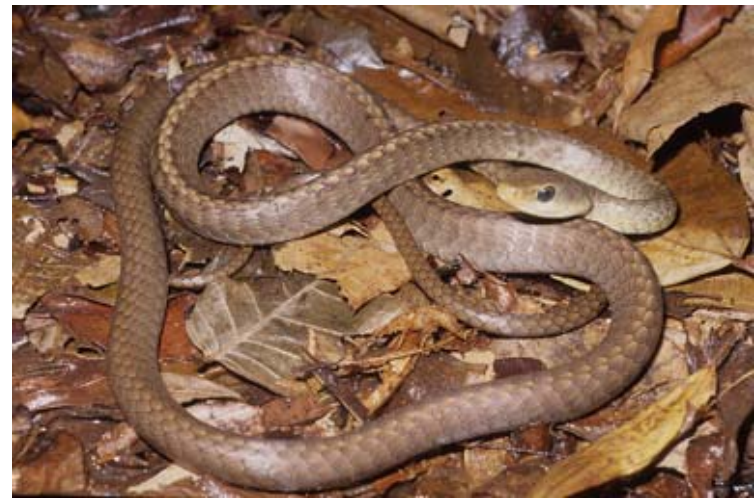

FIGURA 4.8. Chironius exoletus (cobra-cipó),

Colubridae. $(\mathrm{N}=1)$.

$\mathrm{CRC}=298 \mathrm{~mm}$

Foto: Otavio A. V. Marques

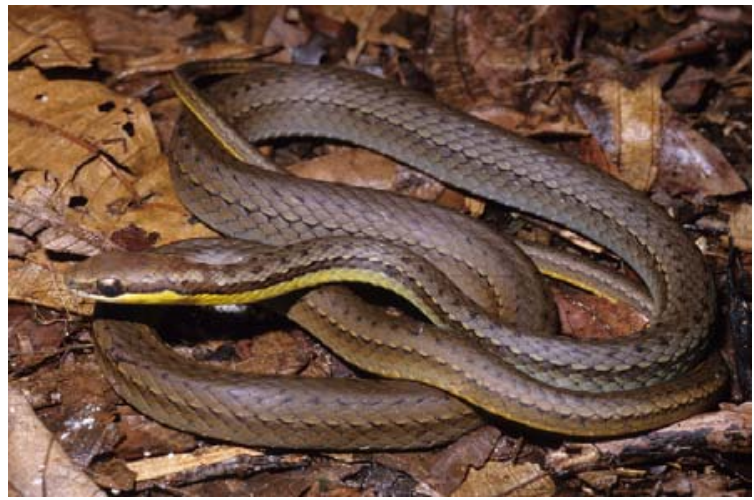

FIGURA 4.10. Echinanthera cephalostriata (papa-rã), Colubridae. $(\mathrm{N}=3)$. CRC médio $=382,5 \mathrm{~mm}$ Foto: Otavio A. V. Marques

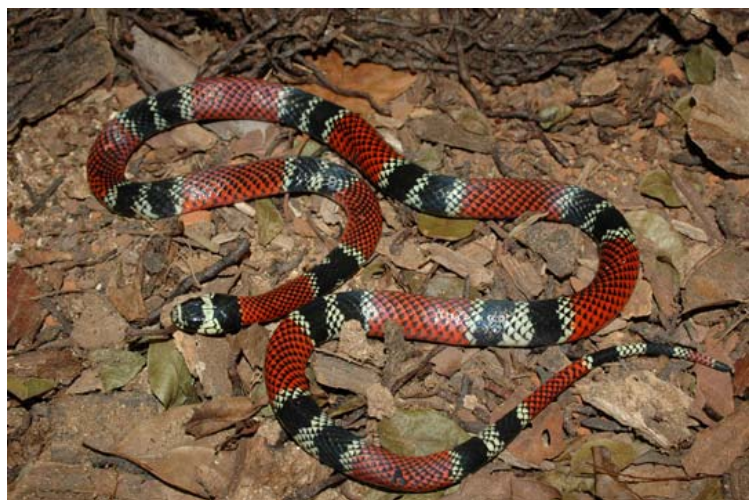

FIGURA 4.12. Erythrolamprus aesculapii monozona (falsa-coral), Colubridae. $(\mathrm{N}=2)$. CRC médio $=525 \mathrm{~mm}$ 


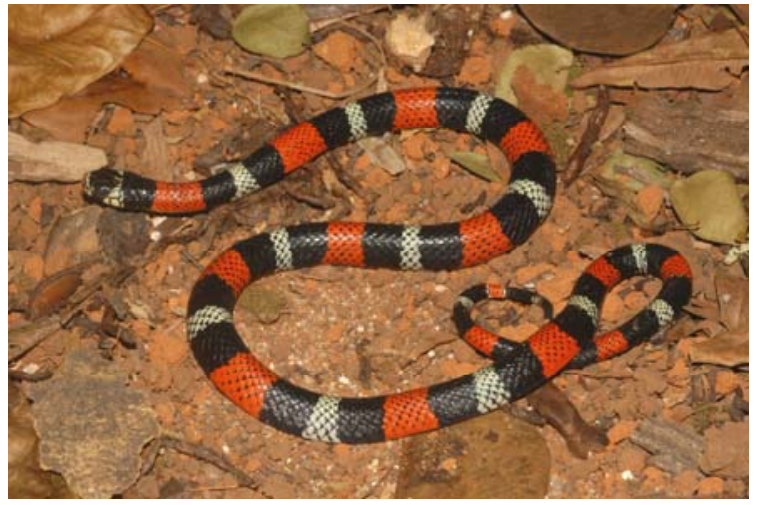

FIGURA 4.13. Erythrolamprus aesculapii venustissimus (falsa-coral), Colubridae. $(\mathrm{N}=11)$.

CRC médio $=574 \mathrm{~mm}$

Foto: Otavio A. V. Marques

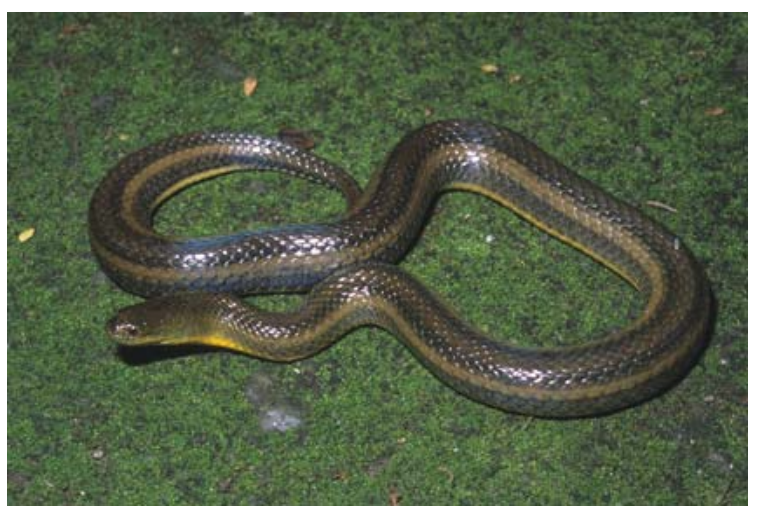

FIGURA 4.15. Helicops modestus (cobrad'água), Colubridae. ( $\mathrm{N}=12)$. CRC médio $=312,3 \mathrm{~mm}$

Foto: Otavio A. V. Marques

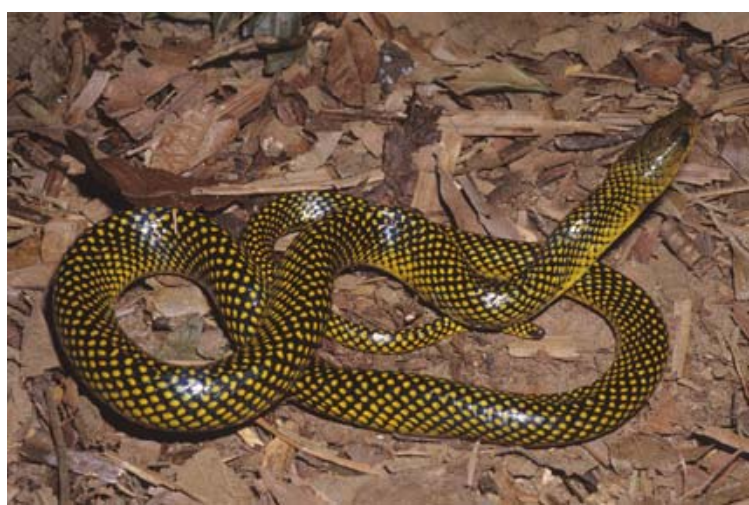

FIGURA 4.17. Liophis miliaris (cobra-d'água), Colubridae. $(\mathrm{N}=58)$.

CRC médio $=332,8 \mathrm{~mm}$

Foto: Otavio A. V. Marques

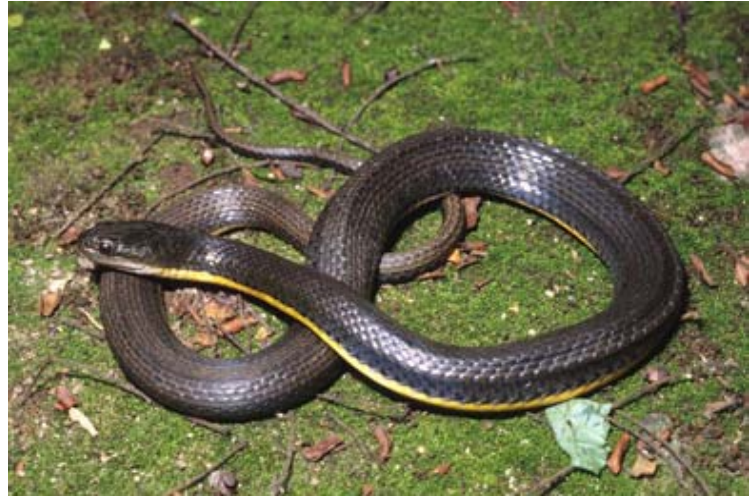

FIGURA 4.14. Helicops carinicaudus (cobrad'água), Colubridae. ( $\mathrm{N}=1)$. $\mathrm{CRC}=153 \mathrm{~mm}$

Foto: Otavio A. V. Marques

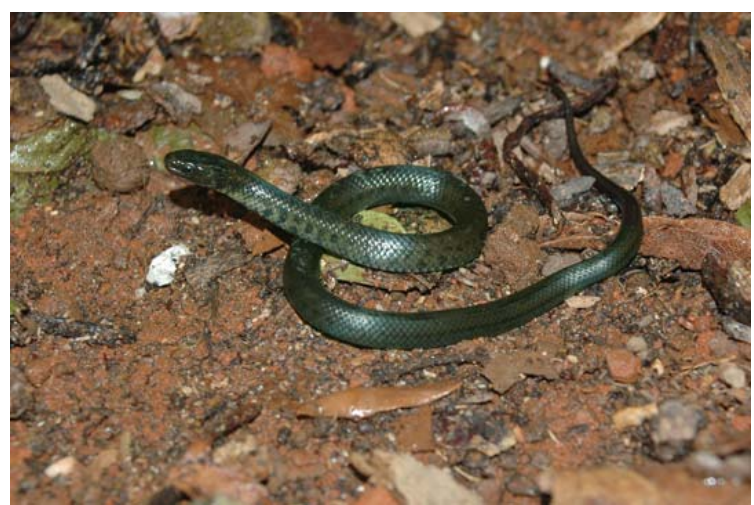

FIGURA 4.16. Liophis jaegeri (cobra-verde), Colubridae. $(\mathrm{N}=1)$. $\mathrm{CRC}=204 \mathrm{~mm}$

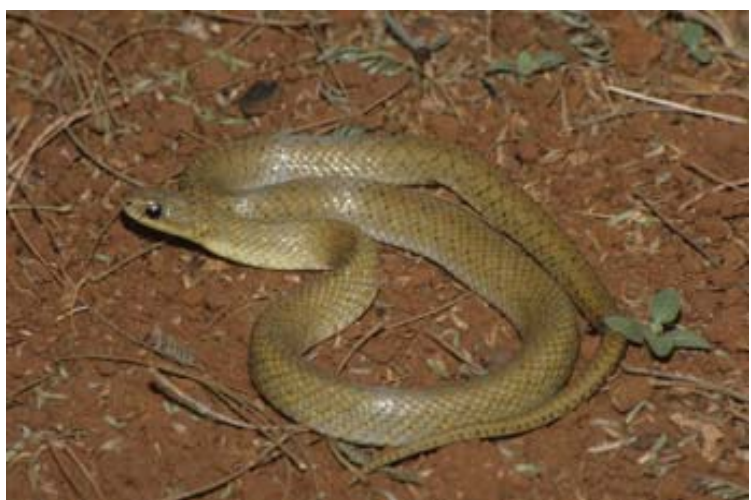

FIGURA 4.18. Liophis poecilogyrus (cobracapim), Colubridae. $(\mathrm{N}=3)$ CRC médio $=525 \mathrm{~mm}$ Foto: Otavio A. V. Marques 


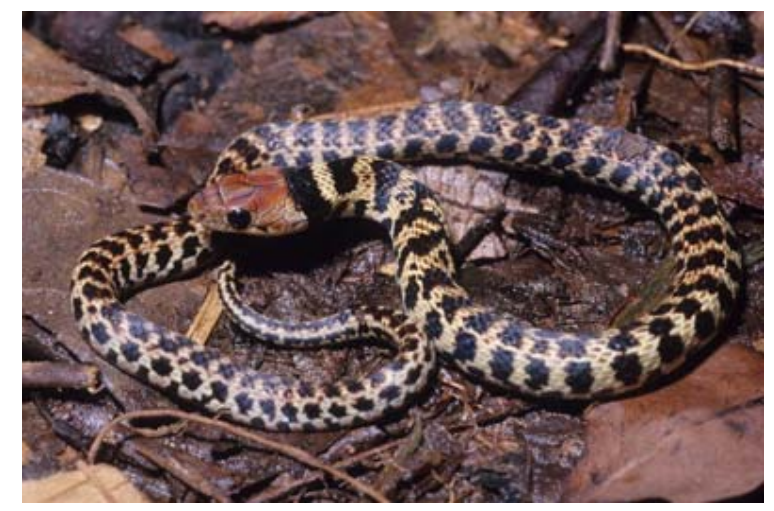

FIGURA 4.19. Liophis poecilogyrus (cobracapim), Colubridae. Indivíduo juvenil.

Foto: Otavio A. V. Marques

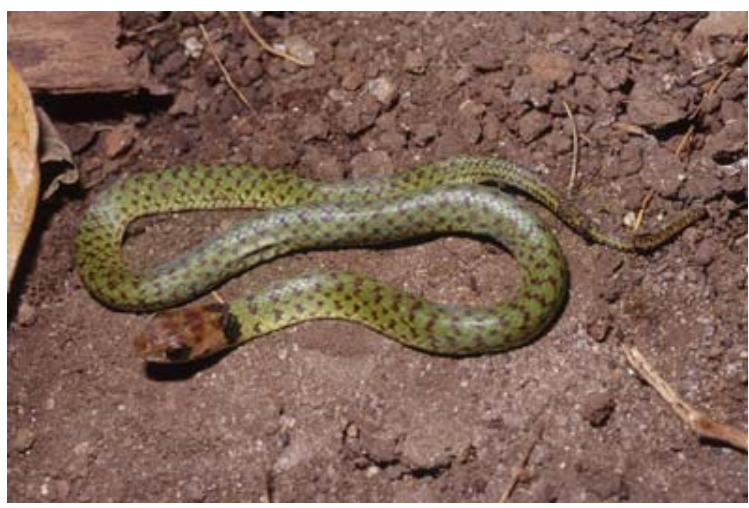

FIGURA 4.21. Liophis typhlus (cobra-verde), Colubridae. Indivíduo juvenil Foto: Otavio A. V. Marques

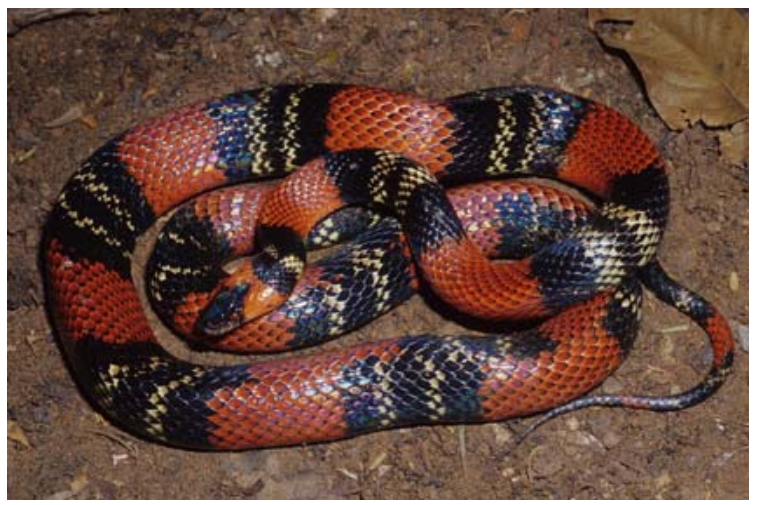

FIGURA 4.23. Oxyrhopus guibei (falsa-coral), Colubridae. $(\mathrm{N}=413)$.

CRC médio $=451,4 \mathrm{~mm}$ Foto: Otavio A. V. Marques

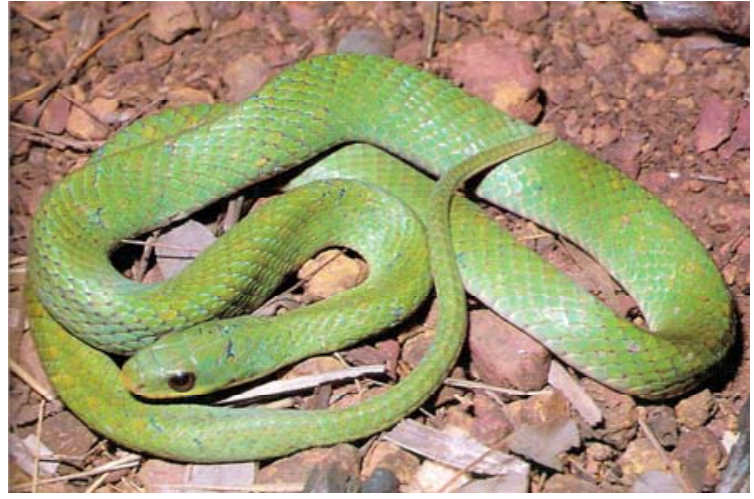

FIGURA 4.20. Liophis typhlus (cobra-verde), Colubridae. $(\mathrm{N}=16)$.

CRC médio $=467,8 \mathrm{~mm}$

Foto: Otavio A. V. Marques

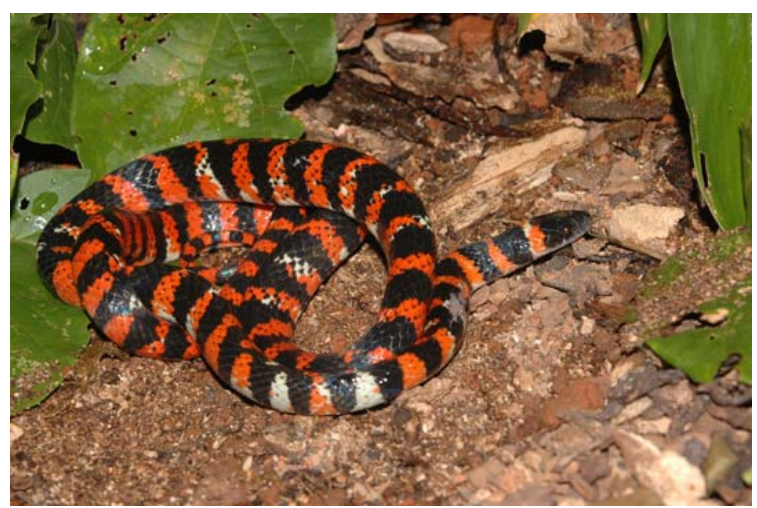

FIGURA 4.22. Oxyrhopus clathratus (falsacoral), Colubridae. $(\mathrm{N}=12)$. $\mathrm{CRC}$ médio $=633,4 \mathrm{~mm}$

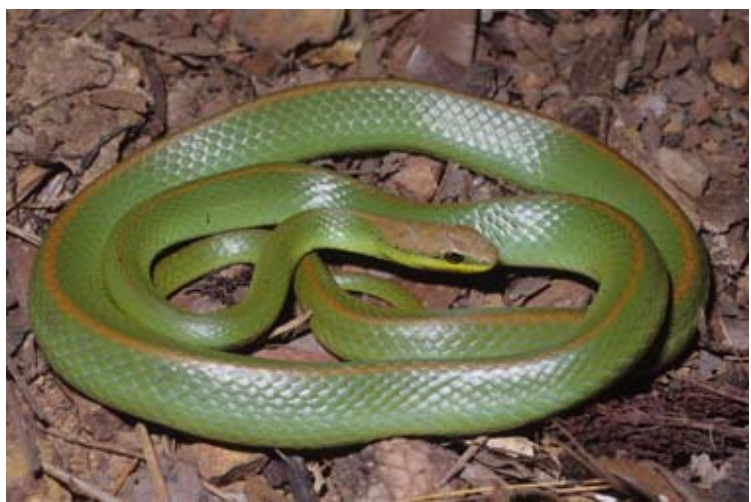

FIGURA 4.24. Philodryas olfersii (boiubu), Colubridae. $(\mathrm{N}=11)$.

CRC médio $=781,9 \mathrm{~mm}$ Foto: Otavio A. V. Marques 


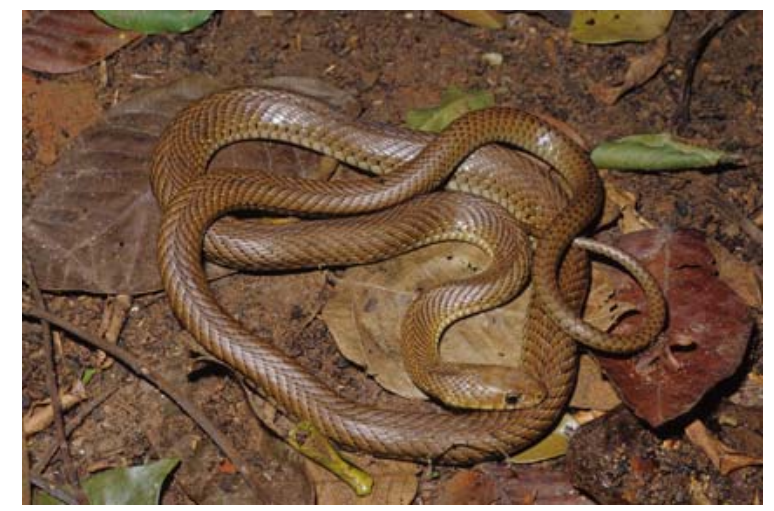

FIGURA 4.25. Philodryas patagoniensis (parelheira), Colubridae. $(\mathrm{N}=114)$.

CRC médio $=524 \mathrm{~mm}$

Foto: Otavio A. V. Marques

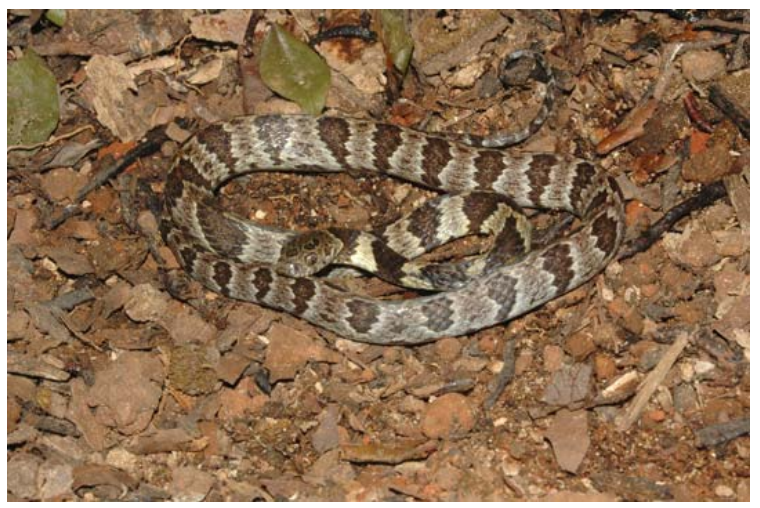

FIGURA 4.27. Sibynomorphus neuwiedi

(dormideira), Colubridae.

$(\mathrm{N}=14)$.

CRC médio $=360,4 \mathrm{~mm}$

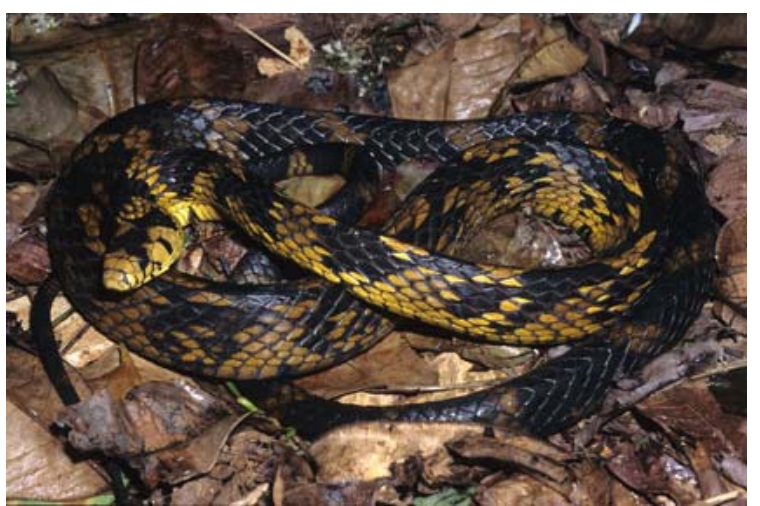

FIGURA 4.29. Spilotes pullatus (caninana), Colubridae. $(\mathrm{N}=5)$.

CRC médio $=1371,4 \mathrm{~mm}$

Foto: Otavio A. V. Marques

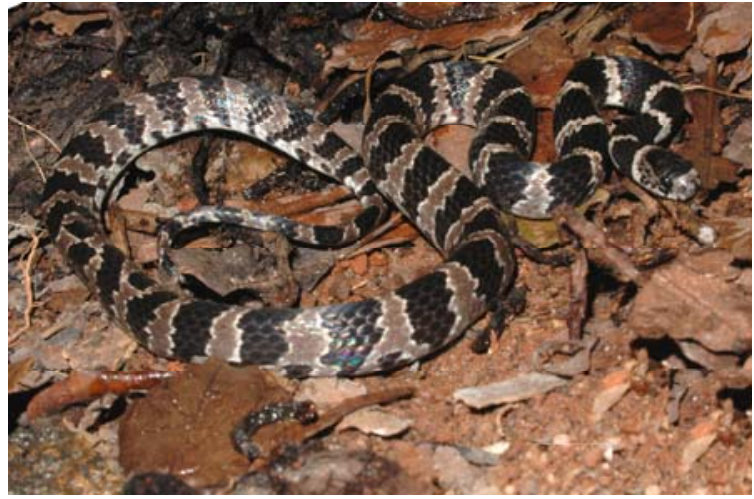

FIGURA 4.26. Sibynomorphus mikanii (dormideira), Colubridae. $(\mathrm{N}=362)$.

CRC médio $=322,5$

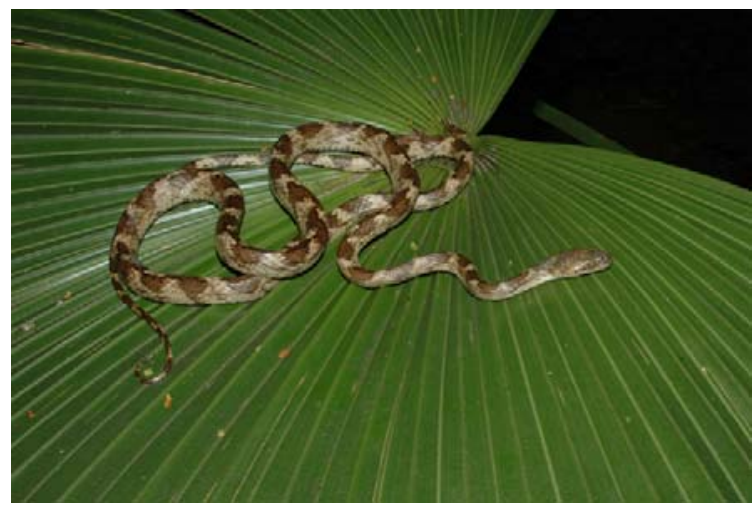

FIGURA 4.28. Siphlophis longicaudatus, Colubridae. $(\mathrm{N}=2)$. CRC médio $=589,6 \mathrm{~mm}$

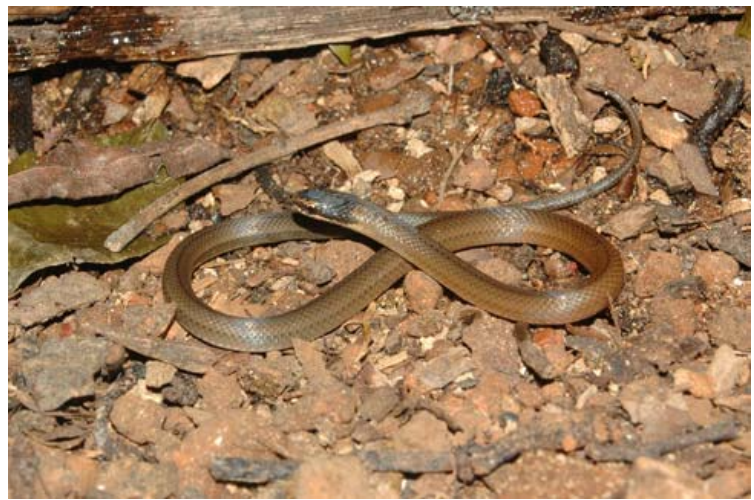

FIGURA 4.30. Taeniophallus affinis, Colubridae. $(\mathrm{N}=5)$. CRC médio $=230,3 \mathrm{~mm}$ 


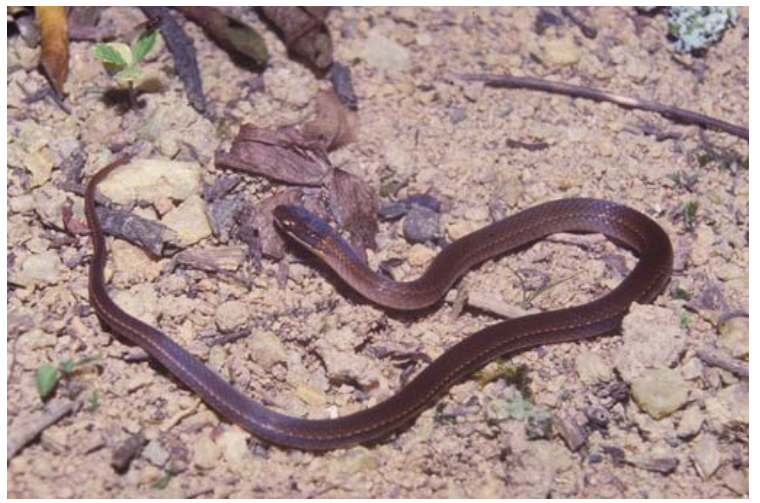

FIGURA 4.31. Taeniophallus persimilis, Colubridae. $(\mathrm{N}=2)$.

$\mathrm{CRC}$ médio $=213 \mathrm{~mm}$

Foto: Cláudio Zamprogno

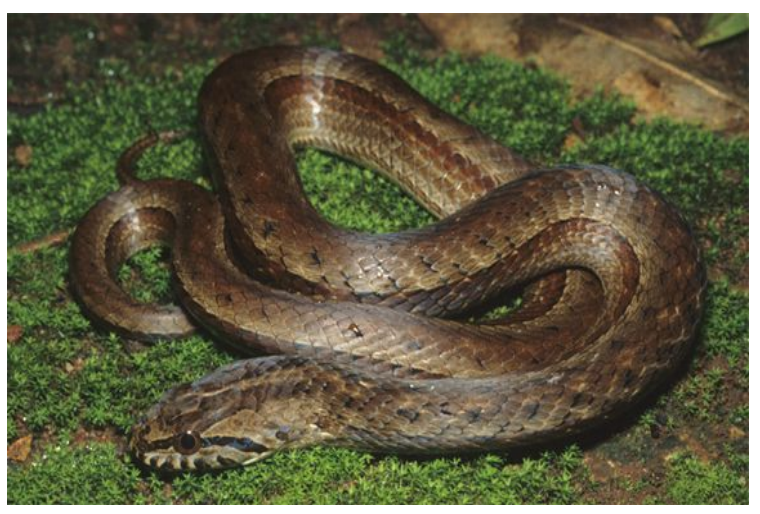

Figura 4.33. Thamnodynastes strigatus

(corre-campo), Colubridae.

$(\mathrm{N}=6)$.

CRC médio $=440,3 \mathrm{~mm}$

Foto: Ivan Sazima

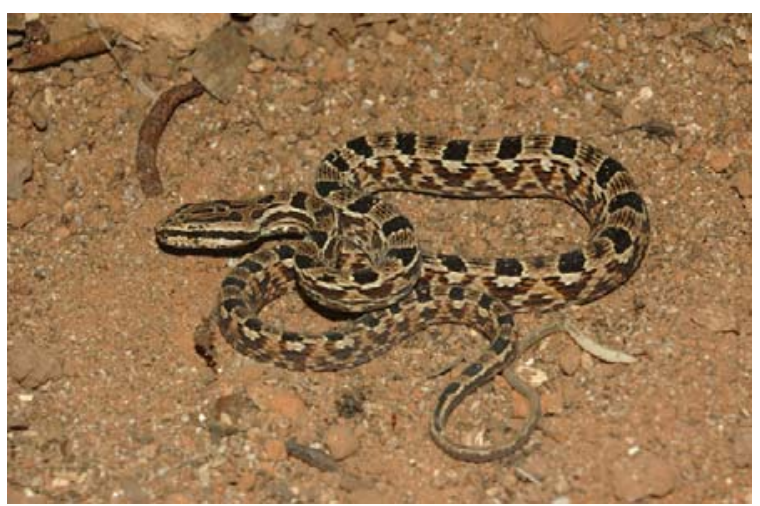

Figura 4.35. Tropidodryas striaticeps (cobracipó), Colubridae. $(\mathrm{N}=5)$.

CRC médio $=496,2 \mathrm{~mm}$

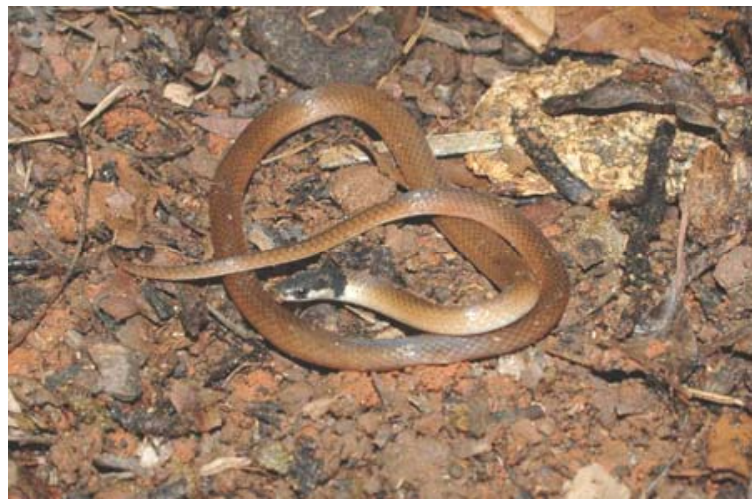

FIGURA 4.32. Tantilla melanocephala (cobra da terra), Colubridae. $(\mathrm{N}=2)$. CRC médio $=278,5 \mathrm{~mm}$

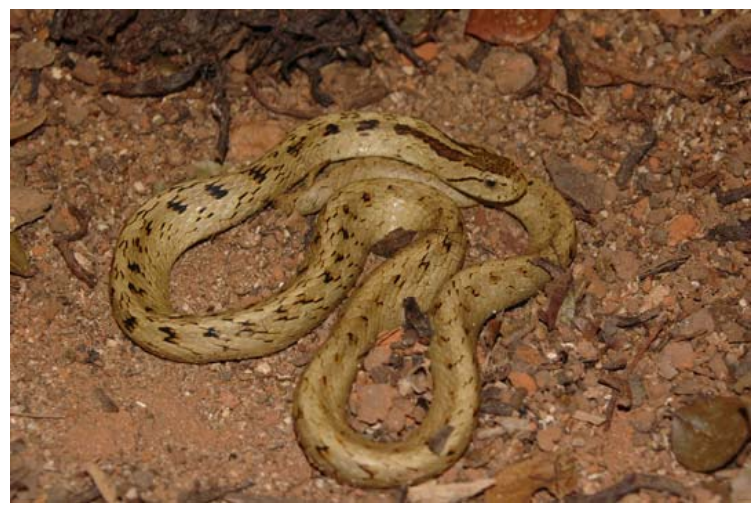

Figura 4.34. Tomodon dorsatus (cobraespada), Colubridae. ( $\mathrm{N}=92)$. $\mathrm{CRC}$ médio $=436,4 \mathrm{~mm}$

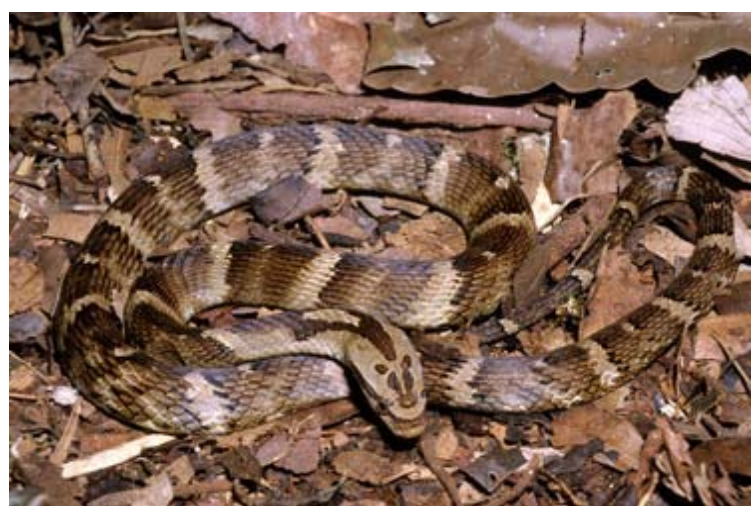

Figura 4.36. Xenodon neuwiedii (quiriripitá), Colubridae. $(\mathrm{N}=44)$. CRC médio $=483,3 \mathrm{~mm}$ Foto: Otavio A. V. Marques 


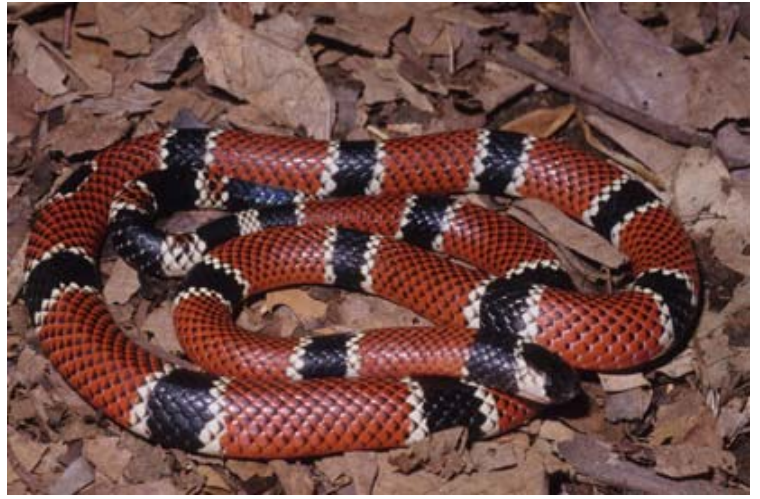

Figura 4.37. Micrurus corallinus (cobracoral), Elapidae. $(\mathrm{N}=5)$. CRC médio $=486,4 \mathrm{~mm}$ Foto: Otavio A. V. Marques

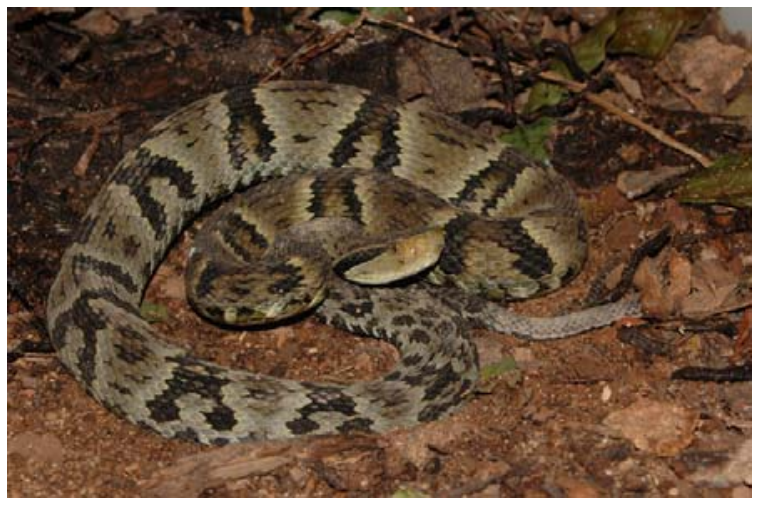

Figura 4.39. Bothrops jararaca (jararaca), Viperidae. $(\mathrm{N}=279)$. $\mathrm{CRC}$ médio $=684 \mathrm{~mm}$

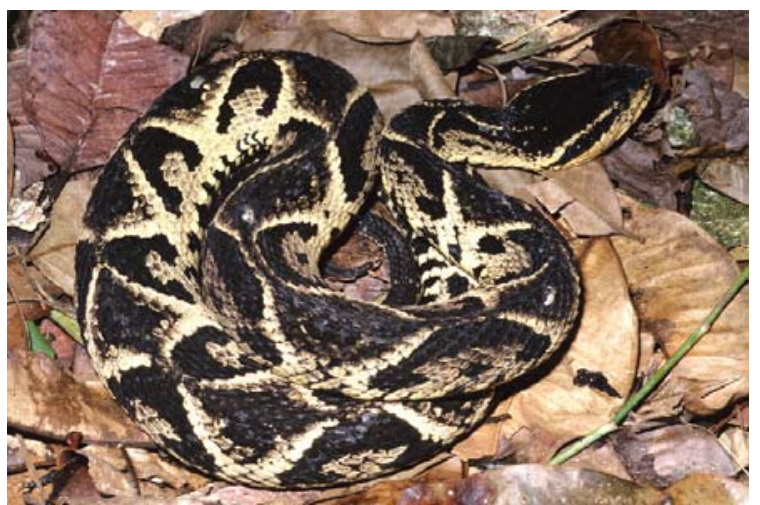

Figura 4.41. Bothrops jararacussu (jararacuçu), Viperidae. $(\mathrm{N}=1) . \mathrm{CRC}=1100 \mathrm{~mm}$ Foto: Otavio A. V. Marques

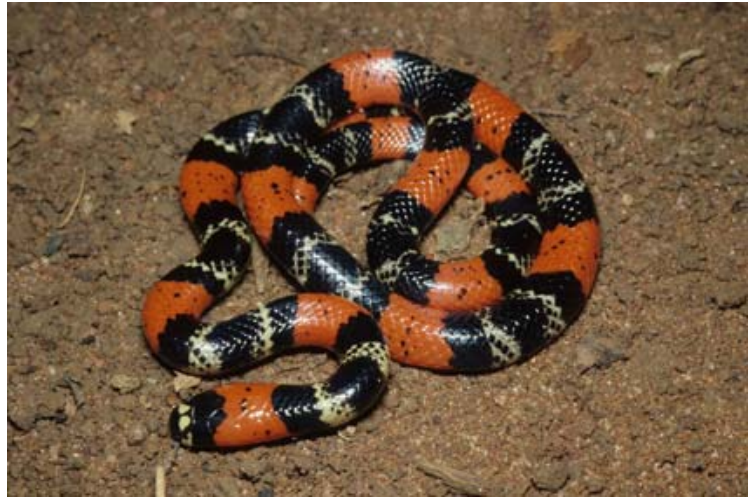

Figura 4.38. Micrurus lemniscatus (cobracoral), Elapidae. $(\mathrm{N}=1)$. $\mathrm{CRC}=373 \mathrm{~mm}$

Foto: Otavio A. V. Marques

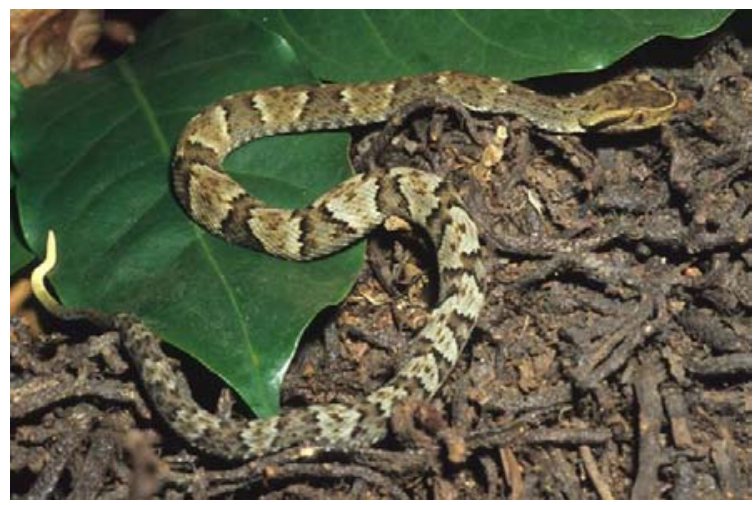

Figura 4.40. Bothrops jararaca (jararaca), Viperidae. Indivíduo juvenil

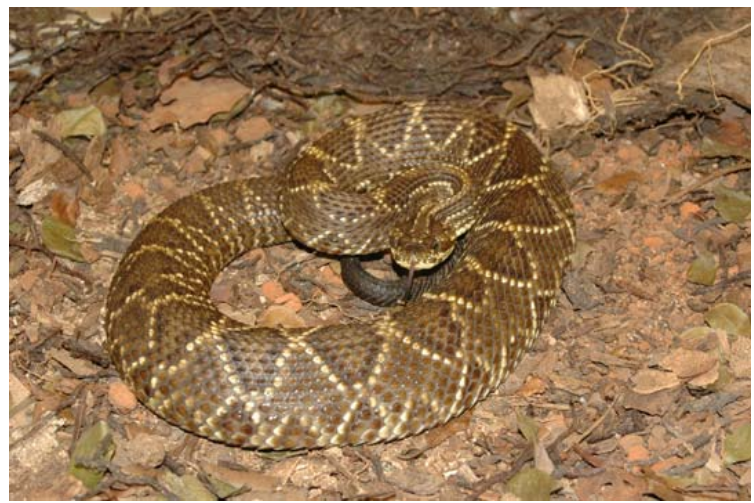

Figura 4.42. Crotalus durissus terrificus (cascavel), Viperidae. $(\mathrm{N}=11)$. CRC médio $=739,7 \mathrm{~mm}$ 


\section{Família Tropidophiidae BRONGERSMA, 1951 (1894)}

\section{Tropidophis paucisquamis (MüLLER, 1901), “jiboinha” (Fig 4.2)}

Espécie rara no MSP, com apenas um indivíduo encontrado na Área Central, no mês de janeiro.

Essa espécie é endêmica da Mata Atlântica e é raramente encontrada, mesmo em áreas conservadas, provavelmente devido ao pequeno tamanho corporal ( $150 \mathrm{~mm}$ ), hábito arborícola e atividade noturna. A espécie é vivípara e a dieta é constituída de pequenos anfíbios anuros (CARVALHO, 1951)

\section{Família Colubridae OPPEL, 1811}

\section{Apostolepis assimilis (REINHARDT, 1872), "falsa-coral” (Fig. 4.3)}

Espécie de abundância intermediária no MSP $(N=56)$ com distribuição nas áreas Norte $(\mathrm{N}=19)$ e Central $(\mathrm{N}=16)$.

Possui hábitos predominantemente fossoriais ou criptozóicos (FERRAREZZI, 1993; FERRAREZZI; BARBO e ALBUQUERQUE, 2005), atividade no período noturno e dieta constituída de anfisbenídeos e répteis fossoriais alongados (cf. SAVITZKY, 1979; FERRAREZZI; BARBO e ALBUQUERQUE, 2005). Dois indivíduos continham serpentes da espécie Liotyphlops beui, recém ingeridos no estômago. Um deles, $(\mathrm{CRC}=224)$, continha um exemplar de $L$. beui $(\mathrm{CRC}=215 \mathrm{~mm})$ que correspondia a $96 \%$ de seu comprimento e $133 \%$ de sua massa.

A espécie é ovípara. Duas fêmeas $(C R C=518$ e 645) provenientes dos meses novembro e março apresentaram quatro e seis folículos vitelogênicos secundários, respectivamente.

A atividade sazonal apresentou picos nos meses de dezembro $(\mathrm{N}=11) \mathrm{e}$ $\operatorname{março~}(\mathrm{N}=13)$ (Fig. 6). 


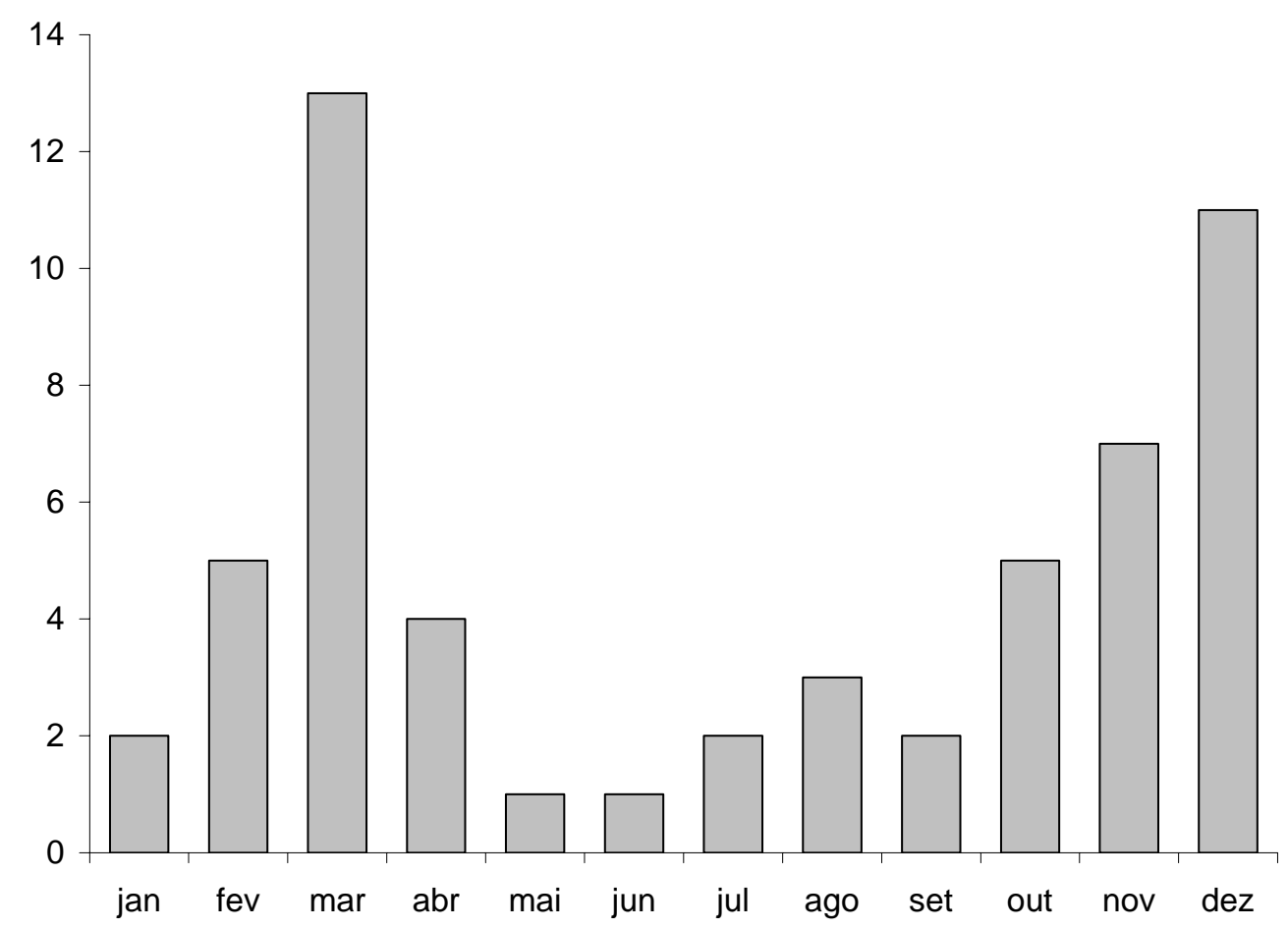

FIGURA 6. Atividade de Apostolepis assimilis $(\mathrm{N}=56)$, entre agosto de 2003 e março de 2007.

Atractus pantostictus Fernandes \& PuORTo, 1993, “fura-terra” (Fig. 4.4)

Espécie de abundância intermediária no $\operatorname{MSP}(N=28)$, com registros de distribuição nas áreas Norte e Central. Apresenta hábitos criptozóicos e fossoriais, e atividade no período noturno. A dieta é especializada em minhocas $(\mathrm{N}=2)$.

A espécie é ovípara. Três fêmeas ( $C R C=365,320$ e 363) apresentaram três ovos cada, com diâmetro de $32.32 \mathrm{~mm}, 28.7 \mathrm{~mm}$ e $32.95 \mathrm{~mm}$, respectivamente. Outro indivíduo $(\mathrm{CRC}=374 \mathrm{~mm})$ apresentava quatro ovos, e o maior deles com diâmetro de $31.39 \mathrm{~mm}$.

O período de maior atividade foi o início da estação chuvosa, entre novembro $(N=4)$ e dezembro $(N=3)$.

\section{Atractus reticulatus (BoulengeR, 1885), "cobra-da-terra", (Fig. 4.5)}

Espécie de abundância intermediária no MSP $(N=32)$, com registros de ocorrência nas regiões mais ao sul da Área Central. Possui ecologia semelhantes a de Atractus pantostictus. Dois indivíduos continham fragmentos de minhocas no estômago. 
Duas fêmeas $(\mathrm{CRC}=314$ e 364) continham três ovos no oviduto cada, com os maiores diâmetros de $39.5 \mathrm{~mm}$ e $39.39 \mathrm{~mm}$ respectivamente, enquanto outra fêmea $(C R C=278)$ apresentava apenas um ovo, com diâmetro de $49.32 \mathrm{~mm}$.

Foi mais abundante durante a estação chuvosa, entre outubro e março ( $\mathrm{N}=$ 22).

Atractus zebrinus (JAN, 1862), "cobra-da-terra", (Fig. 4.6)

Espécie rara no MSP $(N=1)$. Possui ecologia semelhante a de $A$. pantostictus e $A$. reticulatus. O único exemplar registrado foi coletado dentro da mata, na Área Sul do município (Núcleo Curucutu), próximo às áreas de campos de altitude (MALAGOLI, 2006) ${ }^{4}$, e não forneceu informações sobre reprodução e dieta. É provável que essa espécie pudesse se distribuir nas áreas centrais do MSP, nos bairros de Campo Limpo e Campo Belo, onde historicamente havia enclaves de campos naturais.

\section{Chironius bicarinatus (WIED, 1820), “cobra-cipó”, (Fig. 4.7)}

Espécie de abundância intermediária no MSP $(N=35)$. Possui hábito arborícola, atividade no período diurno e é encontrada com freqüência nas regiões da Serra do Mar (MARQUES; ETEROVIC e SAZIMA, 2001; (observação pessoal). No MSP foi registrada em maior quantidade nas áreas Central e Sul, e sempre esteve associada a fragmentos de florestas, como o Parque do Carmo, e matas próximas às represas da região de Parelheiros.

Foi mais ativa durante o final da estação chuvosa no mês de março $(\mathrm{N}=7)$ e durante o mês de maio $(\mathrm{N}=6)$. Apresenta dieta especializada em anfíbios anuros, principalmente hilídeos $(\mathrm{N}=1$ ) e leptodactilídeos (RODRIGUES, 2007). Um indivíduo apresentou carapaças de insetos no intestino, possivelmente um conteúdo alimentar secundário. A espécie é ovípara, e duas fêmeas (CRC = 864 e $967 \mathrm{~mm})$, recebidas nos meses de dezembro e janeiro, apresentavam seis e 10 ovos no oviduto com os maiores diâmetros de 40,5 e 38,22 mm, respectivamente.

\footnotetext{
${ }^{4}$ MALAGOLI, L. São Paulo, 2006 (comunicação pessoal)
} 


\section{Chironius exoletus (LINNAEUs, 1758), "cobra-cipó”, (Fig. 4.8)}

Espécie rara no MSP ( $=1$ ). Possui hábito arborícola (RODRIGUES, 2007), atividade no período diurno e a dieta constituída por anfíbios anuros, como observado em $C$. bicarinatus. Essa espécie pode ser encontrada com freqüência nas áreas de Serra do Mar, durante o período diurno (MARQUES; ETEROVIC e SAZIMA, 2001), e de forma diferente de $C$. bicarinatus, parece ser mais sensível em relação ao grau de preservação ambiental. No MSP foi encontrada no bairro da Lapa.

\section{Clelia quimi Franco, MARQues \& PUORTo, 1997, "muçurana" (Fig. 4.9)}

Espécie rara no MSP $(N=1)$, registrada na extremidade leste da Área Central. Possui hábito terrícola e atividade noturna. O exemplar não forneceu informações sobre a dieta. Como observado em outras espécies do gênero Clelia (incluindo Boiruna), essa espécie provavelmente se alimenta de mamíferos, lagartos e serpentes (VITT e VANGILDER, 1983; FRANCO; MARQUES e PUORTO, 1997; MARQUES; ETEROVIC e SAZIMA, 2001; PINTO e LEMA, 2002). Não foram obtidos dados sobre a reprodução. Pizzatto (2005) encontrou folículos vitelogênicos no mês de julho e ovos nos meses de setembro e outubro, além de filhotes no final da estação chuvosa, sugerindo que o recrutamento ocorra nessa época.

\section{Echinanthera cephalostriata DI-BERNARDO, 1996, "papa-rã" (Fig. 4.10)}

Espécie rara no MSP $(\mathrm{N}=3)$. Apresenta hábito terrícola, provavelmente criptozóico, e atividade diurna. Essa espécie ocorre em áreas preservadas de Floresta Atlântica e é encontrada na serapilheira da mata (observação pessoal). A dieta é constituída de pequenos anfíbios anuros e também de pequenos lagartos (MARQUES; ETEROVIC e SAZIMA, 2001). A espécie é ovípara, porém não foram registradas informações sobre reprodução.

Os registros de distribuição foram nas áreas Norte (Parque Estadual da Cantareira), Central (Jardim João XXIII) e Sul (Núcleo Curucutu).

\section{Echinanthera undulata (WIED, 1824), "papa-rã" (Fig. 4.11)}

Espécie rara no MSP $(N=17)$. Semelhante a $E$. cephalostriata, essa espécie apresenta hábito terrícola, provavelmente criptozóico, atividade diurna, e é encontrada principalmente na serapilheira da mata. A maior abundância foi durante 
a estação chuvosa ( $N=13)$, e as áreas Norte e Sul foram as que apresentaram maior número de registros, devido provavelmente à menor quantidade de fragmentos e a maior quantidade de áreas florestais contínuas.

A dieta é constituída de pequenos anfíbios anuros $(N=2)$. Um indivíduo continha remanescentes de insetos no intestino, provavelmente um conteúdo alimentar secundário. Uma fêmea $(C R C=465 \mathrm{~mm})$ recebida no mês de janeiro possuía cinco folículos vitelogênicos, sendo o maior com $18 \mathrm{~mm}$ de diâmetro. Indivíduos da coleção do IB analisados por Marques (1998) apresentavam folículos vitelogênicos entre os meses de outubro e dezembro, e ovos nos ovidutos entre setembro e janeiro, indicando que essa espécie apresenta ciclo reprodutivo sazonal e recrutamento de jovens na estação chuvosa.

\section{Erythrolamprus aesculapii monozona JAN, 1863, "falsa-coral” (Fig. 4.12)}

Espécie rara no MSP $(N=2)$. Possui hábito terrícola, atividade diurna e a dieta especializada em serpentes, embora possa se alimentar de pequenos lagartos gymnoftalmídeos, quando jovens (Marques ; Puorto, 1994). Um exemplar continha escamas de um colubrídeo não identificado no estômago. Não foram obtidas informações sobre reprodução durante este estudo, porém Marques (1996) aponta que o ciclo reprodutivo seja contínuo.

Os registros de distribuição se concentraram na Área Sul, conectada à Serra do Mar, onde ocorre em simpatria com a coral-verdadeira Micrurus corallinus, da qual pode ser mimética (MARQUES e PUORTO, 1991).

\section{Erythrolamprus aesculapii venustissimus (WIED, 1821), "falsa-coral"}

(Fig. 4.13)

Espécie rara no MSP $(\mathrm{N}=11)$. Da mesma forma que a outra subespécie $E$. a. monozona, apresenta hábito terrícola, atividade diurna e a dieta especializada em serpentes. Um indivíduo continha a cauda de uma serpente da espécie Sibynomorphus mikanii no estômago, indicando que essa presa foi capturada e ingerida pela cabeça. Erythrolamprus aesculapii ssp., na grande maioria das vezes, inicia a ingestão de suas presas pela cauda (MARQUES e PUORTO, 1994) e o fato de esse indivíduo ter ingerido a presa pela cabeça sugere que no momento da captura, a mordida desferida pela E. aesculapii tenha sido próxima à cabeça 
(MARQUES e PUORTO, 1994). O outro exemplar continha escamas de um colubrídeo não identificado no estômago.

A espécie é ovípara. Duas fêmeas, recebidas nos meses de setembro e outubro, possuíam cinco e três folículos ovarianos em vitelogênese secundária, com os maiores diâmetros de 30,4 e 14,5 mm, respectivamente. Uma fêmea, avistada em uma trilha da Serra do Mar em Cubatão no mês de junho de 2002, continha cinco ovos. Apesar de ambos os exemplares apresentarem folículos vitelogênicos no início da estação chuvosa, Marques (1996) indica que a reprodução dessa espécie é contínua.

Os registros de ocorrência concentraram-se nas áreas Norte e Central.

\section{Helicops carinicaudus (WIED, 1825), "cobra-d'agua” (Fig. 4.14)}

Espécie rara no MSP $(\mathrm{N}=1)$. Um indivíduo juvenil foi recebido no mês de março, proveniente do bairro Parque dos Príncipes, na Área Central do MSP. Essa espécie apresenta hábito aquático (SCARTOZZONI, 2005), atividade diurna e noturna (MARQUES, 1998) e é comumente encontrada nas regiões da Serra do Mar (MARQUES; ETEROVIC e SAZIMA, 2001). Não foram obtidas informações sobre a dieta dessa espécie no MSP. Análises em exemplares da coleção do IB, provenientes do litoral sul do estado de São Paulo, constataram a presença de peixes e anfíbios anuros em sua dieta (MARQUES, 1998).

A espécie é vivípara, mas não foram obtidos dados sobre sua reprodução no MSP. Exemplares da coleção do IB, provenientes da Mata Atlântica, indicam reprodução sazonal com a vitelogênese ocorrendo no período de setembro a dezembro, embriões de novembro a março e recrutamento entre fevereiro e abril (MARQUES, 1998; NOGUEIRA e MARQUES, 1998).

\section{Helicops modestus GüNTHER, 1861,“cobra-d'agua” (Fig. 4.15)}

Espécie rara no MSP $(\mathrm{N}=13)$. Semelhante a $H$. carinicaudus, apresenta hábito aquático e atividade diurna e noturna. A dieta é constituída de peixes e eventualmente pequenos anfíbios anuros. Essa espécie é vivípara e uma fêmea deu à luz 20 filhotes no mês de março.

No MSP, os registros de ocorrência distribuíram-se em alguns bairros com áreas verdes na Área Central, provavelmente pela presença de corpos d'água. Em 
áreas de cerrado, essa espécie foi registrada nas bordas de matas de galeria e em corpos d'água (SAWAYA, 2004).

\section{Liophis jaegeri (GÜNTHER, 1858), “cobra-verde” (Fig. 4.16)}

Espécie rara no MSP. Apenas um indivíduo juvenil foi coletado no mês de maio, em um bairro próximo ao Instituto Butantan. Essa espécie apresenta hábitos semi-aquáticos (DIXON, 1980), com atividade diurna e a dieta especializada em pequenos anfíbios anuros.

A espécie é ovípara, porém o exemplar não forneceu dados reprodutivos.

\section{Liophis miliaris (LINNAEUS, 1758), “cobra-d'agua” (Fig. 4.17)}

Espécie comum no MSP ( $N=58)$. Apresenta hábito terrícola e semi-aquático e a atividade diurna. A dieta é constituída de anfíbios anuros $(\mathrm{N}=1)$ e peixes $(\mathrm{N}=$ 1). Foram encontrados remanescentes de insetos no intestino de quatro indivíduos, provavelmente um item alimentar secundário. A espécie é ovípara. Uma fêmea $(C R C=905)$ apresentou 20 folículos vitelogênicos durante o mês de dezembro, com o maior deles medindo 17,76 mm de diâmetro. Pizzatto (2003) encontrou folículos vitelogênicos e ovos nos ovidutos de setembro a dezembro.

Foi mais ativa durante os meses de janeiro $(N=9)$, fevereiro $(N=11)$ e março $(\mathrm{N}=21)$ (Fig. 7). O recrutamento dos filhotes ocorreu entre os meses de janeiro e março.

Essa espécie distribuiu-se nas áreas Central e principalmente próxima às represas da Área Sul. 


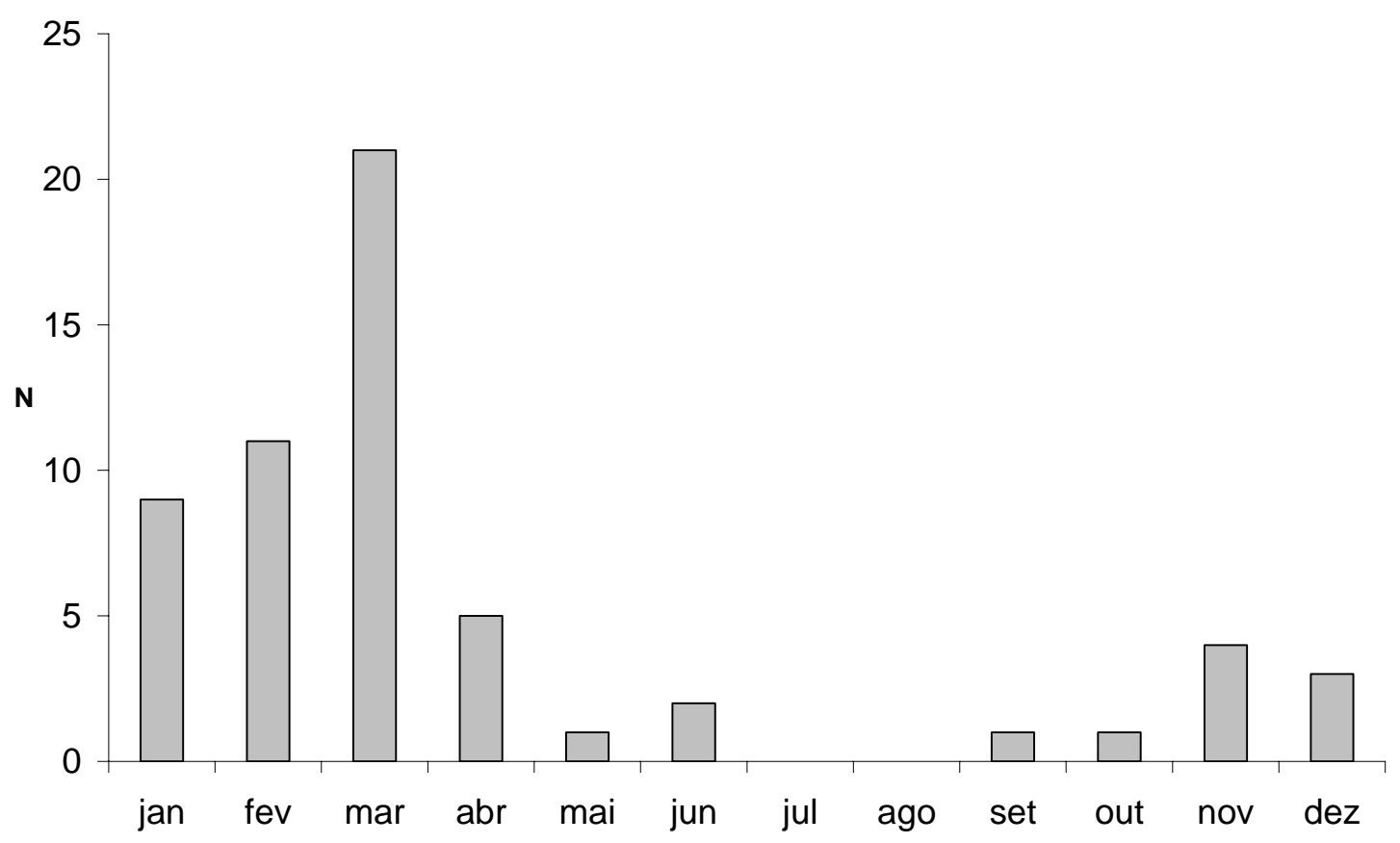

FIGURA 7. Atividade sazonal de Liophis miliaris entre agosto de 2003 e março de 2007.

\section{Liophis poecilogyrus (WIED, 1824), "cobra-capim" (Fig. 4.18 e 4.19)}

Espécie rara no MSP $(\mathrm{N}=3)$. Apresenta hábito terrícola e atividade diurna (MARQUES, ETEROVIC e SAZIMA, 2001). Os exemplares não forneceram informações sobre dieta, porém, como observado em outras espécies do gênero, se alimenta principalmente de anfíbios anuros.

A espécie é ovípara. Uma fêmea ( $C R C=536 \mathrm{~mm}$ ) coletada no mês de outubro continha oito ovos no oviduto, com o maior medindo 25,8 mm de diâmetro, e apenas um folículo vitelogênico de $21 \mathrm{~mm}$. Outra fêmea $(C R C=580 \mathrm{~mm})$, recebida no mês de novembro, apresentava três folículos vitelogênicos, com o maior medindo $20,7 \mathrm{~mm}$. É possível que esse exemplar já tivesse feito a postura dos ovos antes da coleta.

\section{Liophis typhlus (LINNAEUS, 1758), "cobra-verde" (Fig. 4.20 e 4.21)}

Espécie rara no MSP $(\mathrm{N}=16)$. Apresenta hábito terrícola e atividade diurna. $A$ dieta é constituída principalmente por anfíbios anuros. Um indivíduo continha patas de uma espécie de anuro (Rhinella sp.) no estômago, enquanto outro continha remanescentes de insetos no intestino, provavelmente um conteúdo alimentar secundário. Cinaqui-Filho (1997) constatou que $50 \%$ dos itens alimentares de $L$. 
typhlus correspondiam a anfíbios da espécie Rhinella sp., sugerindo que essa espécie seja especializada nesse tipo de presa, de forma diferente do observado em outras espécies do gênero Liophis.

A espécie é ovípara. Uma fêmea coletada no mês de dezembro (CRC $=790$ $\mathrm{mm}$ ) apresentava sete folículos vitelogênicos, com o maior medindo 33,7 mm. Duas outras fêmeas coletadas no mês de janeiro ( $C R C=535$ e 674 mm) apresentavam quatro e sete folículos vitelogênicos, com os maiores medindo 15,3 e 20,9 mm, respectivamente. Uma fêmea coletada no mês de junho ( $\mathrm{CRC}=595 \mathrm{~mm}$ ) apresentava oito folículos vitelogênicos, com o maior medindo 14,2 mm. CinaquiFilho (2007) sugere que o ciclo reprodutivo das fêmeas seja contínuo na região sudeste, havendo predominância de fêmeas reprodutivas no verão e no outono.

\section{Oxyrhopus clathratus DUMÉRIL, BIBRON \& DUMÉRIL, 1854, "falsa-coral"}

(Fig. 4.22)

Espécie rara no MSP $(\mathrm{N}=12)$. Apresenta hábito terrícola e atividade noturna (MARQUES, ETEROVIC e SAZIMA, 2001; observação pessoal). Não foram obtidas informações sobre a dieta, mas outras espécies da tribo Pseudoboini se alimentam de roedores principalmente na fase adulta, e de lagartos na fase juvenil (MARQUES e SAZIMA, 2004). Exemplares da coleção do IB, provenientes do litoral sul do Estado de São Paulo, apresentavam vestígios de roedores, além de um lagarto gymnophtalmidae no estômago de um indivíduo juvenil (MARQUES, 1998).

A espécie é ovípara, mas não foram obtidos dados sobre sua reprodução no MSP.

Distribuiu-se na Área Central e principalmente na Área Sul.

\section{Oxyrhopus guibei Hoge \& RomANo, 1977, "falsa-coral" (Fig. 4.23)}

Espécie dominante no MSP $(\mathrm{N}=413)$. Apresenta hábito terrícola e atividade noturna, porém alguns fornecedores relataram que no momento da coleta, alguns exemplares estavam ativos no período diurno. A dieta é constituída de lagartos na fase juvenil, e de roedores na fase adulta. Do total de indivíduos analisados, 11,4 \% forneceram dados sobre a dieta $(N=47)$. Destes, 13 continham roedores no estômago, 23 continham pêlos de roedores no intestino, seis continham lagartixas da espécie Hemidactylus mabouia no estômago, um continha fragmentos de insetos 
no intestino (conteúdo alimentar secundário), um continha uma cauda de lagarto não identificado, e três continham escamas de um lagarto, provavelmente Ophiodes sp..

A espécie é ovípara. Cinqüenta e três fêmeas forneceram informações sobre o ciclo reprodutivo (Fig. 8).

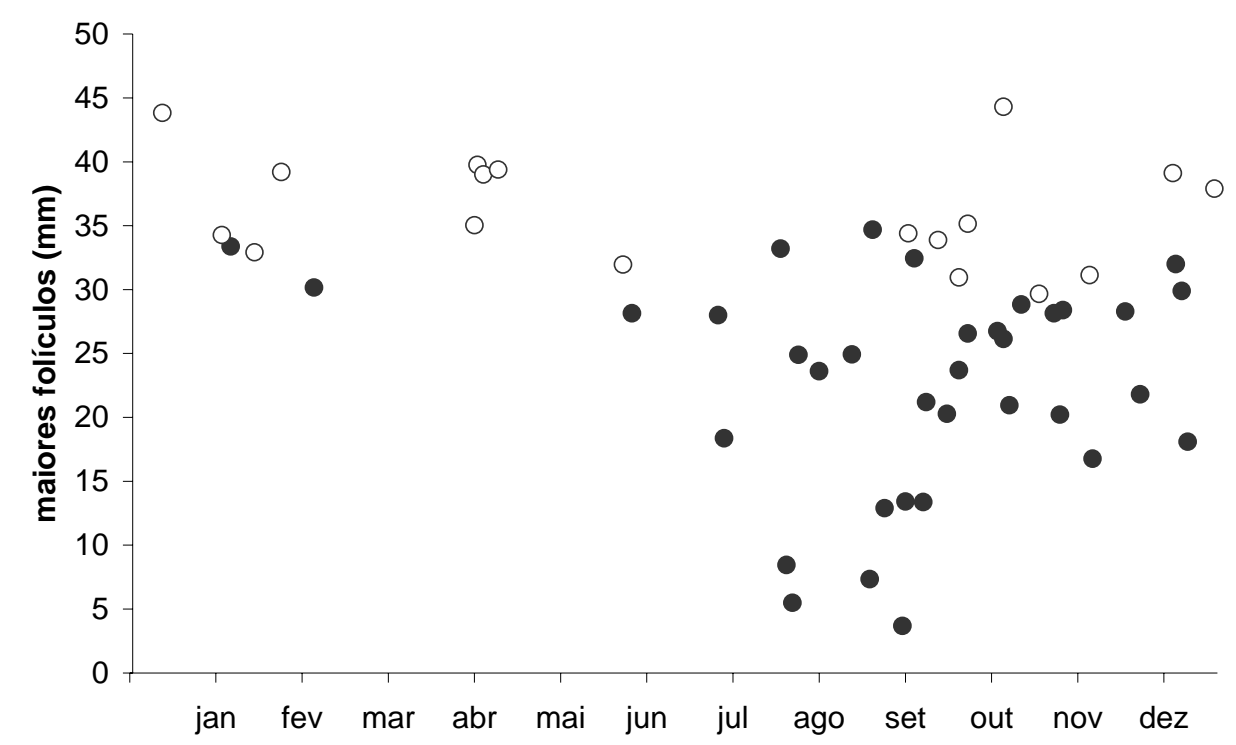

FIGURA 8. Variação sazonal do diâmetro dos maiores folículos vitelogênicos e ovos das fêmeas de Oxyrhopus guibei, recebidos entre agosto de 2003 e março de 2007. Folículos (círculos sólidos) e ovos (círculos abertos).

A presença de folículos vitelogênicos e ovos, em vários meses do ano, sugerem que essa espécie tenha o ciclo reprodutivo contínuo, como observado por Pizzatto ; Marques (2002) para O. guibei no sudeste do Brasil.

Foram observados dois picos de atividade ao longo do ano. O primeiro pico ocorreu nos meses de abril $(N=40)$ e maio $(N=38)$, e o outro no início da estação chuvosa, nos meses de setembro $(N=47)$, outubro $(N=54)$ e novembro $(N=71)$ (Fig. 9). 


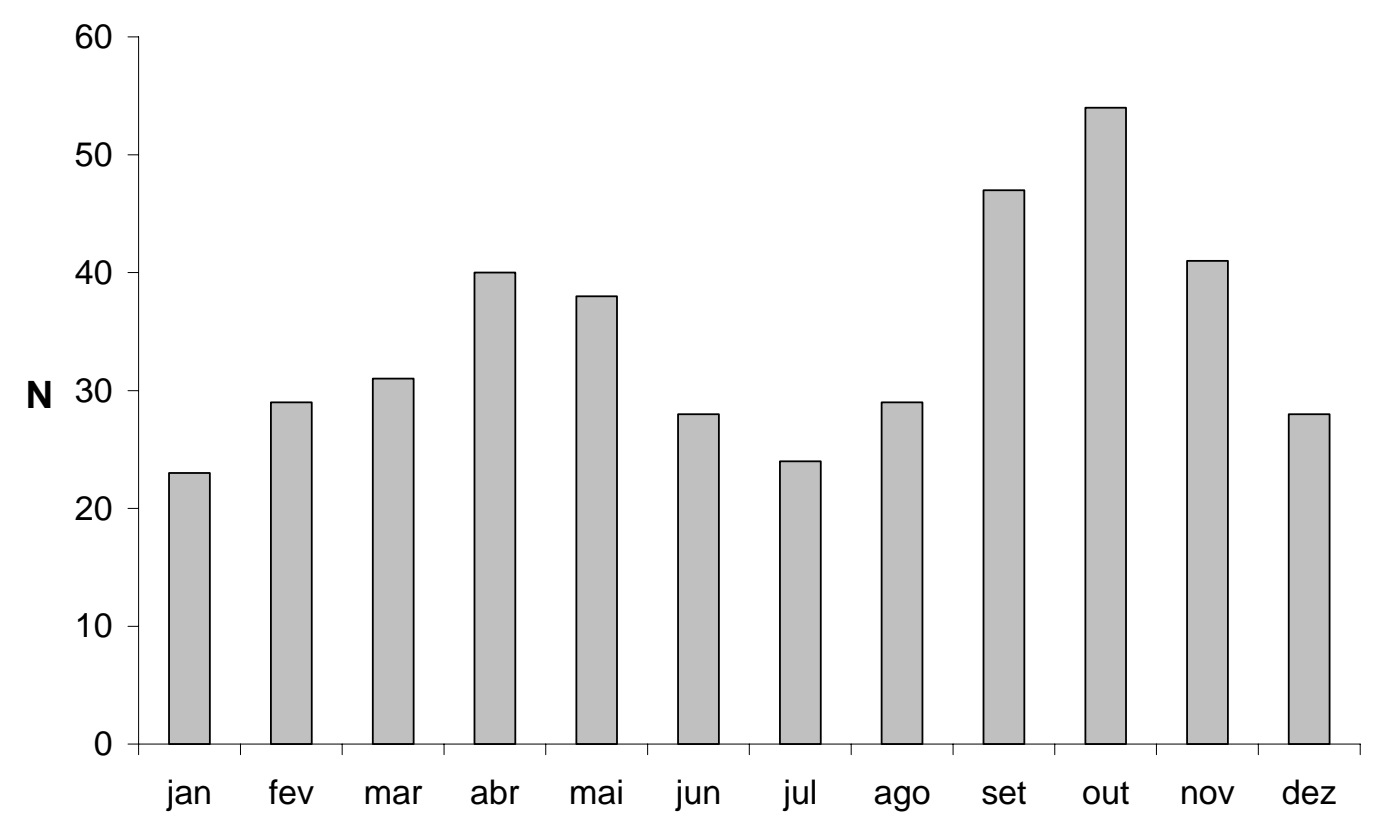

FIGURA 9. Atividade sazonal de Oxyrhopus guibei entre agosto de 2003 e março de 2007.

Distribuiu-se principalmente nas áreas Norte $(N=35)$ e Central $(N=181)$, observada inclusive em áreas com pouca ou nenhuma cobertura vegetal, como terrenos desabitados.

Philodryas olfersii (LICHTENSTEIN, 1823), "boiubu" (Fig. 4.24)

Espécie rara no MSP $(\mathrm{N}=11)$. Apresenta hábito terrícola e semi-arborícola, e atividade diurna (HARTMANN e MARQUES, 2005). A dieta é constituída de pequenos vertebrados, como roedores, lagartos, anfíbios anuros e aves (HARTMANN e MARQUES, 2005). Dois exemplares continham pêlos de roedores no intestino.

A espécie é ovípara. Três fêmeas, recebidas nos meses de setembro, outubro e janeiro $(C R C=885,788$ e $1020 \mathrm{~mm})$ continham 11, sete e 11 folículos vitelogênicos, com os maiores medindo 30, 14,8 e 18,3 mm, respectivamente. Uma fêmea, recebida no mês de novembro, continha sete ovos no oviduto, com o maior medindo 49,95 mm.

Distribuiu-se na Área Central e principalmente na Área Norte. 


\section{Philodryas patagoniensis (GIRARD, 1857) "parelheira" (Fig. 4.25)}

Espécie comum no MSP ( $N=114)$. Apresenta hábito terrícola e atividade diurna (HARTMANN e MARQUES, 2005). A dieta é constituída de mamíferos, anfíbios anuros, pequenos lagartos, aves e eventualmente serpentes (HARTMANN e MARQUES, 2005).

Do total, 12 exemplares ( $10 \%)$ forneceram informações sobre a dieta. Um indivíduo continha dois roedores no estômago, cinco continham pelos de roedores no intestino e outro indivíduo apresentava no estômago a cauda de uma lagartixa da espécie Hemidactylus mabouia. Três outros continham anfíbios anuros: Leptodactylus marmoratus $(N=1)$, Physalaemus sp. $(N=1)$, e uma espécie não identificada juntamente com remanescentes de insetos no intestino. Um exemplar continha a cauda de uma serpente Sibynomorphus mikanii no estômago, e outro exemplar continha um jovem de Oxyrhopus guibei.

A espécie é ovípara. Treze fêmeas continham folículos vitelogênicos, com diâmetros variando de 5,4 a 31,9 mm. Uma fêmea recebida no mês de novembro continha seis ovos no oviduto, com o maior medindo 43,91 mm. Outras duas fêmeas recebidas no mês de dezembro continham 13 e 14 ovos no oviduto, com os maiores diâmetros medindo 33,4 e 40,5 mm, respectivamente, sendo que a última, além dos ovos, possuía 11 folículos vitelogênicos, com o maior medindo 5,36 mm.

Foi mais ativa nos meses de dezembro $(N=15)$ e de janeiro $(N=17)$, além de ser também abundante no final da estação chuvosa (fevereiro e março) e no início da estação seca (abril e maio) (Fig. 10).

Distribuiu-se em todas as áreas do MSP, mas principalmente na Área Central. 


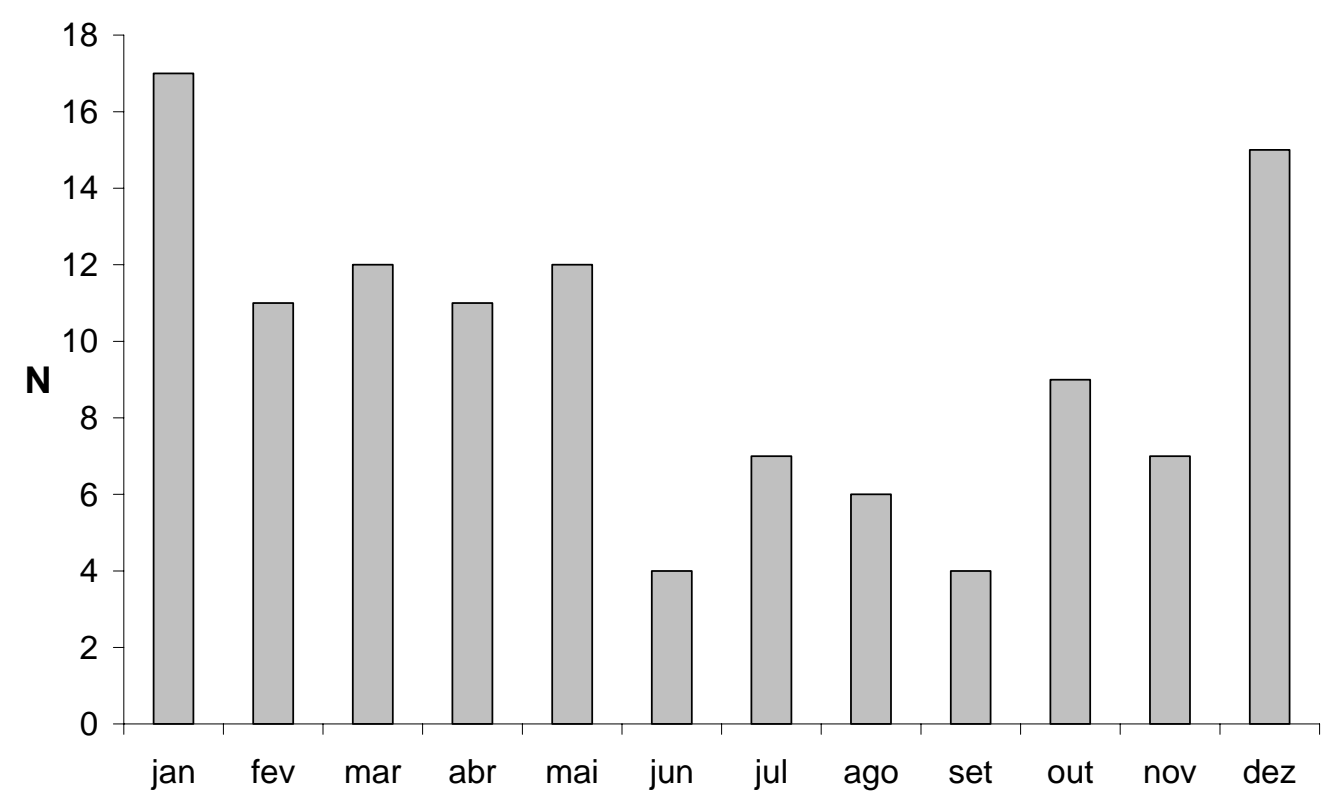

FIGURA 10. Atividade sazonal de Philodryas patagoniensis entre agosto de 2003 e março de 2007.

\section{Sibynomorphus mikanii (SCHLEGEL, 1837) "dormideira" (Fig. 4.26)}

Segunda espécie dominante no MSP $(\mathrm{N}=362)$. Apresenta hábito terrícola e atividade noturna (OLIVEIRA, 2001) embora tenha sido observada ativa durante o dia por alguns fornecedores. Apresenta dieta especializada em lesmas da Família Veronicellidae $(\mathrm{N}=36)$. Provavelmente devido ao baixo valor calórico e a rápida digestão desse tipo de presa, essa serpente pode ingerir várias lesmas, como observado em dois exemplares.

A espécie é ovípara (OLIVEIRA, 2001). Quarenta e duas fêmeas continham folículos vitelogênicos e 15 continham ovos no oviduto (Fig. 11). 


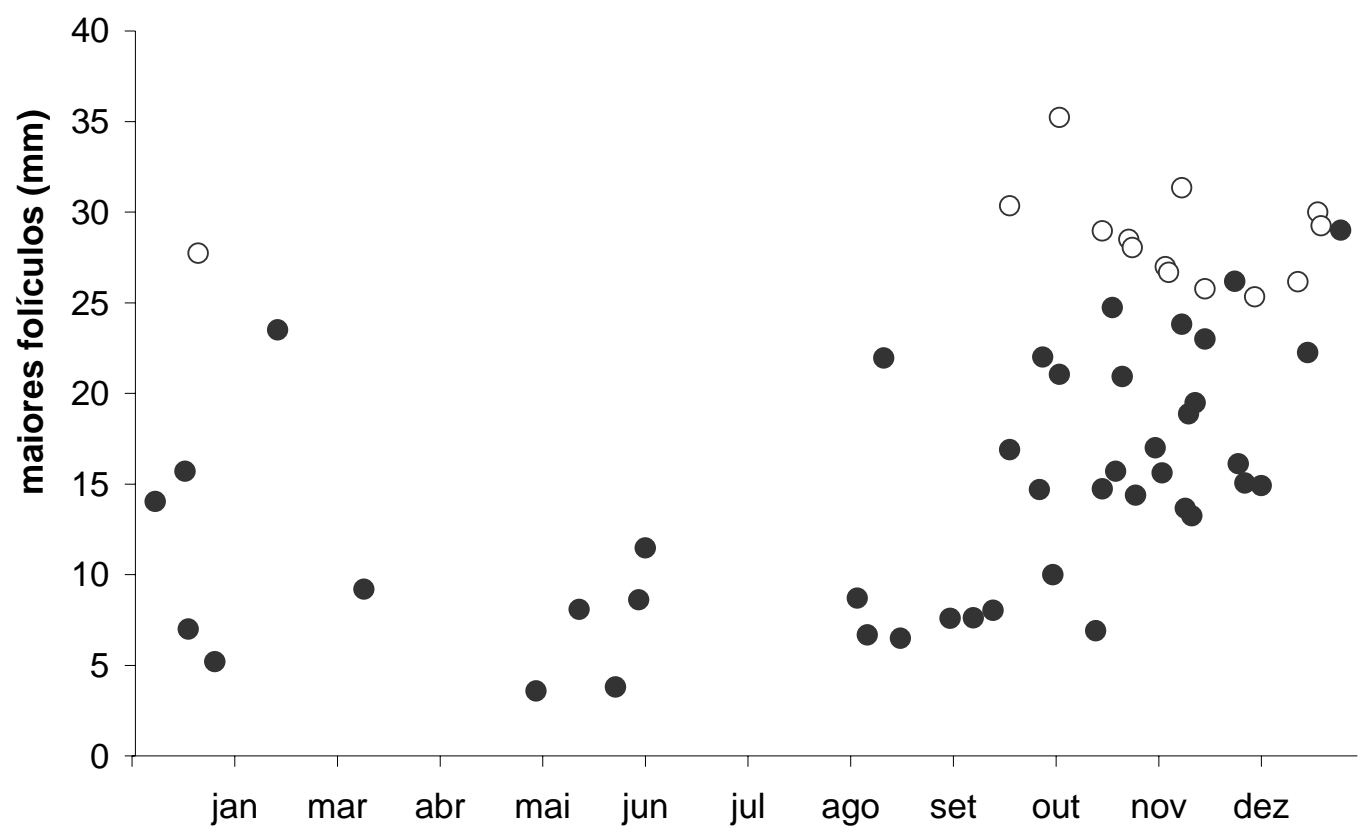

FIGURA 11. Variação sazonal dos maiores diâmetros dos folículos vitelogênicos de fêmeas de Sibynomorphus mikanii, entre agosto de 2003 e março de 2007. Folículos (círculos sólidos) e ovos (círculos abertos).

Foi mais ativa durante a estação chuvosa e durante o mês de maio (Fig. 12), o que deve estar relacionado ao período de recrutamento dos filhotes, à maior disponibilidade de presas, e/ou procura por parceiros para acasalamentos, pois a cópula dessa espécie foi observada durante os meses do outono (ROJAS e BARBO, 2007). A distribuição foi registrada para todas as áreas do MSP, mas principalmente nas áreas Central e Norte, onde foi a segunda mais abundante. Na Área Sul foi observado apenas um registro. 


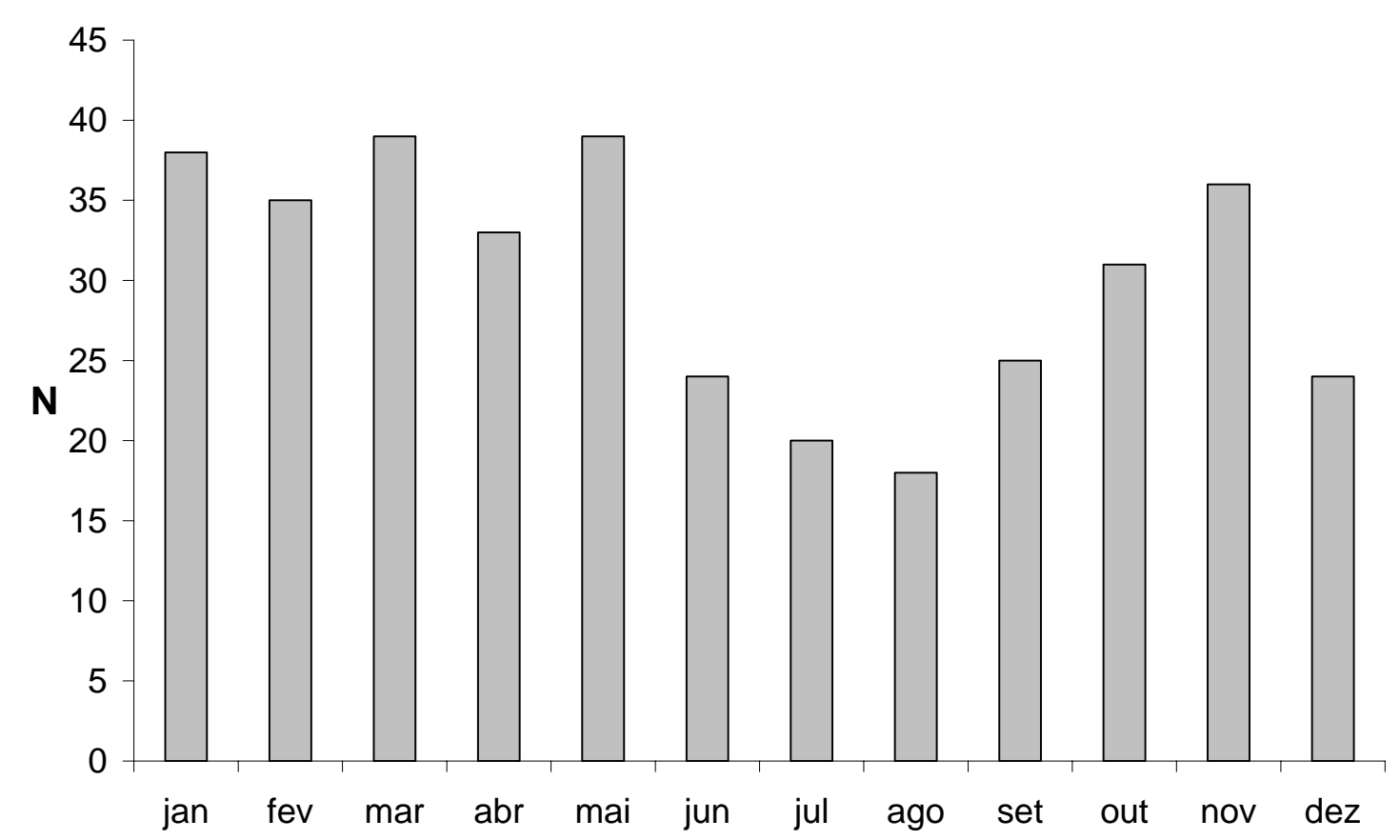

FIGURA 12. Atividade sazonal de Sibynomorphus mikanii entre agosto de 2003 e março de 2007.

Sibynomorphus neuwiedi (IHERING, 1911) "dormideira" (Fig. 4.27)

Espécie rara no MSP $(\mathrm{N}=14)$. Apresenta hábito terrícola e semi-arborícola, atividade noturna e a dieta especializada em lesmas $(\mathrm{N}=2)$, como Sibynomorphus mikanii.

A espécie é ovípara. Uma fêmea $(C R C=602 \mathrm{~mm})$ recebida no mês de outubro continha cinco folículos vitelogênicos, com o maior medindo $31 \mathrm{~mm}$. Outra fêmea $(C R C=705 \mathrm{~mm})$, recebida no mês de março, continha nove ovos no oviduto, com o maior medindo $29 \mathrm{~mm}$.

Distribuiu-se somente na Área Central.

Siphlophis longicaudatus (ANDERSSON, 1907) (Fig. 4.28)

Espécie rara no MSP $(\mathrm{N}=3)$. Apresenta hábito arborícola e atividade noturna (MARQUES; ETEROVIC E SAZIMA, 2001). A dieta é constituída de lagartos (PRUDENTE; MORATO e MOURA-LEITE, 1998).

A espécie é ovípara, mas não foram obtidas informações sobre reprodução no MSP. Essa espécie se distribuiu na Área Central $(N=2)$, sempre associada às áreas com significativa cobertura vegetal. 


\section{Spilotes pullatus (LINNAEUS, 1758) "caninana" (Fig. 4.29)}

Espécie rara no MSP $(\mathrm{N}=5)$. Apresenta hábito terrícola e semi-arborícola (MARQUES e SAZIMA, 2004), e atividade diurna. A alimentação é constituída por pequenos mamíferos, aves e lagartos (MARQUES; ETEROVIC E SAZIMA, 2001) (MARQUES 2008) $^{5}$. Um exemplar, proveniente da Área Central, continha remanescentes de um morcego não identificado no estômago.

A predação de morcegos é registrada para 10 espécies de colubrídeos (ESBÉRARD e VRCIBRADIC, 1997), inclusive para Pseustes sulphureus, espécie irmã de Spilotes dentro da subfamília Colubrinae (RUFINO e BERNARDI, 1999). Essas espécies caçam ativamente e podem entrar em refúgios para capturar morcegos. Na cidade, os refúgios podem ser árvores e também os forros de telhados das residências.

A espécie é vivípara (HAUZMAN; da COSTA e SCARTOZZONI, 2005). Duas fêmeas $(C R C=472$ e $470 \mathrm{~mm}$ ), recebidas no mês de agosto, possuíam sete e quatro folículos vitelogênicos, com o maior medindo 23,8 e 49,7 mm.

\section{Taeniophallus affinis (GüNTHER, 1858) (Fig. 4.30)}

Espécie rara no MSP $(N=7)$. Apresenta hábito terrícola e também criptozóico, e atividade diurna (MARQUES; ETEROVIC E SAZIMA, 2001; obs. pess.). A dieta é constituída por pequenos anfíbios anuros e lagartos. Um indivíduo, coletado no Parque Estadual das Fontes do Ipiranga, continha um anfisbenídeo (Amphisbaena dubia) no estômago (BARBO e MARQUES, 2003; BARBO e SAWAYA, 2008). Anfisbenídeos são répteis fossoriais, e eventualmente sobem à superfície, locomovendo-se entre a serapilheira. Na região sul do Brasil, foram observados outros dois exemplares dessa espécie com anfisbenídeos (Amphisbaena mertensi) no estômago (SANCHES, 2004) ${ }^{6}$, indicando o hábito criptozóico dessa espécie.

A espécie é ovípara, porém não foi registrada nenhuma informação sobre a reprodução no MSP.

Distribuiu-se nas áreas Central e Sul do MSP.

\footnotetext{
${ }^{5}$ MARQUES, O.A.V. São Paulo, 2008 (em fase de elaboração)

${ }^{6}$ SANCHES, E. Curitiba, 2004 (comunicação pessoal)
} 


\section{Taeniophallus persimilis (COPE, 1868) (Fig. 4.31)}

Espécie rara no MSP $(\mathrm{N}=2)$. Apresenta hábito e atividade semelhantes à de Taeniophallus affinis. A dieta é constituída de pequenos anfíbios anuros e lagartos (MARQUES; ETEROVIC e SAZIMA, 2001). Como observado em T. affinis, provavelmente também utiliza outros recursos alimentares, como anfisbenídeos (BARBO e MARQUES, 2003).

A espécie é ovípara (MARQUES; ETEROVIC e SAZIMA, 2001), mas nenhum dos dois exemplares forneceu informações sobre reprodução.

Os dois exemplares foram coletados na Área Norte do MSP, na borda da mata do Parque Estadual da Cantareira (BERTANI, 2005) ${ }^{7}$.

\section{Tantilla melanocephala (LINNAEUS, 1758) "cobra-da-terra" (Fig. 4.32)}

Espécie rara no MSP $(N=2)$. Apresenta hábito terrícola e criptozóico, e atividade diurna (MARTINS e OLIVEIRA, 1998). A dieta é constituída por lacraias, principalmente da espécie Otostigmus sp. (Scolopendridae) (MARQUES e PUORTO, 1998).

A espécie é ovípara. Uma fêmea recebida no mês de novembro $(C R C=267)$ continha três folículos vitelogênicos, com o maior medindo $11 \mathrm{~mm}$. A vitelogênese para essa espécie foi observada do início até a metade da estação chuvosa (MARQUES e PUORTO, 1998).

Os dois exemplares foram coletados na Área Norte do MSP.

\section{Thamnodynastes strigatus (GÜNTHER, 1858) "corre-campo" (Fig. 4.33)}

Espécie rara no MSP $(\mathrm{N}=6)$. Apresenta hábito terrícola e atividade noturna. A dieta é constituída por anfíbios anuros, pequenos mamíferos, peixes e lagartos (BERNARDE et al. 2000). Não foram obtidos dados sobre a dieta dessa espécie no MSP.

A espécie é vivípara. Uma fêmea (CRC $=571 \mathrm{~mm}$ ) recebida no mês de fevereiro, continha 15 folículos vitelogênicos, com o maior medindo 14,4 mm. Outra fêmea $(C R C=598 \mathrm{~mm})$ recebida no mês de novembro possuía 24 embriões nos ovidutos, com o maior medindo $23,3 \mathrm{~mm}$.

Distribuiu-se nas áreas Norte e Central do MSP.

\footnotetext{
${ }^{7}$ BERTANI, R. São Paulo, 2005 (comunicação pessoal)
} 


\section{Tomodon dorsatus DUMÉRIL, BIBRON \& DUMÉRIL, 1854 "cobra-espada"}

(Fig. 4.34)

Espécie comum no MSP ( $N=92)$. Apresenta hábito terrícola e atividade diurna (MARQUES; ETEROVIC e SAZIMA, 2001; observação pessoal). A dieta é especializada em lesmas ( $N=2$ ) (BIZERRA; MARQUES e SAZIMA, 2005).

A espécie é vivípara. Uma fêmea recebida no mês de outubro ( $C R C=412$ $\mathrm{mm}$ ) continha um folículo vitelogênico, com diâmetro de 10,47 mm. Duas outras fêmeas $(C R C=474$ e $530 \mathrm{~mm})$, recebidas no mês de dezembro, possuíam 10 folículos vitelogênicos cada, com os maiores medindo 12,9 e 17,7 mm. Duas fêmeas recebidas no mês de janeiro $(\mathrm{CRC}=551$ e $514 \mathrm{~mm})$ continham 11 e 14 folículos vitelogênicos, com os maiores medindo 18,1 e $17 \mathrm{~mm}$.

Os nascimentos dos filhotes ocorreram nos meses de junho $(N=1)$ com 11 filhotes, janeiro $(N=2)$ com 13 e 14 filhotes, fevereiro $(N=2)$ com 12 e 17 filhotes, e março $(N=4)$, com 10,13, 13 e 14 filhotes.

Essa espécie foi mais ativa nos meses de outubro $(\mathrm{N}=12)$, novembro $(\mathrm{N}=$ 20), dezembro $(N=11)$ e março $(N=11)$ (Fig. 13).

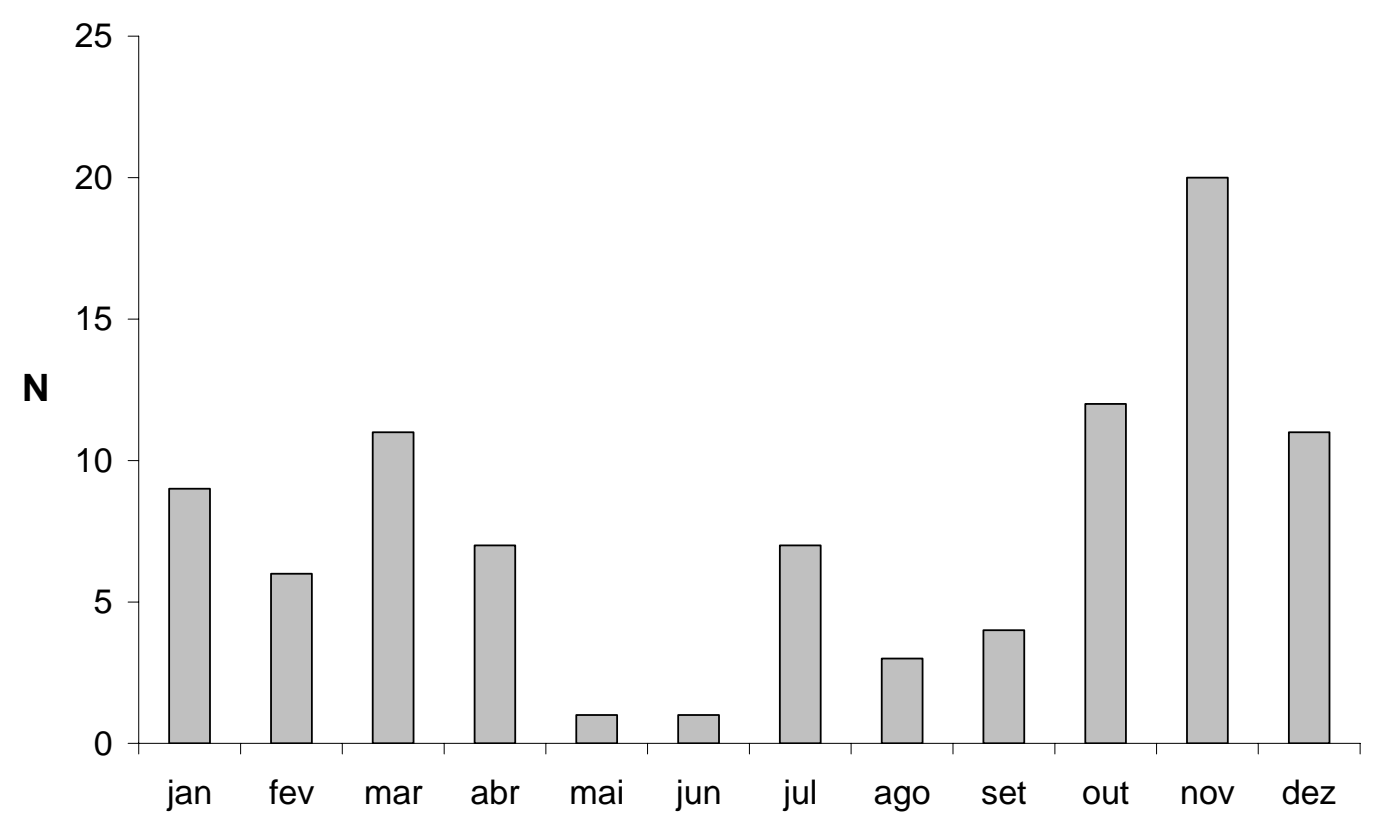

FIGURA 13. Atividade sazonal de Tomodon dorsatus entre agosto de $2003 \mathrm{e}$ março de 2007. 


\section{Tropidodryas striaticeps (COPE, 1869) "cobra-cipó" (Fig. 4.35)}

Espécie rara no MSP $(N=5)$. Apresenta hábito semi-arborícola e atividade diurna (SAZIMA e PUORTO, 1993). A dieta é constituída de pequenos lagartos na fase juvenil e mamíferos e aves na fase adulta (SAZIMA e PUORTO, 1993; MARQUES, 1998; MARQUES; ETEROVIC e SAZIMA, 2001).

A espécie é ovípara (STENDER-OLIVEIRA, 2006) ${ }^{8}$, mas não foram obtidas informações sobre sua biologia reprodutiva.

A distribuição correspondeu a algumas áreas de mata do MSP, como os bairros de Perus, Cantareira, Imigrantes e Água Funda (Parque do Estado).

\section{Xenodon neuwiedii (GüNTHER, 1863) "quiriripitá" (Fig. 4.36)}

Espécie comum no MSP ( $N=44)$. Apresenta hábitos terrícolas e atividade diurna. A dieta é especializada em anfíbios anuros, principalmente da Família Bufonidae (JORDÃO, 1996). Dos 11 conteúdos alimentares analisados, sete eram remanescentes de insetos, provavelmente conteúdos alimentares secundários, e quatro eram vestígios de anfíbios anuros.

A espécie é ovípara. Uma fêmea recebida no mês de junho $(C R C=652 \mathrm{~mm})$ continha 12 folículos vitelogênicos, com o maior medindo 23,8 mm. Duas fêmeas recebidas nos meses de outubro e novembro $(\mathrm{CRC}=640$ e $479 \mathrm{~mm})$ continham nove e oito folículos vitelogênicos, com os maiores medindo 27,5 e 24,1 mm, respectivamente. Três outros exemplares, recebidos nos meses de fevereiro, março e abril $(C R C=823,632$ e $625 \mathrm{~mm}$ ), continham oito, três e seis folículos vitelogênicos, com os maiores diâmetros medindo 27,0 21,0 e 18,8 mm, respectivamente.

\section{Família Elapidae BoIE, 1827}

\section{Micrurus corallinus (MERREM, 1820) "coral-verdadeira" (Fig. 4.37)}

Espécie rara no MSP $(N=5)$. Apresenta hábito fossorial e atividade predominantemente diurna (MARQUES; ETEROVIC e SAZIMA, 2001). A dieta é constituída principalmente de répteis alongados (anfisbenídeos, serpentes e pequenos lagartos gimnoftalmídeos) e também de anfíbios cecilídeos (MARQUES e SAZIMA, 1997).

\footnotetext{
${ }^{8}$ STENDER-OLIVEIRA, F. São Paulo, 2006 (comunicação pessoal)
} 
Não foram obtidos dados sobre a reprodução dessa espécie no MSP, porém Marques (1996) observou a presença de folículos vitelogênicos entre os meses de setembro e dezembro, e postura de ovos nos meses de dezembro e janeiro. É possível que essa espécie possua um ciclo reprodutivo sazonal (MARQUES, 1996).

No MSP, essa espécie foi encontrada apenas em regiões com remanescentes florestais, localizadas nas áreas Norte e Central. Apesar de ser muito comum nas florestas da Serra do Mar, não foi obtido nenhum registro de ocorrência para a Área Sul durante o período de amostragem, provavelmente devido ao hábito fossorial e a ocorrência no interior das florestas.

Micrurus lemniscatus (LINNAEUS, 1758) "coral-verdadeira" (Fig. 4.38)

Espécie rara no MSP $(\mathrm{N}=1)$. Apresenta hábito fossorial e atividade diurna e noturna (SAZIMA e ABE, 1991; observação pessoal) A dieta é constituída por répteis alongados e peixes (CUNHA e NASCIMENTO 1978, 1982).

Não foram obtidos dados sobre a reprodução dessa espécie no MSP.

O único exemplar foi registrado na Área Sul, próximo à represa Billings.

\section{Família Viperidae LAURENTI, 1768}

\section{Bothrops jararaca (WIED, 1824), “jararaca” (Fig. 4.39 e 4.40)}

Terceira espécie mais abundante no MSP $(N=279)$. Apresenta hábito terrícola e semi-arborícola e atividade principalmente noturna (SAZIMA, 1992; MARQUES; ETEROVIC e SAZIMA, 2001), mas também diurna. A dieta na fase juvenil é constituída de presas ectotérmicas, como pequenos anfíbios anuros e lagartos, e de roedores na fase adulta. Do total de exemplares analisados, 54 apresentavam conteúdos alimentares, como roedores $(N=7)$, pêlos de roedores $(N$ = 34), lagartixas da espécie Hemidactylus mabouia $(N=6)$, anfíbios $(N=1)$, além de remanescentes de insetos $(N=6)$, provavelmente conteúdos alimentares secundários.

Foi mais ativa durante a estação chuvosa, nos meses de novembro $(N=34)$, dezembro $(\mathrm{N}=31)$, janeiro $(\mathrm{N}=31)$ e março $(\mathrm{N}=48)$ (Fig. 14)

A espécie é vivípara. Foi observada a presença de folículos vitelogênicos em quase todos os meses do ano, com diâmetros variando entre 5,2 e 38,6 mm. A presença de embriões foi observada entre os meses de outubro e março, com 
diâmetros variando entre 18,7 e $49,5 \mathrm{~mm}$. A fecundidade variou entre 11 e 40 embriões ( $\mathrm{N}=14)$.

Foi registrada nas áreas Norte e Sul do MSP, associada a remanescentes florestais desta região. Também foi bastante comum em parques florestais da Área Central do MSP, como o Parque do Estado e o Parque do Carmo.

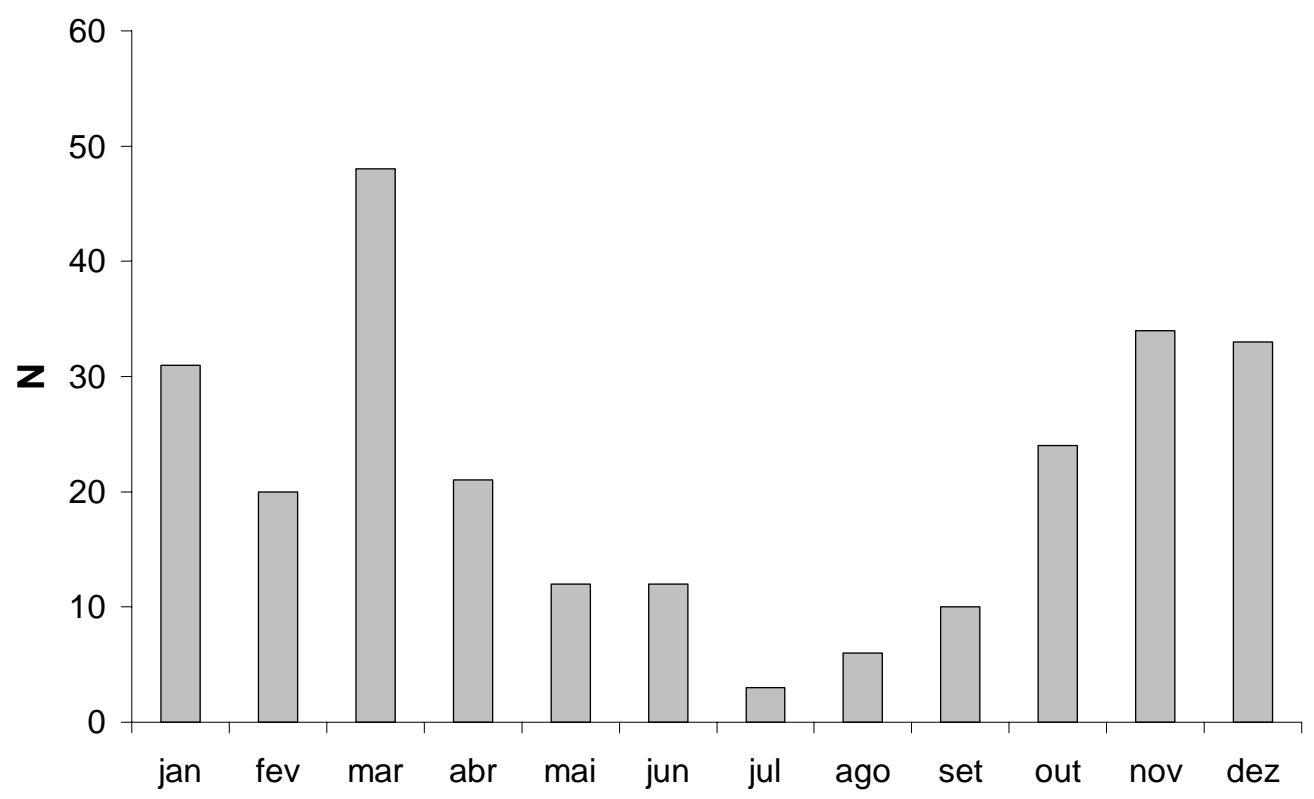

FIGURA 14. Atividade sazonal de Bothrops jararaca entre agosto de 2003 e março de 2007.

\section{Bothrops jararacussu LACERDA, 1884, “jararacussu” (Fig. 4.41)}

Espécie rara no MSP $(N=1)$. Apresenta hábito terrícola e atividade noturna. $A$ dieta na fase juvenil, como em $B$. jararaca, é constituída por presas ectotérmicas, e na fase adulta, por roedores (MARQUES; ETEROVIC e SAZIMA, 2001). O único indivíduo registrado era uma fêmea, coletada na Área Central dentro de uma casa, em região não arborizada e desconectada de qualquer área florestal.

A espécie é vivípara, mas não forneceu nenhuma informação sobre a biologia reprodutiva.

\section{Crotalus durissus terrificus LAURENTI, 1768, "cascavel” (Fig. 4.42)}

Espécie rara no MSP $(\mathrm{N}=11)$. Apresenta hábito terrícola e atividade noturna, apesar de ter sido registrada em atividade durante o dia por Sawaya (2004). A dieta é constituída de roedores ( $N=1$; observação pessoal). 
A espécie é vivípara. Duas fêmeas recebidas nos meses de agosto e dezembro continham 13 e nove folículos vitelogênicos, com os maiores medindo 31,6 e $34,2 \mathrm{~mm}$, respectivamente.

No MSP se distribuiu nas áreas Norte e Central, sempre associada às áreas abertas. Essa espécie é típica de áreas de cerrado, porém nos últimos anos tem sido encontrada com mais freqüência no MSP. Uma das hipóteses para esse fato é a dispersão através de corredores de desmatamento, que ocorrem nas cidades do entorno, como verificado por Bastos et al. (2005) para o Rio de Janeiro. A grande incidência de desmatamentos decorrentes da urbanização, associada com a abundância de roedores na cidade, provavelmente facilitaram a colonização dessa espécie em áreas onde antes não ocorria.

\subsection{1 - Uso do Substrato}

O hábito terrícola foi o mais comum (Fig. 15), apresentado por $45 \%$ do total de espécies do MSP. As serpentes de hábito semi-arborícola, fossorial e criptozóico representaram $13 \%$ cada, e as de hábito aquático e arborícola $8 \%$ cada.

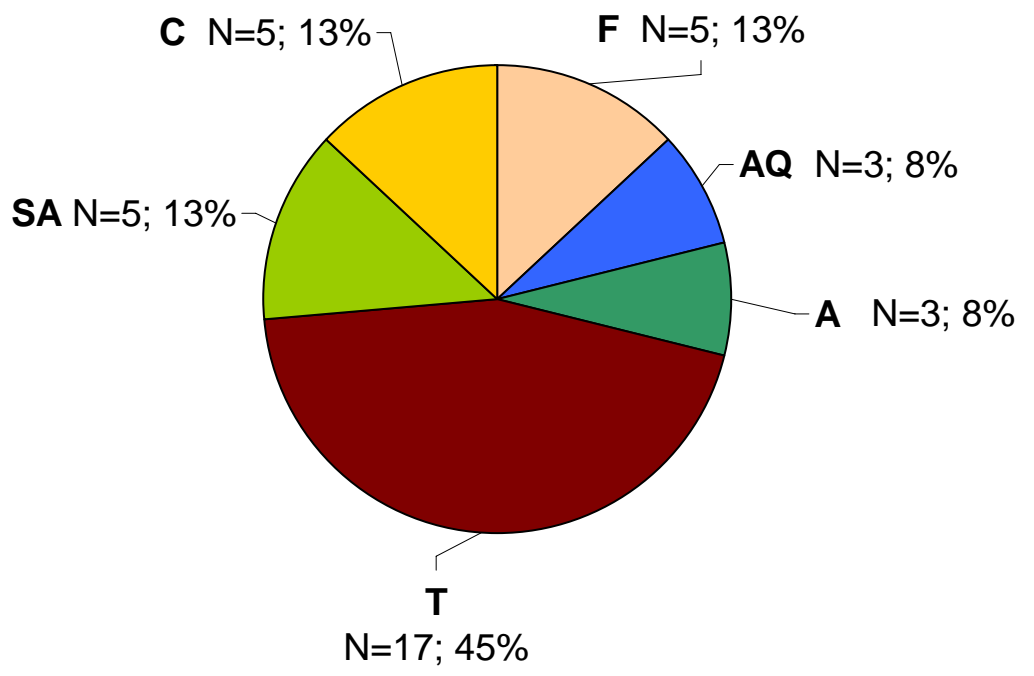

FIGURA 15. Número absoluto $(\mathrm{N})$ e porcentagem das espécies registradas no Município de São Paulo em relação ao uso do substrato. $\mathbf{T}=$ terrícola; $\mathbf{A}=$ arborícola; $\mathbf{C}=$ criptozóica; $\mathbf{F}=$ fossorial; $\mathbf{S A}=$ Semi-arborícola; $\mathbf{A Q}=$ aquática. 


\subsection{2 - Dieta}

A maior parte das serpentes amostradas (39\%) alimenta-se exclusivamente ou predominantemente de anfíbios anuros (Fig. 16), 21 \% de mamíferos, 21 \% de invertebrados (minhocas, moluscos e artrópodes), além de serpentes e anfisbenídeos (11\%), peixes (5\%) e lagartos (3\%).

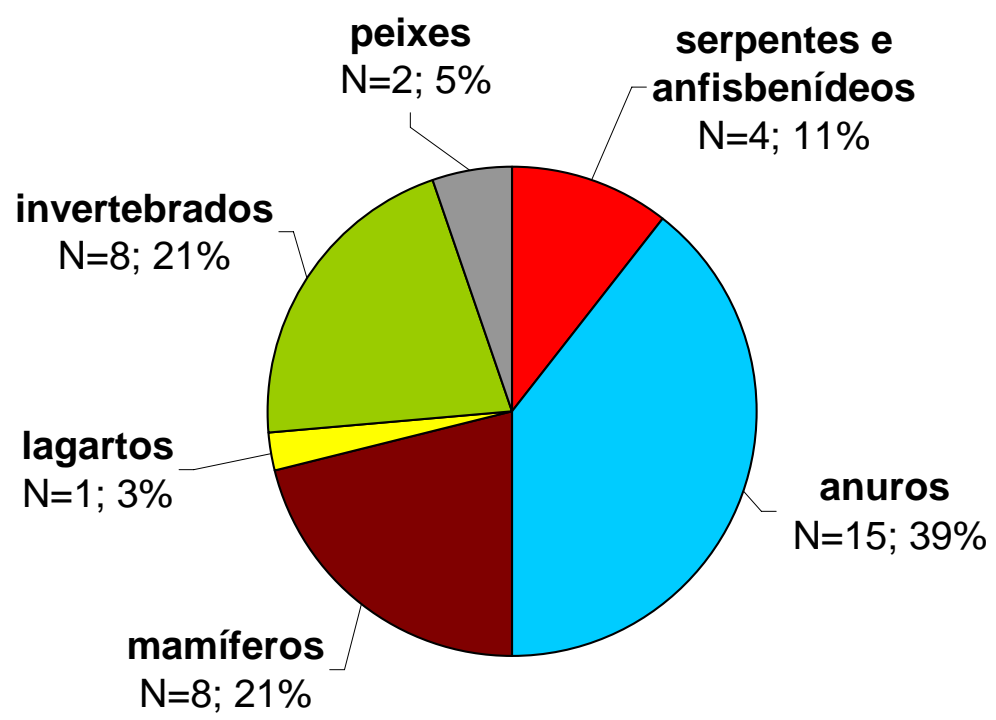

FIGURA 16. Número absoluto (N) e porcentagem das espécies registradas no Município de São Paulo em relação à dieta.

\subsection{3 - Atividade Sazonal}

Durante o período de 44 meses, foi observado pico de abundância sazonal das serpentes na estação chuvosa, geralmente entre outubro e março (Fig. 17). O número de serpentes registradas no MSP durante a estação seca ( $N=622$; abril a setembro) foi significativamente menor $\left(\chi^{2}=67,07 ; p<<0,001 ; g\right.$. I. $\left.=1 ; N=1742\right)$ do que aquele esperado na estação chuvosa $(N=1120)$. 


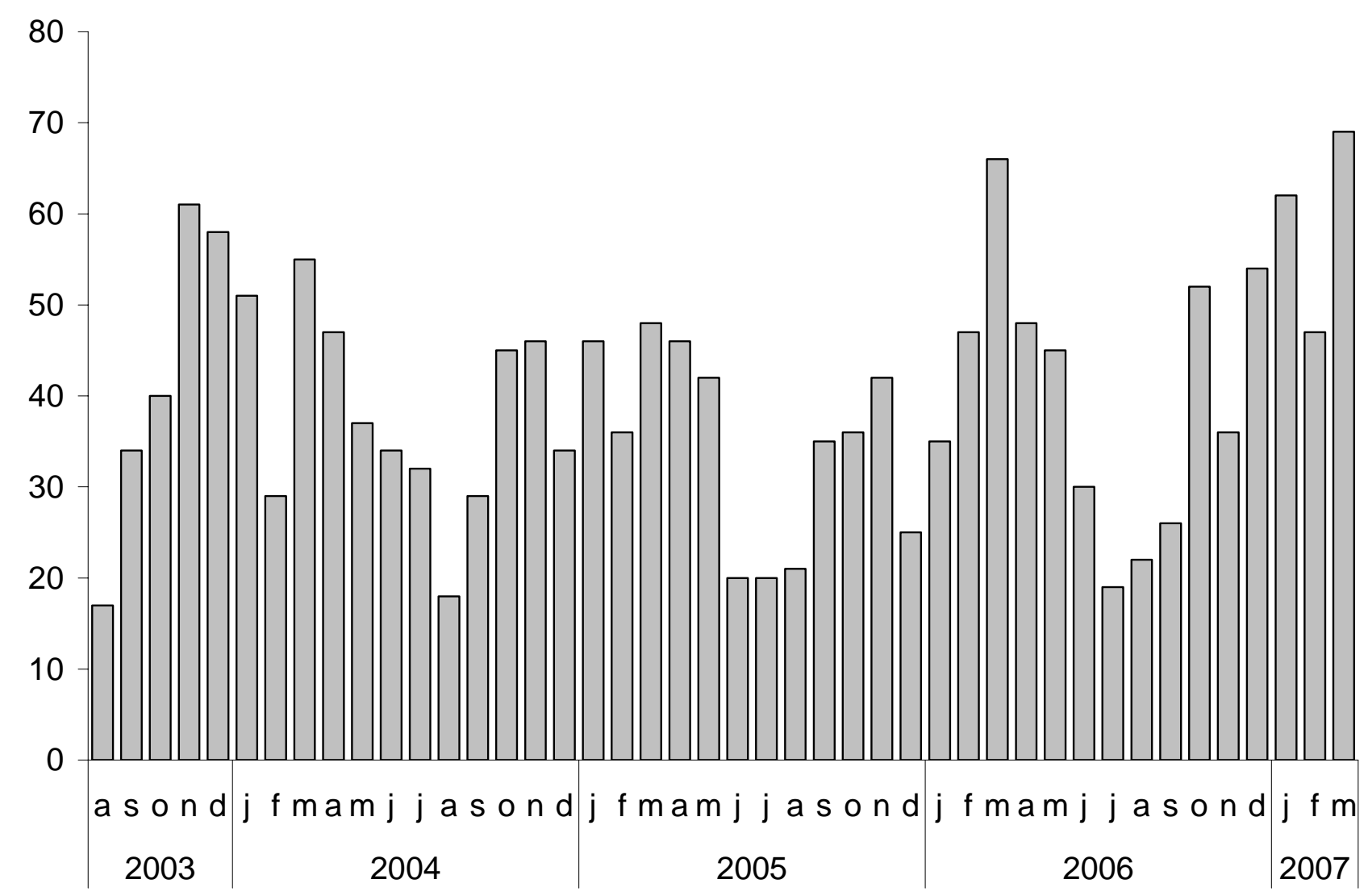

FIGURA 17. Atividade sazonal das serpentes, incluindo jovens e adultos provenientes do MSP, recebidas no período de 44 meses de amostragem.

\section{3 - DIVERSIDADE E DISTRIBUIÇÃO}

A riqueza de serpentes do MSP correspondeu a 38 espécies. Um levantamento realizado nas coleções do MZUSP e Instituto Butantan referente a um período de aproximadamente 100 anos, registrou 68 espécies para a região (MARQUES, 2008) ${ }^{9}$, indicando que a riqueza encontrada neste estudo provavelmente não corresponde ao número total de espécies que ocorrem na região.

Considerando conjuntamente as três áreas do MSP, a espécie dominante (Fig. 18) foi Oxyrhopus guibei, representada por 24\% do total ( $N=413$; Tabela 1 ), seguida de Sibynomorphus mikanii, representada por $21 \%(\mathrm{~N}=362)$ e Bothrops jararaca, com 16\% ( $\mathrm{N}=279)$.

\footnotetext{
${ }^{9}$ MARQUES, O. A. V. São Paulo, 2008 (em fase de elaboração)
} 


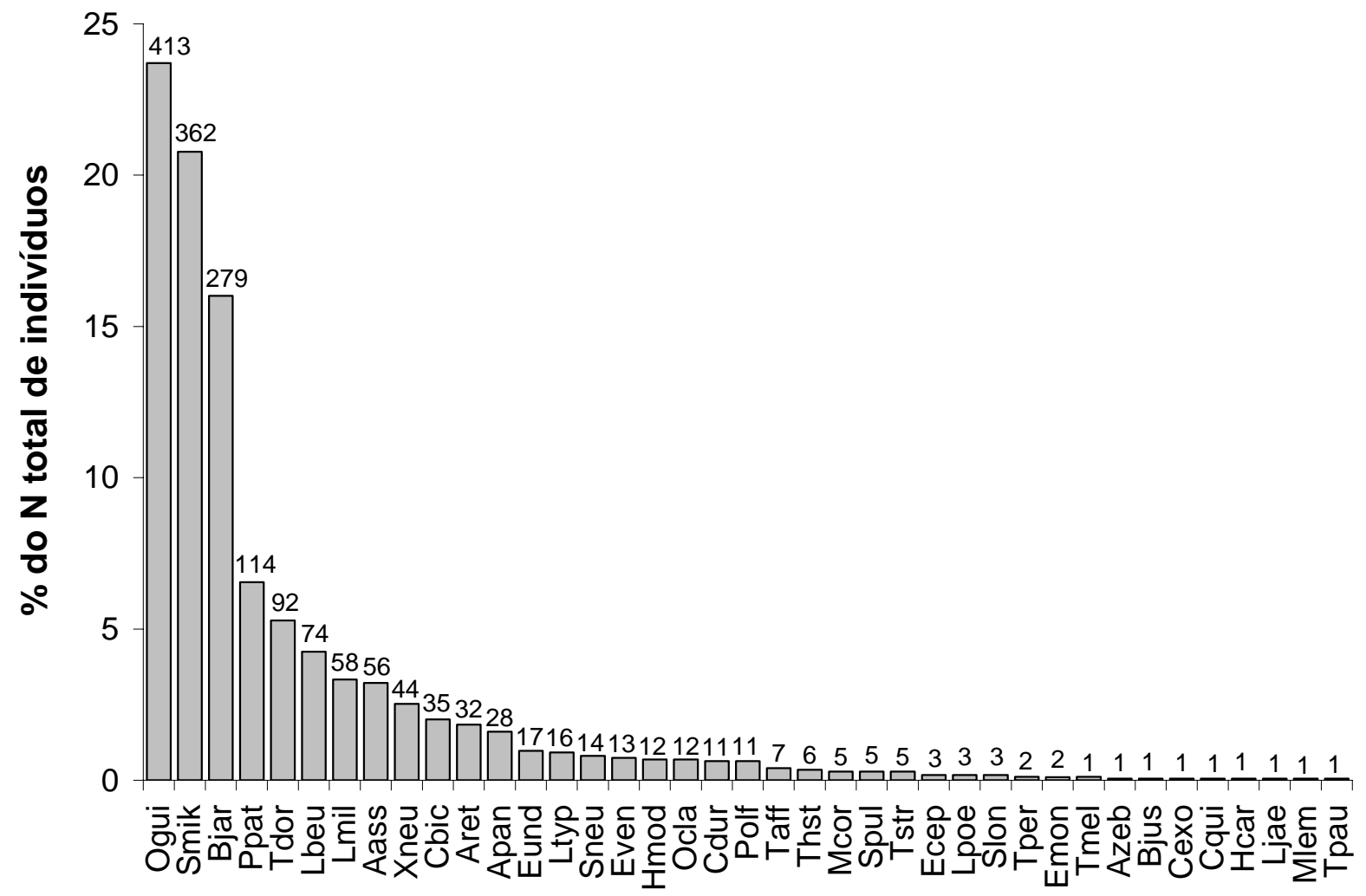

FIGURA 18. Abundância relativa de espécies de serpentes, em porcentagem do número total de indivíduos ( $\mathrm{N}=1742$ ), encontradas no Município de São Paulo. O número de indivíduos de cada espécie está indicado acima de cada barra.

Legenda: Aass $=$ Apostolepis assimilis; Apan $=$ Atractus pantostictus; Aret $=$ Atractus reticulatus; Azeb = Atractus zebrinus; $\mathbf{B j a r}=$ Bothrops jararaca; Bjus = Bothrops jararacussu; Cbic = Chironius bicarinatus; Cexo = Chironius exoletus; Cqui = Clelia quimi; Cdur = Crotalus durissus; Emon = Erythrolamprus aesculapii monozona; Even = Erythrolamprus a. venustissimus; Ecep = Echinanthera cephalostriata; Eund = Echinanthera undulata; Hcar = Helicops carinicaudus; Hmod = Helicops modestus; Lbeu = Liotyphlops beui; Ljae = Liophis jaegeri; Lmil = Liophis miliaris; Lpoe = Liophis poecilogyrus; Ltyp = Liophis typhlus; Mcor = Micrurus corallinus; Mlem = Micrurus lemniscatus; Ocla = Oxyrhopus clathratus; Ogui = Oxyrhopus guibei; Polf $=$ Philodryas olfersii; Ppat $=$ Philodryas patagoniensis; Slon = Siphlophis longicaudatus; Smik = Sibynomorphus mikanii; Sneu = Sibynomorphus neuwiedi; Spul = Spilotes pullatus; Taff $=$ Taeniophallus affinis; Tper = Taeniophallus persimilis; Tmel = Tantilla melanocephala; Thst = Thamnodynastes strigatus; Tdor $=$ Tomodon dorsatus; $\mathbf{T p a u}=$ Tropidophis paucisquamis; $\mathbf{T s t r}=$ Tropidodryas striaticeps; $\mathbf{X n e u}=$ Xenodon neuwiedii. 
Além das três espécies dominantes, outras três espécies foram consideradas comuns (entre 74 e 115 indivíduos ou 4,2 a 6,6\%), seis apresentaram abundância intermediária (entre 28 e 58 indivíduos ou 1,6 a 3,3\%), e 26 foram consideradas raras (entre um e 17 indivíduos ou menos de 1\%).

O grande número de espécies raras e a inclinação ascendente da curva de rarefação de espécies (Fig. 19) confirmam que ainda não foram registradas todas as espécies que devem ocorrer no município.

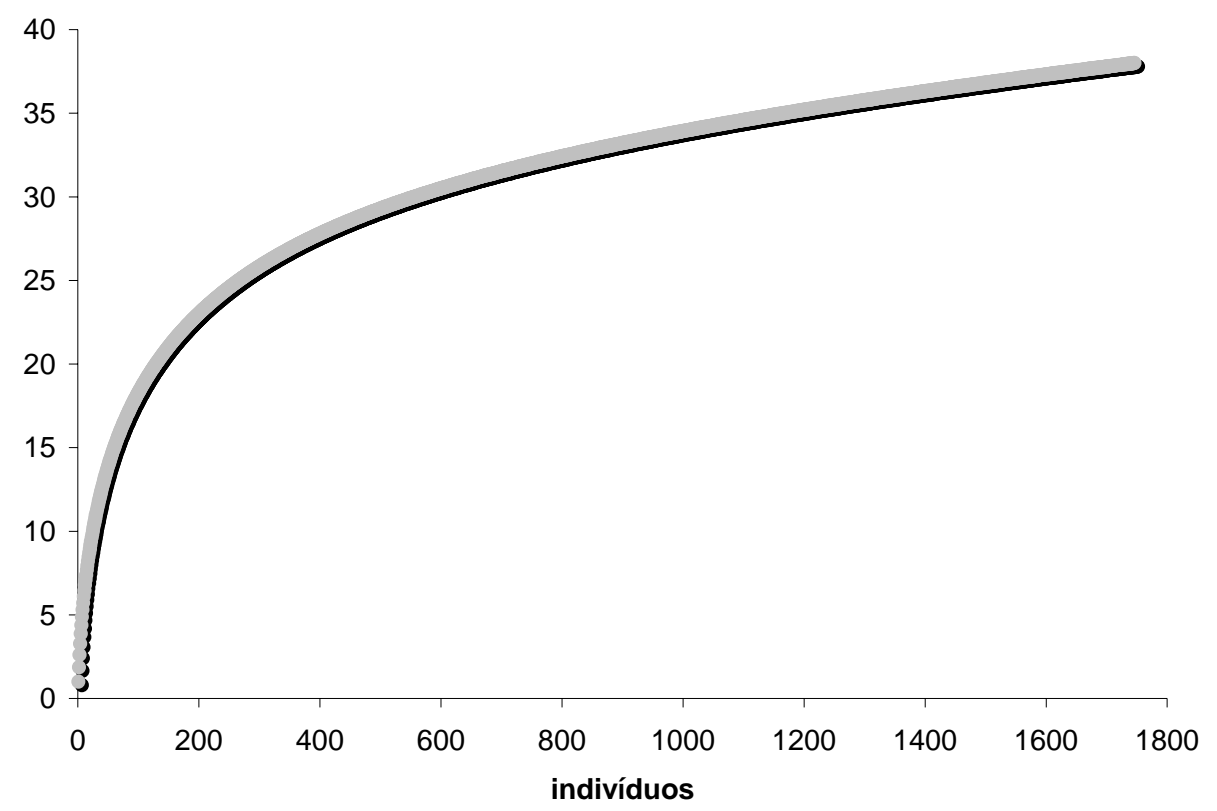

FIGURA 19. Curva de rarefação de espécies gerada a partir de 1000 aleatorizações na ordem de amostragem das 1742 serpentes registradas no Município de São Paulo, entre agosto de 2003 e março de 2007.

Do total de 1742 indivíduos (38 espécies), 1051 de 36 espécies possibilitaram a obtenção de coordenadas geográficas correspondentes ao local de captura (Fig. 20). Alguns pontos ilustrados no mapa podem conter mais de um registro, ou seja, no mesmo local (endereço) pode ter sido coletado mais de um indivíduo e/ou mais de uma espécie. 


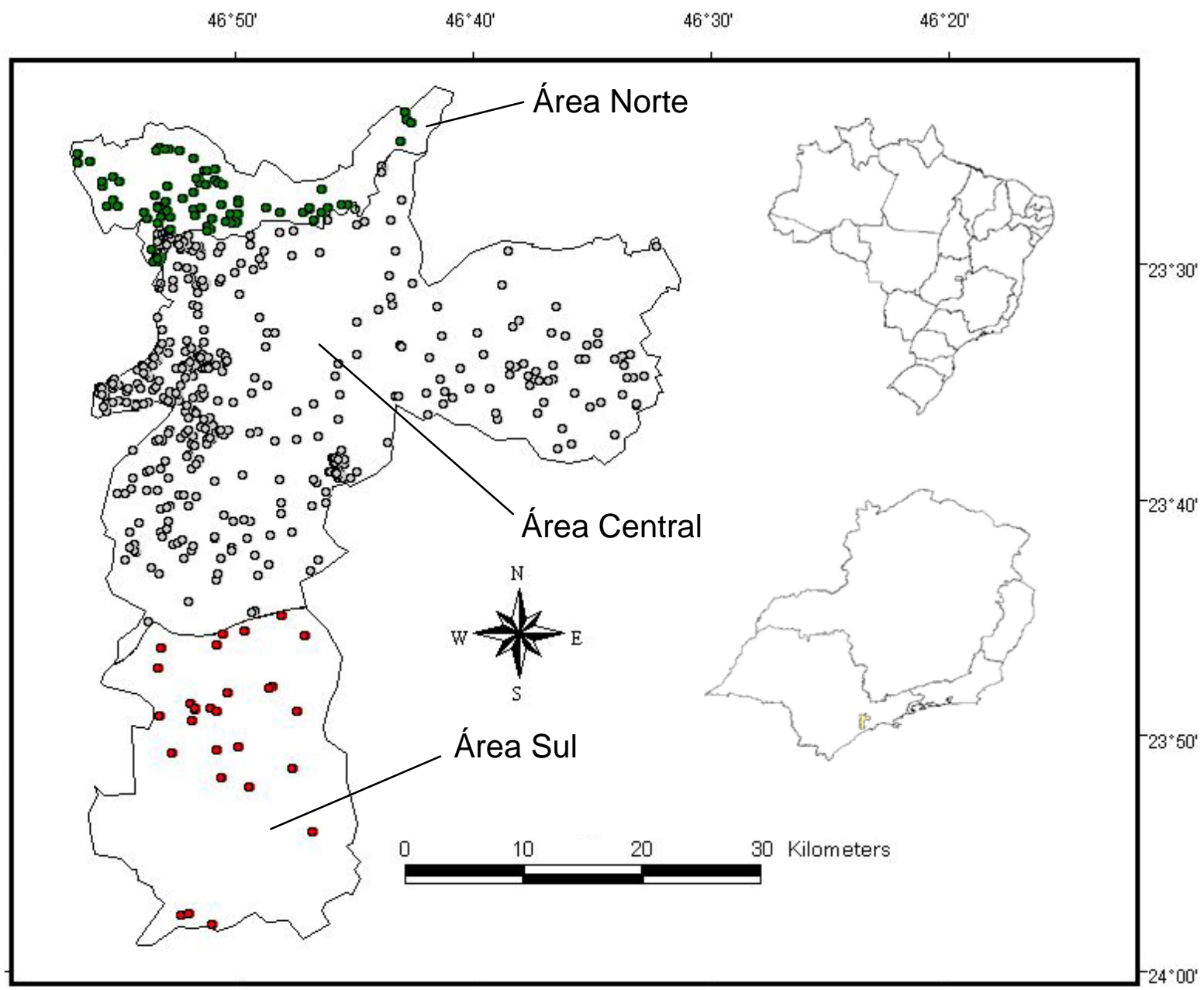

FIGURA 20. Distribuição das serpentes recebidas pelo Instituto Butantan entre agosto de 2003 e março de 2007 nas três áreas do Município de São Paulo $(\mathrm{N}=1051)$.

A área que apresentou o maior número de registros foi a Central $(N=718)$, com riqueza observada de 33 espécies (Tabela 2; Fig. 21) e dominância de Oxyrhopus guibei (25\%), seguida pela Área Norte $(N=226)$, com riqueza observada de 20 espécies e dominância de Bothrops jararaca (25\%), e Área Sul ( $=107$ ), com riqueza observada de 15 espécies e dominância de Bothrops jararaca (37\%).

A análise da riqueza e dominância pelo método da rarefação para $N=107$ indivíduos (número de indivíduos registrados na Área Sul), indicou que a Área Central apresentou, em média, maior riqueza estimada de espécies (18 spp.) em relação à Área Norte (16 spp.), mas essa diferença não foi significativa (Tabela 2). 
Mas considerando os intervalos de confiança das estimativas, a riqueza estimada por rarefação para $\mathrm{N}=107$ indivíduos das áreas Central e Norte não foram significativamente diferentes da riqueza observada para a Área Sul $(N=15$ espécies).

TABELA 2. Número de indivíduos, riqueza observada, riqueza estimada por rarefação ( $\mathrm{N}=$ 107 indivíduos) e intervalo de confiança a 95\%; espécie dominante, dominância observada, dominância estimada por rarefação $(N=107)$ e intervalo de confiança a 95\%, das serpentes encontradas nas três áreas do MSP.

Espécies dominantes: Bothrops jararaca, Oxyrhopus guibei e Bothrops jararaca

\begin{tabular}{|c|c|c|c|c|}
\hline & \multicolumn{3}{|c|}{ áreas } & \multirow[t]{2}{*}{ total } \\
\hline & Norte & Central & Sul & \\
\hline número de indivíduos & 226 & 718 & 107 & 1051 \\
\hline riqueza observada & 20 & 33 & 15 & 36 \\
\hline riqueza estimada $(\mathrm{N}=107)$ & 16 & 18 & - & - \\
\hline intervalo de confiança (95\%) & $13-19$ & $15-22$ & - & - \\
\hline espécie dominante & Bothrops & Oxyrhopus & Bothrops & Oxyrhopus \\
\hline dominância observada & $25 \%$ & $25 \%$ & $37 \%$ & $25 \%$ \\
\hline dominância estimada ( $N=107)$ & $26 \%$ & $25 \%$ & - & - \\
\hline intervalo de confiança (95\%) & $22-32 \%$ & $21-34 \%$ & - & - \\
\hline
\end{tabular}

A dominância da Área Central, também estimada pelo método da rarefação, foi de 25 \%, com intervalo de confiança (95 \%) entre 21 e 34 \%. Essa dominância foi um pouco menor do que aquela estimada para a Área Norte (Tabela 2). Assim, a dominância estimada por rarefação para $N=107$ indivíduos nas áreas Central e Norte não foram significativamente diferentes entre si, mas foram significativamente menores daquela observada para a Área Sul (37\%). 


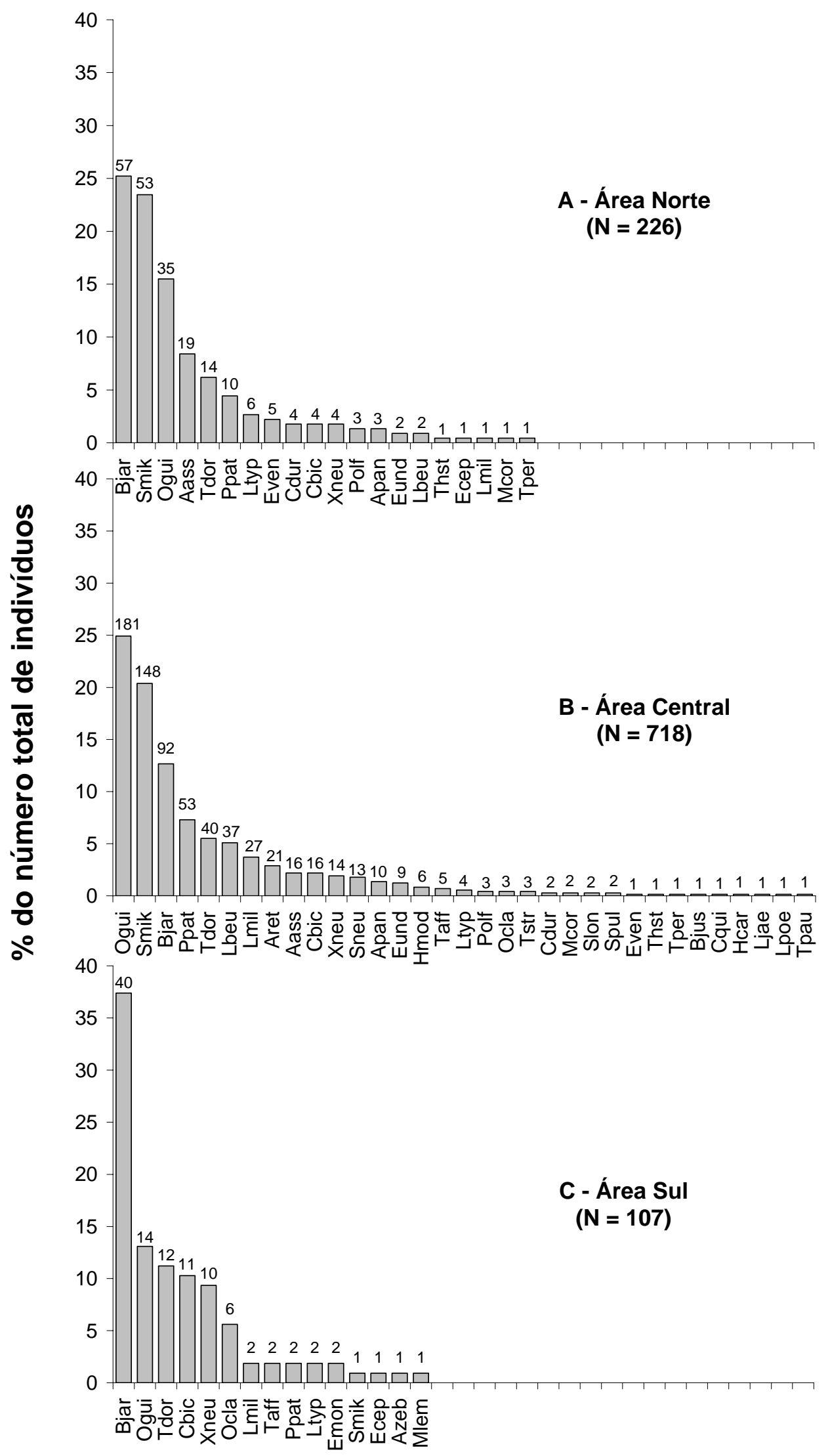

FIGURA 21. Abundância relativa de espécies nas três áreas do MSP. O nome das espécies segue a legenda da Fig. 18 (pág. 47 acima). O número de indivíduos é indicado acima de cada barra. 
As curvas de rarefação de espécies para cada área (Fig. 22) indicam que ainda não foram registradas todas as espécies que devem ocorrer nas três áreas, e também que as áreas Norte e Central apresentam maior riqueza de espécies em relação à Área Sul.

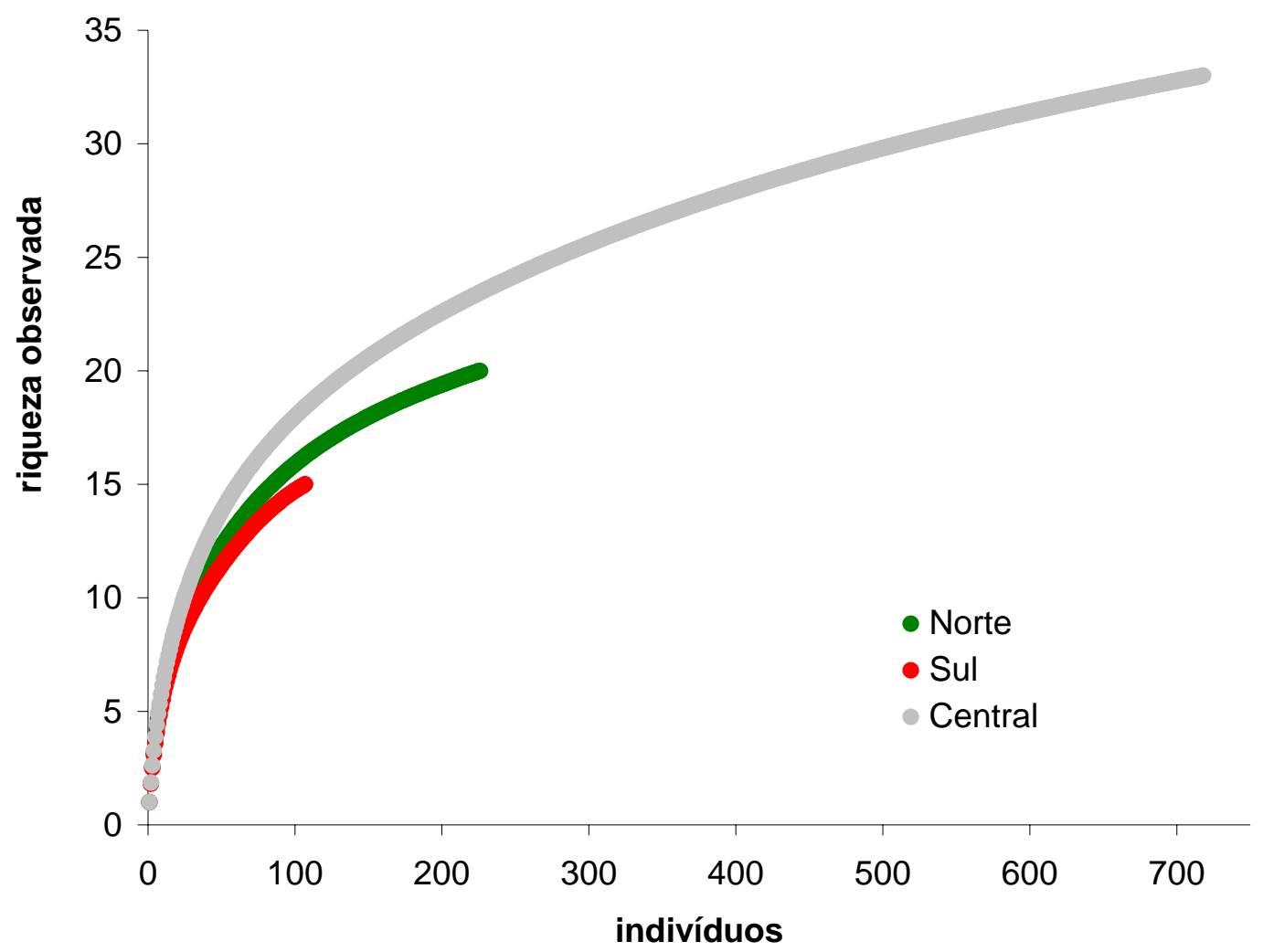

FIGURA 22. Curvas de rarefação de espécies das três áreas do MSP, geradas a partir de 1000 aleatorizações na ordem de amostragem dos indivíduos. 


\section{4 - DISCUSSÃO}

\section{1 - COMPOSIÇÃo}

Atualmente, ainda ocorrem pelo menos 38 espécies de serpentes no Município de São Paulo. Este número corresponde a pouco mais da metade (56\%) das 68 espécies registradas na coleção do Instituto Butantan e MZUSP, referentes a um período aproximado de 100 anos (MARQUES, 2008) ${ }^{10}$, indicando que a riqueza encontrada neste estudo provavelmente não corresponde ao número total de espécies que ocorrem na região.

Segundo Marques; Eterovic e Sazima (2001), ao longo de toda a Serra do Mar ocorrem cerca de 80 espécies de serpentes. Durante o século $X X$, quase toda a vegetação florestal da cidade foi destruída devido ao crescimento urbano (PREFEITURA DO MUNICÍPIO DE SÃO PAULO, 2002). O mesmo ocorreu com outras fisionomias vegetais do município, por exemplo, alguns relictos de Cerrado e os campos naturais (campos de altitude), um ecossistema singular e pouco estudado. A perda destes ambientes provavelmente causou o desaparecimento das espécies que ocorrem apenas nestas formações, justificando em parte essa diminuição pronunciada da riqueza de espécies. Entretanto, as curvas de rarefação (Figs. 19 e 22, págs. 48 e 52) indicam que ainda existem espécies para serem registradas na região. Assim, além da perda de ambiente, certamente o método de coleta utilizado neste estudo também dificulta o registro de algumas espécies, pela tendência de coleta por parte dos fornecedores.

\section{2 - HISTÓRIA NATURAL}

A predominância de serpentes terrícolas e batracófagas parece ser determinada por fatores históricos decorrentes da grande proporção da linhagem de "xenodontíneos sulamericanos" nesta taxocenose (cf. CADLE e GREENE, 1993). Além dos condicionantes históricos na estruturação dessa fauna, alguns fatores ecológicos também podem ser apontados como responsáveis pelos padrões observados, como a heterogeneidade ambiental da área, que originalmente incluía fisionomias florestais e abertas.

\footnotetext{
${ }^{10}$ MARQUES O. A. V. São Paulo, 2008 (em fase de elaboração)
} 
A plasticidade no uso do ambiente, o hábito predominantemente noturno e a dieta composta por invertebrados e roedores podem ser os fatores responsáveis pela abundância das seis espécies mais comuns no ambiente urbano (cf. PUORTO; LAPORTA-FERREIRA e SAZIMA, 1991). As espécies Oxyrhopus guibei e Sibynomorphus mikanii possuem hábitos noturnos sendo que a primeira se alimenta de pequenos lagartos (quando juvenil) e roedores (quando adulta), e a segunda de moluscos (PIZZATTO e MARQUES, 2002; OLIVEIRA, 2001). Essas espécies podem ocorrer em áreas abertas (cf. SAWAYA, 2004), porém S. mikanii também pode ser encontrada nas bordas de áreas florestais (observação pessoal). Ambas são muito comuns nas áreas mais urbanizadas da cidade, e são encontradas com freqüência em terrenos baldios. Podem ocorrer inclusive agregações de indivíduos de S. mikanii para desovas comunitárias (ALBUQUERQUE e FERRAREZZI, 2004). Bothrops jararaca, outra espécie noturna, se alimenta de presas ectotérmicas na fase juvenil e de presas endotérmicas na fase adulta (MARTINS; MARQUES e SAZIMA, 2002; SAZIMA, 1992). De forma diferente das duas primeiras, esta espécie esteve sempre associada com as áreas verdes e fragmentos florestais (e. g. Parque do Estado e Cantareira). A disponibilidade de presas parece ser um dos fatores determinantes para a abundância destas três espécies. A produção de lixo na cidade favorece a proliferação de roedores e também de insetos, que servem de alimento para animais ectotérmicos, principalmente para a lagartixa-de-parede Hemidactylus mabouia, muito comum na cidade e freqüentemente encontrada nos tratos digestivos dos juvenis de Bothrops jararaca, Oxyrhopus guibei e também de Philodryas patagoniensis.

As espécies Philodryas patagoniensis e Tomodon dorsatus possuem hábitos diurnos. A primeira apresenta dieta generalista, alimentando-se de anfíbios anuros, pequenos lagartos, aves e roedores (HARTMANN e MARQUES, 2005) e a segunda apresenta dieta especializada em lesmas (BIZERRA; MARQUES e SAZIMA, 2005). Ambas são terrícolas e são associadas a áreas florestadas, porém $P$. patagoniensis também ocorre em áreas abertas (HARTMANN e MARQUES, 2005).

A espécie Liotyphlops beui é ativa principalmente no período noturno (PARPINELLI, 2007) ${ }^{11}$ e se alimenta de larvas de formigas. É a única com hábitos estritamente fossoriais dentre as espécies comuns.

\footnotetext{
${ }^{11}$ PARPINELLI, L. São Paulo, 2007 (comunicação pessoal)
} 
Pelo fato da maioria dos exemplares serem trazidos por moradores da cidade, que não empregam um esforço intensivo de coleta, a maior abundância de determinadas espécies deve estar associada a encontros ocasionais. Há uma tendência dos coletores em capturar serpentes menos propensas à fuga durante a captura e/ou encontro acidental, com coloração conspícua e que tenham parte de sua atividade relacionada ao período diurno (cf. ZANELLA e CECHIN, 2006). Esse pode ser um dos motivos da amostragem relativamente baixa de serpentes com hábitos arborícolas (ver MARQUES, 1998). Entretanto, a baixa disponibilidade do substrato arbóreo na cidade também pode ser um dos fatores limitantes para a ocorrência de espécies associadas a este substrato. Da mesma forma, a baixa ocorrência de serpentes aquáticas também pode ser resultado da perda da qualidade desse ambiente na cidade. Os poucos corpos d'água que ainda poderiam oferecer recursos para essas espécies encontram-se no interior das reservas florestais, e nas represas da região sul, que enfrentam o problema da poluição e contaminação de lençóis freáticos.

A atividade sazonal das serpentes, como observado em outras taxocenoses, apresentou pico na estação chuvosa, nesse caso, correspondente aos meses de outubro a março. Fatores abióticos, como umidade e temperatura (LILLYWHITE, 1987) e bióticos, como a reprodução (GIBBONS e SEMLITSCH, 1987) são determinantes no metabolismo das serpentes. Baixas temperaturas podem diminuir o metabolismo e conseqüentemente a atividade das serpentes (cf. SAWAYA, 2004). Nos meses de abril a setembro, o município de São Paulo apresenta significativa queda de temperatura, o que pode ser também um dos fatores determinantes na queda de atividade das serpentes (cf. LILLYWHITE, 1987).

Outro fator relacionado à atividade sazonal de serpentes é a incorporação de novos indivíduos à população (recrutamento de filhotes) (HENDERSON; DIXON e SOINI, 1978; SAWAYA, 2004). A maioria das espécies apresenta o recrutamento de filhotes na estação chuvosa (entre outubro e março). O período de estação chuvosa corresponde também ao nascimento de anfíbios e lagartos, presas importantes para $42 \%$ das espécies de serpentes amostradas.

\section{3 - DIVERSIDADE E DISTRIBUIÇÃO}

Até o final do registro das 1742 serpentes o acréscimo de espécies foi lento (Fig. 19, Pág. 48), e a curva de rarefação indica que ainda há espécies não 
registradas no município. Se houver um esforço intensivo de coleta, o número pode se elevar um pouco mais, mas provavelmente o padrão de abundância relativa (Fig. 18, Pág. 47) não seria alterado de forma importante.

Em outras taxocenoses de serpentes brasileiras (cf. MARTINS, 1994; MARQUES, 1998; CECHIN, 1999, SAWAYA, 2004) os viperídeos foram as espécies dominantes. Isso provavelmente está relacionado à dependência destas espécies por ambientes estruturalmente complexos, como as áreas preservadas e reservas florestais da cidade. No presente estudo, que no total apresentou dois colubrídeos como espécies dominantes (Oxyrhopus guibei e Sibynomorphus mikanii), existem poucas áreas florestais preservadas e essas duas espécies parecem de alguma forma se beneficiar de áreas alteradas. Bothrops jararaca esteve sempre associada a áreas florestadas, como o Parque do Estado e Parque do Carmo na Área Central, e foi dominante nas áreas Norte e Sul, possivelmente pela presença de grandes remanescentes florestais como a Serra da Cantareira e a Serra do Mar.

O ambiente urbano exerce grande pressão sobre populações de animais silvestres (KOENIG, SHINE e SHEA, 2002). Neste estudo, apesar de listadas 38 espécies, quase 70\% corresponderam a espécies raras (entre um e 17 indivíduos), ou seja, poucas espécies são muito abundantes ou comuns, e muitas são raras, provavelmente mais exigentes em relação ao estado de conservação local.

A maior parte dos registros de distribuição se concentrou na Área Central, mesmo esta apresentando o maior índice de urbanização da cidade. Um dos motivos que naturalmente concentra a maior parte dos registros de ocorrência nessa área é a localização do Instituto Butantan, que exerce um papel expressivo no recebimento de serpentes, principalmente em um raio de $5 \mathrm{~km}$.

Dois dos principais parques estaduais da cidade localizam-se na região central (Parque do Estado e Parque do Carmo). As áreas florestadas conservadas concentram naturalmente grande riqueza de espécies, porém diminuem a taxa de encontro de serpentes pela população. Isso é causado pela provável permanência das serpentes em seus respectivos micro-ambientes na mata, explicando o menor número de indivíduos capturados nas áreas Norte e Sul. As regiões mais urbanizadas de certa forma facilitam o encontro de pessoas com as serpentes, pois com a perda de ambiente algumas espécies passam a utilizar com mais freqüência, outros tipos de ambientes, como os quintais domiciliares e os terrenos baldios. 
A Área Norte apresentou riqueza de 20 espécies (Fig. 21A, pág. 51) e a curva de rarefação (Fig. 22, pág. 52) indica que ainda existem espécies para serem registradas. Esta área se localiza na região da Serra da Cantareira e do Jaraguá e a menor ocorrência de registros, quando comparadas com a Área Central, deve-se ao fato explicado acima, ou também pela maior freqüência de encontros de espécies mais tolerantes a áreas alteradas, no caso Sibynomorphus mikanii e Oxyrhopus guibei. A maior parte dos registros de Bothrops jararaca, espécie dominante nessa área, ocorreu nos limites da Serra da Cantareira, onde há habitações de periferia e onde a incidência de roedores é mais alta, provavelmente devido à deposição de lixo doméstico nas bordas da mata.

A Área Sul contém as represas Billings e Guarapiranga e alcança os limites da Serra do Mar. Essa região é composta quase completamente por florestas e provavelmente por isso apresentou o menor número de registros.

As estimativas de riqueza pelo método da rarefação para $\mathrm{N}=107$ indivíduos para as áreas Central e Norte apresentaram, em média, 18 e 16 espécies, respectivamente, enquanto que a Área Sul apresentou riqueza observada de 15 espécies para 107 indivíduos amostrados.

Embora as três áreas não apresentem diferenças significativas em relação à riqueza de espécies, os resultados indicam que as Áreas Norte e Central apresentam maior diversidade, pois suas dominâncias são significativamente menores em relação à observada para a Área Sul. A maior diversidade está relacionada ao maior número de espécies e à maior equitatividade, ou seja, menor dominância (MAGURRAN, 1988). É possível que o menor número de espécies registrados na Área Sul esteja relacionado ao maior valor de dominância observado nesta área, mesmo após a utilização do método de rarefação de espécies. Entretanto, a maior diversidade de serpentes observada nas áreas Central e Norte pode estar relacionada às influências de componentes da fauna de Cerrado na Área Central e da fauna da Serra da Mantiqueira na Área Norte.

A espécie dominante nas áreas Norte e Sul foi Bothrops jararaca. Esta serpente é muito comum na faixa litorânea da Serra do Mar e na Serra da Cantareira, e se alimenta de presas ectotérmicas na fase juvenil, principalmente anfíbios anuros e lagartos, e na fase adulta de presas endotérmicas, principalmente roedores. 
Em ambientes urbanizados, os anfíbios anuros são encontrados menos freqüentemente, pois geralmente necessitam de ambientes que apresentem corpos d'água, normalmente associados a áreas verdes e, portanto, é esperado que a urbanização atue negativamente sobre suas populações (KNUTSON, et al., 1999). Entretanto, a lagartixa-de-parede Hemidactylus maboiua, extremamente abundante em áreas urbanas, foi o item alimentar mais utilizado pelos juvenis de $B$. jararaca, além de ser encontrada freqüentemente nos estômagos de juvenis de Oxyrhopus guibei.

Na Área Norte, Sibynomorphus mikanii foi quase tão abundante quanto $B$. jararaca. Apesar de ser a segunda espécie mais abundante no total, S. mikanii parece ocorrer com maior freqüência em localidades próximas a áreas verdes, às vezes em seu interior, provavelmente pela maior disponibilidade de presas.

A Área Central apresenta poucas áreas verdes em relação às outras duas, que são em sua maioria compostas por florestas. A espécie dominante foi Oxyrhopus guibei provavelmente mais tolerante à urbanização, ocorrendo tanto em ambientes degradados como em áreas próximas a fragmentos florestais. Um dos fatores que pode favorecer o sucesso desta espécie é a abundância de itens alimentares, como lagartixas e roedores, e a reprodução contínua (PIZZATTO ; MARQUES, 2000).

Na Área Sul, 73\% das espécies, de um total de 15 espécies registradas são típicas da Serra do Mar. Um esforço de coleta mais intensivo, utilizando vários métodos de amostragem combinados (e. g. SAWAYA, 2004; ZANELLA e CECHIN, 2006), possivelmente aumentaria a riqueza de espécies, talvez em número próximo daquela encontrada em outras localidades da Serra do Mar. Marques (1998), registrou 24 espécies na região da Juréia-Itatins e Hartmann (2005) registrou 39 espécies na região de Ubatuba.

A riqueza de espécies na Serra do Mar é naturalmente mais baixa, quando comparada com as formações de Cerrado e da Serra da Mantiqueira. Para o Cerrado da região de Itirapina - SP, foram registradas 35 espécies (SAWAYA 2004).

Quando analisamos a diversidade de espécies no MSP do sentido Sul para o Norte, observa-se uma diminuição na porcentagem de espécies típicas da Serra do Mar, enquanto que nesse mesmo sentido (Sul - Norte) ocorre um aumento do número de espécies de outras fisionomias. A Área Central é a que apresenta a maior heterogeneidade de espécies, e provavelmente possuía mosaicos de 
vegetação, com áreas de campos naturais, cerrado, florestas de araucárias e influência de componentes da fauna da Serra da Mantiqueira.

Atualmente, poucas áreas remontam a vegetação original do município de São Paulo. O detalhamento da fauna pretérita de répteis (MARQUES et al, 2008) ${ }^{12} \mathrm{e}$ de sua distribuição no município, combinados com as listas de espécies de outras fisionomias de vegetação do entorno (e. g. campos naturais, Cerrado e Serra da Mantiqueira), permitirão compreender de forma detalhada os fatores que determinaram os padrões atuais de distribuição das espécies, apontando ainda algumas regiões relictuais e altamente ameaçadas.

${ }^{12}$ MARQUES O. A. V. São Paulo, 2008 (em fase de elaboração) 


\section{5 - CONCLUSÕES}

Apesar de apresentar relativamente poucas áreas verdes, o município de São Paulo ainda apresenta uma elevada riqueza de espécies de serpentes.

Oxyrhopus guibei, Sibynomorphus mikanii e Bothrops jararaca foram as espécies mais abundantes no município de São Paulo.

As espécies dominantes apresentam hábitos noturnos e a dieta baseada em roedores ou invertebrados, que devem ser itens muito abundantes na cidade.

Serpentes terrícolas e batracófagas foram predominantes no município de São Paulo.

Bothrops jararaca, a terceira espécie mais abundante, mas dominante nas áreas Norte e Sul, foi geralmente associada a ambientes florestados, apesar de também ocorrer em áreas alteradas.

Entre as principais regiões climáticas, a Área Central apresentou a maior riqueza, e também a maior heterogeneidade de espécies, provavelmente devido às influências de componentes de fauna do Cerrado e da Serra da Mantiqueira.

Nas áreas Norte e Sul predominaram as espécies da Serra da Mantiqueira e Serra do Mar, respectivamente.

A alta diversidade de espécies de serpentes encontrada no município de São Paulo deve estar relacionada ao mosaico de diferentes formações vegetais que historicamente ocorria na área do município. 


\section{REFERÊNCIAS BIBLIOGRÁFICAS}

AB' SÁBER, A. N. Originalidade do sítio da cidade de São Paulo. Acrópole 295/296, p. 239-246, 1963.

AB' SÁBER, A. N. O mosaico primário de matas e cerrados do Planalto Paulistano. Cadernos de Ciências da Terra 6, p. 24-26, 1970.

ALBUQUERQUE, C. E.; FERRAREZZI, H. A case of communal nesting in the Neotropical snake Sibynomorphus mikanii (Serpentes, Colubridae). Phyllomedusa, 3 (1), p. 73-77, 2004.

ALMEIDA-SANTOS, S. M.; SALOMÃO, M. G., 2002. Reproduction in Neothropical pitvipers with emphasis on species of the genus Bothrops. In: Biology of the vipers. G. W. Schuett, et al. (ed.), p. 445-462. Eagle Mountain. Eagle Mountain Publishing, 2002

BARBO, F. E.; MARQUES, O. A. V. Do aglyphous colubrid snakes prey on live amphisbaenids able to bite? Phyllomedusa 2 (2), p. 113-114, 2003.

BARBO, F. E.; SAWAYA, R. J. Amphisbaenians, municipality of São Paulo, Southeastern Brazil. Checklist 4(1), p. 5-11, 2008.

BASTOS, E. G. M.; ARAÚJO, A. F. B.; SILVA, H. R. Records of the rattlesnakes Crotalus durissus terrificus (Laurenti) (Serpentes, Viperidae) in the state of Rio de Janeiro, Brazil: a possible case of invasion facilitated by deforestation. Revista Brasileira de Zoologia 22 (3), p. 812-815, 2005.

BERNARDE, P. S., MOURA-LEITE, J. C., MACHADO, R. A. ; KOKUBUM, M. N. C. Diet of the colubrid snake Thamnodynastes strigatus (Günther, 1858) from Paraná state Brazil with field notes on anuran predation. Revista Brasileira de Biologia 60(4), p. 695-699, 2000.

BIZERRA, A. F.; MARQUES, O. A. V.; SAZIMA, I. Reprodution and feeding of the colubrid snake Tomodon dorsatus from southeastern Brazil. Amphibia-Reptilia 26, p. 33-38, 2005

BROWN, J. H. On the relationship between distribution and abundance. American Naturalist, 124, p. 255-279, 1984. 
BROWN-Jr., K. S. Conclusions, synthesis and alternative hypotheses. In: Whitmore, T. C., Prance, G. T. (Eds.), Biogeography and Quaternary History in Tropical America. Oxford: Clarendon Press, p. 175-196, 1987.

CADLE, J. E.; GREENE, H. W. Phylogenetic patterns, biogeography, and the ecological structure of Neotropical snake assemblages. In: RICKLEFS, R. E.; SCHLUTER, D. (Eds). Species diversity in ecological communities: historical and geographical perspectives. Chicago: University of Chicago Press, 1993.

CARVALHO, A. L.. Observações sôbre "Tropidophis paucisquamis" (Muller, 1901). Revista Brasileira de Biologia 11, p. 239-248, 1951.

CAUGHLEY, G., The analysis of vertebrate populations. John Wiley and Sons, London, UK., 1978

CECHIN, S. Z. História natural de uma comunidade de serpentes na região da depressão central (Santa Maria), Rio Grande do Sul, Brasil Tese (Doutorado em Zoologia). Pontífica Universidade Católica do Rio Grande do Sul, RS, 1999.

CINAQUI-FILHO, E. Dieta, Reprodução e Atividade da Serpente Liophis Typhlus (Colubridae, Xenodontinae, Xenodontini) no Estado de São Paulo, Região Sudeste do Brasil. 86 f. Monografia (Conclusão de Curso). Faculdade de Ciências Biológicas. Universidade Metodista de São Paulo, 2007.

COLWELL, R. K. EstimateS: Statistical estimation of species richness and shared species from samples. Version 5. User's Guide and application published at: http://viceroy.eeb.uconn.edu/estimates, 1997. Acesso: 02/abr/2007

$\mathrm{CRISCI}, \mathrm{J}$. V. The voice of historical biogeography. Journal of Biogeography 28, $\mathrm{p}$. 157-168, 2001.

CUNHA, O. R.; NASCIMENTO, F. P. Ofídios da Amazônia X - As cobras da região leste do Pará. Publicações Avulsas do Museu Paraense Emílio Goeldi 31, p. 1218, 1978

CUNHA, O. R.; NASCIMENTO, F. P. Ofídios da Amazônia XIV - As espécies de Micrurus, Bothrops, Lachesis e Crotalus do sul do Pará e oeste do Maranhão, incluindo as áreas de cerrado deste estado. (Ophidia: Elapidae e Viperidae) Boletim do Museu Paraense Emílio Goeldi 112, p. 1-58, 1982. 
DI-BERNARDO, M. Revalidation of the genus Echinanthera Cope, 1894, and its conceptual amplification (Serpentes, Colubridae). Comunicações do Museu de Ciências da PUCRS, Série Zoologia 5(13), p. 225-256, 1992.

DI-BERNARDO, M. A new species of the Neotropical snake genus Echinanthera Cope, 1894 from southeastern Brazil (Serpentes, Colubridae). The Snake 27(2), p. 120-126, 1996.

DI-BERNARDO, M. História Natural de uma comunidade de serpentes da borda oriental do planalto das Araucárias, Rio Grande do Sul, Brasil. Tese (Doutorado em Zoologia), Universidade Estadual Paulista, campus de Rio Claro, SP, 1998.

DISLICH, R.; CERSÓSIMO, L.; MANTOVANI, W. Análise da estrutura de fragmentos florestais no Planalto Paulistano - SP. Revlsta Brasileira de Botânica, São Paulo, v.24, n.3, p.321-332, 2001.

DIVA-GIS Version 5.2.0.4, disponível em: http://www.diva-gis.org, acessado em 03/08/05, 2005.

DIXON, J. R. The neotropical colubrid snake genus Liophis. The generic concept. Milwaukee Public Museum, Contributions in Biology and Geology, p. 31-38, 1980.

DIXON, J. Prey items of 20 species of the neotropical colubrid snake genus Liophis. Herpetological Review, 20, p. 139-141, 1989.

ELTON, C. S. Animal ecology. Meuthen, London, 1927.

ÉSBERARD, C. E. L.; VRCIBRADIC, D. Snakes preying on bats: new records from Brazil and a review of recorded cases in the Neotropical Region. Revista Brasileira de Zoologia 24 (3), p. 848-853, 2007.

ESRI. ArcView GIS Help (versão 3.2) Environmental Systems Research Institute, Inc. New York. USA., 1999

ETEROVIC, A.; DUARTE, M. R. Exotic snakes in Sao Paulo City, southeastern Brazil: why xenophobia? Biodiversity and Conservation, 11 (2), p. 327-339, 2002.

FERRAREZZI, H. Sistemática Filogenética de Elapomorphus, Phalotris e Apostolepis (Serpentes: Colubridae: Xenodontinae). 237 f. Dissertação 
(Mestrado em Zoologia). Departamento de Zoologia, Universidade de São Paulo, 1993.

FERRAREZZI, H; BARBO, F. E. ; ALBUQUERQUE, C. E. Phylogenetic relationships of a new species of Apostolepis from Brazilian Cerrado with notes on the assimilis group (Serpentes: Colubridae: Xenodontinae: Elapomorphini). Papéis Avulsos de Zoologia, 45 (16), p. 215-229, 2005.

FITCH, H. S. Reproductive cycles of lizards and snakes. Mus. Nat. Hist. Misc. Publ. 52, p.1-247, 1970.

FITCH, H. S. Reproductive cycles in neotropical reptiles. Occas. Pap. Mus. Nat. Hist. Univ. Kansas 96, p. 1-53, 1982

FRANCO, F. L.; MARQUES, O. A. V.; PUORTO, G. Two new species of colubrid snakes of the genus Clelia from Brazil. Journal of Herpetology 31 (4), p. 483-490, 1997.

GIBBONS, V. P. J.; SEMLITSCH, R. D. Activity pattern. In SEIGEL, R. A.; J. T. COLLINS ; S. S. NOVAK (Eds). Snakes: Ecology and Evolutionary Biology. New York, MacMillan Publishing Co., 1987.

GOTELLI, N. J. Quantifying biodiversity: procedures and pitfalls in the measurement and comparison of species richness. Ecology Letters 4, p. 379-391, 2001.

GOTELLI, N. J.; ENTSMINGER, G. L. EcoSim: Null models software for ecology. Version 7.0., 2001. Acquired Intelligence Inc.; Kesey - Bear. http://homepages.together.net/ gentsmin/ecosim.htm. Acessado em: 4/mai/2007

GRAHAM, C. H.; FERRIER, S.; HUETTMAN, F.; MORTIZ, C.; PETERSON, A. T. New developments in museum-based informatics and applications in biodiversity analysis. Trends in Ecology and Evolution 19, p. 497-503, 2004.

GREENE, H. W. Ecological, evolutionary and conservation implications of feeding biology of Old World cat snakes, genus Boiga (Colubridae). Proc. Calif. Acad. Sci. 46, p. 193-207, 1989.

GREENE, H. W.; LOSOS, J. B. Systematics, natural history and conservation. BioScience 38, p. 458-452, 1988 
GREENE, H. W. Systematics and natural history, foundations for understanding and conserving biodiversity. Amererican Zoology 34, p. 48-56, 1994.

GREENE, H. W. Snakes: The Evolution of Mystery in Nature. Berkley, University of California Press, 1997.

HARTMANN, P. A. 2005. História Natural e Ecologia de duas taxocenoses de serpentes na Mata Atlântica. 117 f. Tese (Doutorado em Zoologia), Universidade Estadual Paulista, campus de Rio Claro, SP, 2005.

HARTMANN, P. A.; MARQUES, O. A. V. Diet and habitat use of two sympatric Philodryas (Colubridae) in South Brazil. Amphibia-Reptilia 26, p. 25-31, 2005.

HAUZMAN, E.; Da COSTA, A. C. O. R.; SCARTOZZONI, R. R. Spilotes pullatus Reproduction. Herpetological Review 36 (3), p. 328, 2005.

HENDERSON, R. W.; DIXON, J.; SOINI, P. On the seasonal incidence of tropical snakes. Milw. Public. Mus. Contrib. Biol. Geol. 17, p. 1-15, 1978

HENDERSON, R. W.; DIXON, J. R.; SOINI, P. 1979. Resource partitioning in Amazonian snake communities. Milwalkee Public Museum, Contributions in Biology and Geology 22, p. 1-11, 1979

HIJMANS, R. J., GUARINO, L., CRUZ, M.; ROJAS E. Computer tools for spatial analysis of plant genetic resources data: 1. DIVA-GIS. Plant Genetic Resources Newsletter, 127, p. 15-19, 2001.

HILLIS, D. M. American molecular naturalist (review of Avise, J. C. 1994. Molecular Markers, Natural History and Evolution, Chapman; Hall, New York). Ecology 76, p. 1017-1018, 1995.

HUTCHINSON, G. E. Concluding remarks. Cold Spring Harbor Symposia on Quantitative Biology 22, p.415-427, 1957.

JORDÃO, R. S. Estudo comparativo da alimentação e reprodução de Waglerophis merremii e Xenodon neuwiedii (Serpentes: Colubridae). Dissertação (Mestrado em Zoologia). Instituto de Biociências, Universidade de São Paulo, São Paulo, 1996. 
KLEIN, R. M. Ecologia da flora e vegetação do Vale do Itajaí. Sellowia 32, p. 165389, 1980.

KNUTSON, M. G.; SAUER, J. R.; OLSEN. D. A.; MOSSMAN, M. J.; HEMESATH, L. M. ; LANNOO, M. J. Effects on landscape composition and wetland fragmentation on frog and toad abundance and species richness in lowa and Wisconsin, USA. Conservation Biology 13(6), p. 1437-1446, 1999.

KOENIG, J.; SHINE, R.; SHEA, G. The dangerous of life in the city: patterns of activity, injury and mortality in suburban lizards (Tiliqua scincoides). Journal of Herpetology 36, (1), p. 62-68, 2002

KREBS, C. J. The experimental analysis of distribution and abundance. New York, Harper Row, 1978

LAPORTA-FERREIRA, I. L.; SALOMÃO, M. G.; SAWAYA, P. Biologia de Sibynomorphus (Colubridae - Dipsadinae) - Reprodução e hábitos alimentares. Revista Brasileira de Biologia 46, p. 793-799, 1986.

LAURANCE, W. F. Comparative responses of five arboreal marsupials to tropical forest fragmentation. Journal of Mammalogy 71, p. 641-653, 1990

LEITÃO-FILHO, H. F. Diversity of arboreal species in Atlantic rain forest. Anais da Academia Brasileira de Ciências 66 (1), p. 91-96, 1994.

LILLYWHITE, H. B. Temperature, Energetics, and Phisiological Ecology. p. 422-465. In: SEIGEL, R. A.; COLLINS, J. T.; NOVAK, S. S. (Eds). Snakes: Ecology and Evolutionary Biology, New York: MacMillan Publ. Co., 1987.

LOVEJOY, T. E. et al. Edge and other effects of isolation on Amazon forest fragments, p. 257-285. In: SOULE, M. E. (Ed.), Conservation Biology: The Science of Scarcity and Diversity. Sunderland: Sinauer Associates Inc, 1986.

MACARTHUR, R. H. Geographical ecology: patterns in the distribution of species. New York, Harper Row, 1972.

MAGURRAN, A. E. Ecological diversity and its measurement. Princeton, Princeton University Press, 1988. 
MANTOVANI, W. Cobertura Vegetal do Município de São Paulo. Relatório Interno da Secretaria do Meio Ambiente da Prefeitura do Município de São Paulo. Atlas Ambiental do Município de São Paulo. 32 p, 2000.

MARQUES, O. A. V. História Natural de Micrurus corallinus (Serpentes, Elapidae). Dissertação (Mestrado em Ecologia). Departamento de Ecologia Geral, Universidade de São Paulo, 1992.

MARQUES, O. A. V. Biologia Reprodutiva da cobra-coral Erythrolamprus aesculapii, uma serpente ofiófaga. Revista Brasileira de Zoologia 13, p. 747-753, 1996.

MARQUES, O. A. V. Composição faunística, história natural e ecologia de serpentes da Mata Atlântica, na região da Estação Ecológica Juréia-Itatins, SP. 135 f. Tese (Doutorado em Zoologia), Departamento de Zoologia, Universidade de São Paulo, 1998.

MARQUES, O. A. V.; PUORTO, G. Padrões cromáticos, distribuição e possível mimetismo em Erythrolamprus aesculapii (Serpentes, Colubridae), no sudeste do Brasil. Memórias do Instituto Butantan 53, p. 127-134, 1991.

MARQUES, O. A. V.; PUORTO, G. Dieta e comportamento alimentar de Erythrolamprus aesculapii, uma serpente ofiófaga. Revista Brasileira de Biologia 54, p. 253-259, 1994.

MARQUES, O. A. V.; PUORTO, G. Feeding, reproduction and growth in the crowned snake Tantilla melanocephala (Colubridae), from southeastern Brazil. AmphibiaReptilia 19, p. 311-318, 1998.

MARQUES, O. A. V.; ETEROVIC, A.; ENDO, W. Seazonal activity of snakes in the Atlantic Forest in southeastern Brazil. Amphibia-Reptilia 22, p. 103-111, 2000.

MARQUES, O. A. V.; ETEROVIC, A.; SAZIMA, I. Serpentes da Mata Atlântica guia ilustrado para a Serra do Mar. 184 pp, Ribeirão Preto, Editora Holos, 2001.

MARQUES, O. A. V.; SAWAYA, R. J.; STENDER-OLIVEIRA, F.; FRANÇA, F. G. R. Ecology of the colubrid snake Pseudablabes agassizii in south-eastern South America. Herpetological Journal. 16, p. 37-45, 2006. 
MARQUES, O. A. V. ; SAZIMA, I. Diet and feeding behavior of the coral snake, Micrurus corallinus, from the Atlantic forest of Brazil. Herpetological Natural History 5 (1), p. 88-93, 1997.

MARQUES, O. A. V.; SAZIMA, I. História natural dos répteis da Estação Ecológica Juréia-Itatins, p. 257-277. In: MARQUES, O. A. V.; DULEBA, W. (eds.). Estação Ecológica Juréia-Itatins: Ambiente Físico, Flora e Fauna. Ribeirão Preto: Holos Editora, 2004.

MARTINS, M. História natural e ecologia de uma taxocenose de serpentes em mata primaria na região de Manaus, Amazônia Central, Brasil. 94 f. Tese (Doutorado em Ecologia), Departamento de Biologia, Universidade Estadual de Campinas, 1994.

MARTINS, M ; OLIVEIRA, M. E. Natural history of snakes in forests of the Manaus Region, Central Amazonia, Brazil. Herpetological Natural History 6 (2), p. 78-150, 1998.

MARTINS, M.; MARQUES, O. A. V.; SAZIMA, I. Ecological and phylogenetic correlates of feeding habits in neotropical pitvipers of the genus Bothrops, p. 307327. In: Biology of the vipers. G. W. Schuett et al. (eds.), Eagle Mountain: Eagle Mountain Publishing, 2002.

MARTINS, M., ARAUJO, M. S.; SAWAYA, R. J.; NUNES, R. Diversity and evolution of microhabitat use, body size and morphology in a monophyletic group of Neotropical pitvipers (Bothrops). Journal of Zoology 254, p. 529-538, 2001.

MELO, A. S.; PEREIRA, R. A. S; SANTOS, A. J.; SHEPHERD, G. J.; MACHADO, G.; MEDEIROS, H. F. ; SAWAYA, R. J. Comparing species richness among assemblages using sample units: Why not use extrapolation methods to standardize different samplesizes? Oikos 101, p. 398-410, 2003.

MMA - MINISTÉRIO DO MEIO AMBIENTE. Fragmentação de Ecossistemas: causas, efeitos sobre a biodiversidade e recomendações políticas públicas. Brasília, DF, 510 p., 2003.

MUSHINSKY, H. R. Foraging Ecology, p. 302-334. In: Seigel, R. A., Collins, J. T.; Novak, S. S. (eds.), Snakes, Ecology and Evolutionary Biology, New York: McMillan Publishing Company, 1987. 
MYERS, C. W.; CADLE, J. E. A new genus for South American snakes related to Rhadinaea obtusa Cope (Colubridae) and resurrection of Taeniophallus Cope for the Rhadinaea brevirostris group. American Museum Novitates 3102, p. 1- 33, 1994.

NIX, H. A.; GILLISON, A. N. Towards an operational framework for habitat and wildlife management. p. 39-55 In: J. Kikkawa (ed.) Wildlife management in the forests and forestry-controlled lands in the tropics of the southern hemisphere. Brisbane, Queensland University Press, 1985.

NOGUEIRA, C.; MARQUES, O. A. V. Reprodução e hábitos alimentares de Helicops carinicaudus (Serpentes: Colubridae) na Mata Atlântica. In: XXII Congresso Brasileiro de Zoologia. Recife, PE, 1998, p. 272.

NOGUEIRA, C.; SAWAYA, R. J.; MARTINS, M. Ecology of the Pitviper, Bothrops moojeni, in the Brazilian Cerrado. Journal of Herpetology 37, p. 653-659, 2003.

OLIVEIRA, J. L. Ecologia de três espécies de dormideira, Sibynomorphus (Serpentes:Colubridae). 92 f. Dissertação (Mestrado em Ecologia), Instituto de Biociências, Universidade de São Paulo, SP, 2001

OUTEIRAL, A. B.; CECHIN, S.Z. Phylodryas patagoniensis (NCN) Diet. Herpetological Review, 34 (2), 2003.

PETRONE, P. Aldeamentos paulistas. São Paulo, Editora da Universidade de São Paulo, 1995.

PIMM, S. L.; RUSSEL, G. J.; GITTLEMAN, J. L.; BROOKS, T. M. The future of biodiversity. Science 269, p. 347-350, 1995.

PINTO, C. C.; LEMA, T. Comportamento alimentar e dieta de serpentes, gêneros Boiruna e Clelia (Serpentes: Colubridae). Iheringia, Série Zoologia, 92 (2), p. 9-19, 2002.

PIZZATTO, L. Reprodução de Liophis miliaris (Serpentes: Colubridae) no Brasil: influência histórica e variações geográficas 103 f. Dissertação (Mestrado em Ecologia) - Instituto de Biologia, Universidade Estadual de Campinas, São Paulo, 2003. 
PIZZATTO, L. Body size, reproductive biology and abundance of the rare pseudoboini snakes genera Clelia and Boiruna (Serpentes, Colubridae) in Brazil. Phyllomedusa 4 (2), p. 111-122, 2005.

PIZZATTO, L.; MARQUES, O. A. V. Reproductive biology of the false coral snake Oxyrhopus guibei (Colubridae) from southeastern Brazil. Amphibia-Reptilia 23, p. 495-504, 2002.

POUGH, F. H.; GROVES, J. D. Specialization of the body form and food habits of snakes. American Zoology. 23, p. 443-454, 1983.

POUGH, H. F.; ANDREWS, R. M.; CADLE, J. E.; CRUMP, M. L.; SAVITZKY, A. H. ; WELLS, K. D. Herpetology. New Jersey, Pearson Prentice-Hall, 2004.

PRANCE, G. T. A review of the phytogeographic evidences for Pleistocene climate changes in the neotropics. Annals of the Missouri. Botanical Garden 69, p. 594$624,1982 a$.

PRANCE, G. T. Forest refuges: evidence from woody angiosperms. p. 137-158. In: Prance, G.T. (Ed.), Biological Diversification in the Tropics. New York: Colombia University Press, 1982b.

PREFEITURA DO MUNICÍPIO DE SÃO PAULO. Fase I: Diagnóstico e bases para a definição de políticas públicas para as áreas verdes no município de São Paulo, Sec. Mun. do Meio Ambiente, Sec. Mun. de Planejamento Urbano São Paulo. In: ATLAS AMBIENTAL DO MUNICÍPIO DE SÃO PAULO, 203 p., 2002.

PRUDENTE, A. L. C.; MORATO S. A. A.; MOURA-LEITE, J. C. Alimentação das espécies de Siphlophis Fitzinger (Serpentes: Colubridae: Xenodontinae: Pseudoboini). Revista Brasileira de Zoologia 15 (2), p. 375-383, 1998.

PUORTO, G.; LAPORTA-FERREIRA, I. L.; SAZIMA, I. Serpentes na selva de pedra. Ciência Hoje 13, p. 66-67, 1991.

RICKLEFS, R. E. Ecology. 896p. New York, W.H. Freeman and Company, 1990.

RODRIGUES, M. G. 2007. Ecomorfologia e uso de recursos das espécies de Chironius (Serpentes: Colubridae) na Serra do Mar. 76 f. Dissertação (Mestrado em Biologia Animal), Universidade Estadual Paulista, campus São José do Rio Preto - SP. 
ROJAS, C. A.; BARBO, F. E. 2007. Atividade sazonal associada ao ciclo reprodutivo de machos de Sibynomorphus mikanii (Serpentes: Colubridae) no Estado de São Paulo. In: Resumos do $\mathbf{3}^{\circ}$ Congresso Brasileiro de Herpetologia. Belém PA.CD-ROM

RUFINO, N.; BERNARDI, J. A. R. Natural History Notes. Pseustes sulphureus. Diet. Herpetological Review 30, p. 103-104, 1999.

SANDERS, $H$. Marine benthic diversity: a comparative study. The American Naturalist 102, p. 243-282, 1968.

SAVITZKY, A. H. The origin of the New World proteroglyphous snakes and its bearing on the study of the venom delivery systems in snakes. Thesis (Ph.D.). University of Kansas, Lawrence, 1979.

SAWAYA, R. J. História natural e ecologia das serpentes de cerrado da região de Itirapina-SP. 145p. Tese (Doutorado em Ecologia), Departamento de Biologia, Universidade Estadual de Campinas, 2004.

SAZIMA, I. Natural history of the jararaca pitvipers, Bothrops jararaca, in southeastern Brazil. p. 199-216. In: Biology of Pitvipers. J. A. Campbell; E. D. Brodie (ed.). Texas: Selva Publishing, 1992.

SAZIMA, I.; ABE, A. S. Habits of Five Brazilian Snakes with Coral-snake Pattern, Including a Summary of Defensive Tactics. Studies on Neotropical Fauna and Environment 26, p. 159-164, 1991.

SAZIMA, I; HADDAD, C. F. B. Répteis da Serra do Japi. In: Morellato, P. C.; LeitãoFilho, H.(org.), História Natural da Serra do Japi: ecologia e preservação de uma área florestal no sudeste do Brasil. Campinas: UNICAMP/FAPESP, 1992.

SAZIMA, I.; PUORTO, G. 1993. Feeding technique of juvenile Tropidodryas striaticeps: probable caudal luring in a colubrid snake. Copeia, 1, p. 222-226.

SCARTOZZONI, R. R. Morfologia de serpentes aquáticas neotropicais: um estudo comparativo. Dissertação (Mestrado em Ecologia), Departamento de Ecologia, Instituto de Biociências, Universidade de São Paulo, 2005. 
SCHARGEL, W. E.; FUENMAYOR, G. R.; MYERS, C. W. An enigmatic new snake from cloud forest of the peninsula de Paria, Venezuela (Colubridae: genus Taeniophallus ?) American Museum Novitates, 3484, p. 1-23, 2005.

SEIGEL, R. A.; FORD, N. B. Reprodutive ecology p. 210-252. In: R. A. Seigel, J. T. Collins; S. S. Novak (eds.), Snakes, Ecology and Evolutionary Biology. New York: McMillan Publishing Company, 1987.

SHINE, R. Reproduction in Australian elapid snakes. II Female reproductive cycles. Australian Journal of Zoology 25, p. 655-666, 1977.

SILVA, L. O. Subsídios para Formulação de uma Política para Áreas Verdes no Município de São Paulo, p. 425-449. In: PHILLIPI J.R. et al. (eds.) A Questão Ambiental Urbana: Cidade de São Paulo. São Paulo, 1993.

STEARNS, S. C. The evolution of life histories. New York, Oxford University Press., 1992.

STRÜSSMANN, C.; SAZIMA, I. The snake assemblage of the Pantanal at Poconé, western Brazil: faunal composition and ecological summary. Studies on Neotropical Fauna Environment, 28(3), p. 157-168, 1993.

THOMAS, W. W., CARVALHO, A. M. A., GARRISON, J., ARBELAEZ, A. L. Plant endemism in two forests in southern Bahia, Brazil. Biodiversity and Conservation 7, p. 311-322, 1998.

UDVARDY, M. D. F. Dynamic zoogeography: with special reference to land animals. New York, Van Nostrand Reinhold, 1969.

USTERI, A. Flora der Umgebung der State São Paulo in Brasilien. Verlag; Jena, Gustav Ficher, 1911.

VITT, L. J. Communities. 335-365. In: R. A. Seigel, J. T. Collins; S. S. Novak (eds.), Snakes, Ecology and Evolutionary Biology. New York: McMillan Publishing Company, 1987.

VITT, L. J.; VANGILDER, L. D. Ecology of a snake community in northeastern Brazil. Amphibia- Reptilia, Leiden, 4, p. 273-296, 1983. 
ZANELLA, N.; CECHIN, S. Z. Taxocenose de serpentes no Planalto Médio do Rio Grande do Sul, Brasil. Revista Brasileira de Zoologia, 23 (1), p. 211-217, 2006.

ZAR, J. H. Bioestatistical Analysis. New Jersey: Prentice Hall, 1996. 